Florida International University FIU Digital Commons

7-15-2008

\title{
Effect of Performance Feedback on Perceived Knowledge and Likelihood to Pursue Continuing Education
}

Lindsey Elizabeth Eberman

Florida International University

DOI: $10.25148 /$ etd.FI08121904

Follow this and additional works at: https://digitalcommons.fiu.edu/etd

\section{Recommended Citation}

Eberman, Lindsey Elizabeth, "Effect of Performance Feedback on Perceived Knowledge and Likelihood to Pursue Continuing Education" (2008). FIU Electronic Theses and Dissertations. 62.

https://digitalcommons.fiu.edu/etd/62 


\title{
FLORIDA INTERNATIONAL UNIVERSITY
}

Miami, Florida

EFFECT OF PERFORMANCE FEEDBACK ON PERCEIVED KNOWLEDGE AND LIKELIHOOD TO PURSUE CONTINUING EDUCATION

\author{
A dissertation submitted in partial fulfillment of the \\ requirements for the degree of \\ DOCTOR OF PHILOSOPHY \\ in \\ CURRICULUM AND INSTRUCTION
}

by

Lindsey E. Eberman

2008 
To: Interim Dean Kingsley Banya

College of Education

This dissertation, written by Lindsey E. Eberman, and entitled Effect of Performance Feedback on Perceived Knowledge and Likelihood to Pursue Continuing Education, having been approved in respect to style and intellectual content, is referred to you for judgment.

We have read this dissertation and recommend that it be approved.

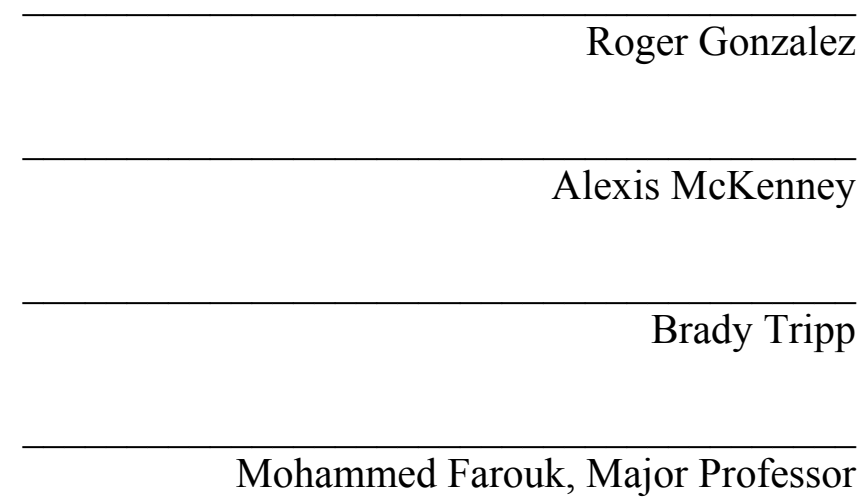

Date of Defense: July 15, 2008

The dissertation of Lindsey E. Eberman is approved.

$\begin{array}{r}\hline \begin{array}{r}\text { Interim Dean Kingsley Banya } \\ \text { College of Education }\end{array} \\ \hline \begin{array}{r}\text { Dean George Walker } \\ \text { University Graduate School }\end{array}\end{array}$

Florida International University, 2008 


\section{DEDICATION}

I dedicate this to my grandmother Margaret Ellen Scram Withrow, the first woman in my family to receive her doctorate (Catholic University, 1973). She was a woman before her time, full of integrity and passion. 


\section{ACKNOWLEDGMENTS}

First and foremost I must thank Dr. Brady Tripp. Without your wisdom, guidance, and unique perspective on life in and out of academia, I would have been lost. I would also like to extend a thank you to Dr. Farouk for his role as committee chair, to Dr. Cleary and Dr. Moseley for their role in the beginning, and Dr. McKenney and Dr. Gonzalez for their role in the end. All of you have left a mark on my work and on my life for your contributions to this dissertation. Additionally, I must extend my gratitude for the assistance of Dr. Isadore Newman and Dr. Linda Bliss who have both made this process as seamless as one's dissertation could be. Your advice has been priceless.

To all my family and friends, I am thankful for your patience and willingness to help, even when it seemed helpless. To my mother and father, thank you for instilling the need to learn and the desire to succeed. To Ryan, you remind me to be content with today, but give me hope for more tomorrow. To Blair, thank you for bringing out the child in me- we will always be young at heart if we have each other. To my running buddies Jenn and Pattie, thank you for helping me find a way to relieve the anxiety to this seemingly impossible obstacle. To all those that helped in my many times of need, you know who you are and I am indebted to you always.

You are special people- friends, family, and colleagues- who have played a significant role in my life. You have helped me find my way to the end of this challenge and I hope you are there by my side and in my heart for the next challenge. 


\title{
ABSTRACT OF THE DISSERTATION \\ EFFECT OF PERFORMANCE FEEDBACK ON PERCEIVED KNOWLEDGE AND \\ LIKELIHOOD TO PURSUE CONTINUING EDUCATION
}

\author{
by \\ Lindsey E. Eberman \\ Florida International University, 2008 \\ Miami, Florida \\ Professor Mohammed Farouk, Major Professor
}

The purpose of this study was to assess the effect of performance feedback on Athletic Trainers' (ATs) perceived knowledge (PK) and likelihood to pursue continuing education (CE). The investigation was grounded in the theories of "the definition of the situation" (Thomas \& Thomas, 1928) and the "illusion of knowing," (Glenberg, Wilkinson, \& Epstein, 1982) suggesting that PK drives behavior. This investigation measured the degree to which knowledge gap predicted CE seeking behavior by providing performance feedback designed to change PK.

A pre-test post-test control-group design was used to measure PK and likelihood to pursue CE before and after assessing actual knowledge. ATs ( $\mathrm{n}=103)$ were randomly sampled and assigned to two groups, with and without performance feedback. Two independent samples t-tests were used to compare groups on the difference scores of the dependent variables. Likelihood to pursue CE was predicted by three variables using multiple linear regression: perceived knowledge, pre-test likelihood to pursue CE, and knowledge gap. 
There was a $68.4 \%$ significant difference $\left(\mathrm{t}_{101}=2.72, p=0.01\right.$, ES $\left.=0.45\right)$ between groups in the change scores for likelihood to pursue CE because of the performance feedback (Experimental group $=13.7 \%$ increase; Control group $=4.3 \%$ increase). The strongest relationship among the dependent variables was between pre-test and post-test measures of likelihood to pursue $\mathrm{CE}\left(\mathrm{F}_{2,102}=56.80, \mathrm{p}<0.01, \mathrm{r}=0.73, \mathrm{R}^{2}=0.53\right)$. The preand post-test predictive relationship was enhanced when group was included in the model. In this model $\left[\mathrm{Y}_{\mathrm{CEpost}}=0.76 \mathrm{X}_{\mathrm{CEpre}}-0.34 \mathrm{X}_{\text {group }}+2.24+\mathrm{E}\right]$, group accounted for a significant amount of unique variance in predicting CE while the pre-test likelihood to pursue $\mathrm{CE}$ variable was held constant $\left(\mathrm{F}_{3,102}=40.28, \mathrm{p}<0.01,: \mathrm{r}=0.74, \mathrm{R}^{2}=0.55\right)$. Pre-test knowledge gap, regardless of group allocation, was a linear predictor of the likelihood to pursue $\mathrm{CE}\left(\mathrm{F}_{1,102}=10.90, \mathrm{p}=.01, \mathrm{r}=.31, \mathrm{R}^{2}=.10\right)$.

In this investigation, performance feedback significantly increased participants' likelihood to pursue CE. Pre-test knowledge gap was a significant predictor of likelihood to pursue $\mathrm{CE}$, regardless if performance feedback was provided. ATs may have selfassessed and engaged in internal feedback as a result of their test-taking experience. These findings indicate that feedback, both internal and external, may be necessary to trigger CE seeking behavior. 


\section{TABLE OF CONTENTS}

CHAPTER

PAGE

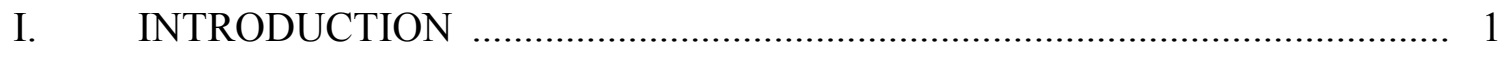

Statement of the Problem ............................................................................. 3

Statement of the Purpose ....................................................................... 4

General Research Questions .................................................................... 4

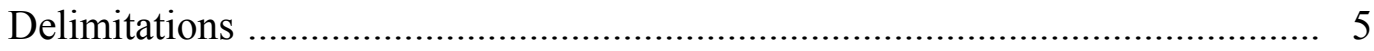

Operational Definitions ......................................................................... 5

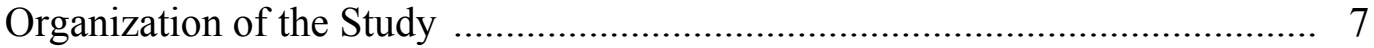

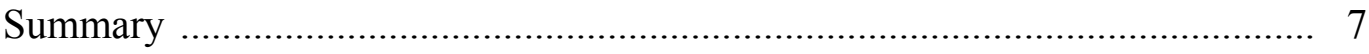

II. LITERATURE REVIEW ..................................................................... 9

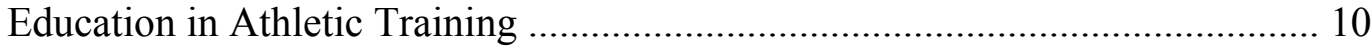

Exercise Associated Muscle Cramping ........................................................ 22

Likelihood to Pursue Continuing Education .................................................... 35

Identifying the Knowledge Gap .......................................................... 38

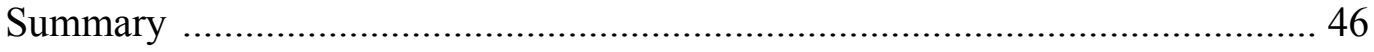

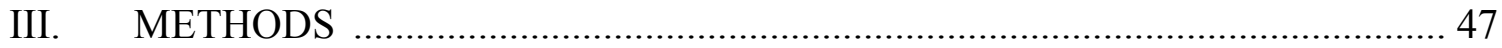

General Research Questions ........................................................................ 47

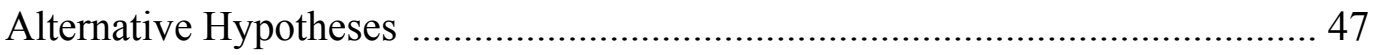

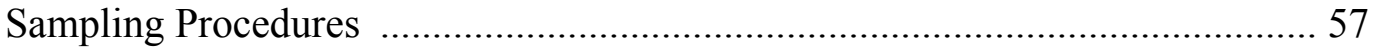

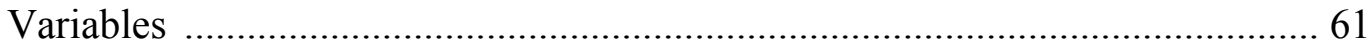

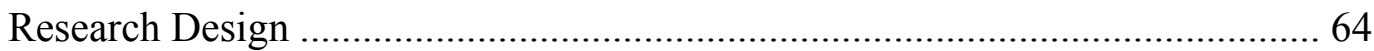

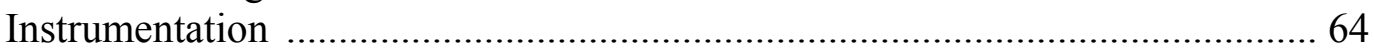

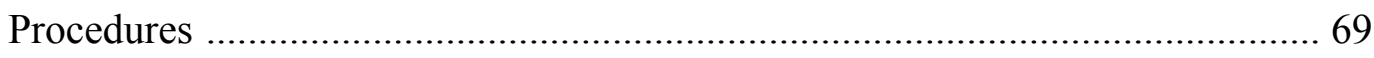

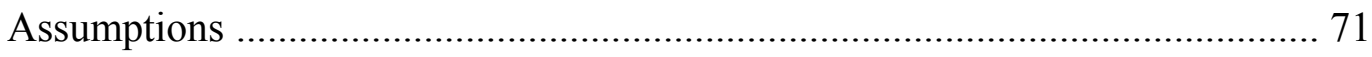

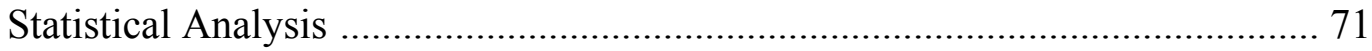

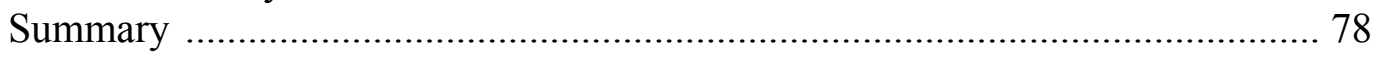

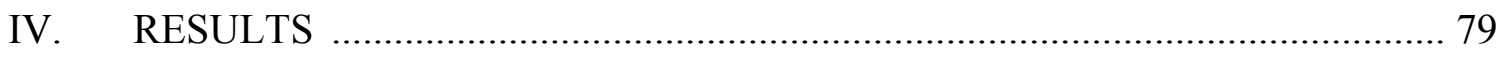

Effect of Performance Feedback .................................................................. 79

Relationship between Perceived Knowledge and Pursuing Continuing

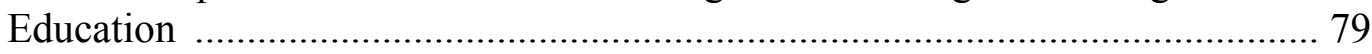

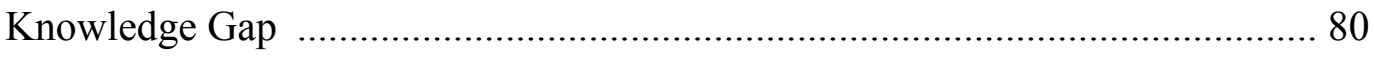

Predictors of Pursuing Continuing Education and Perceived Knowledge........... 81

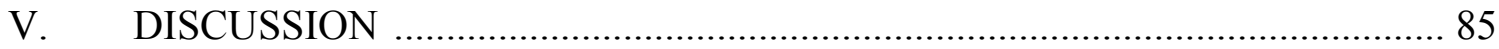

Effect of Performance Feedback ................................................................. 85

Relationship between Perceived Knowledge and Pursuing Continuing

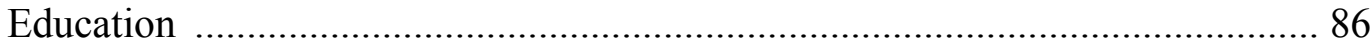

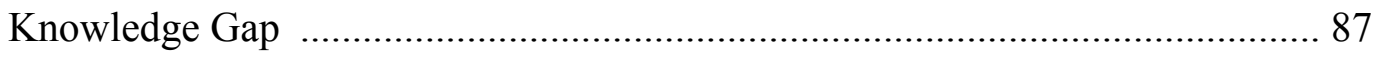

Predictors of Pursuing Continuing Education and Perceived Knowledge........... 88 


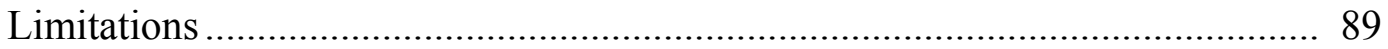

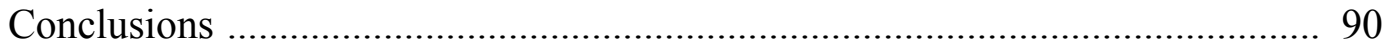

Recommendations for Future Research ....................................................... 91

LIST OF REFERENCES .......................................................................... 93

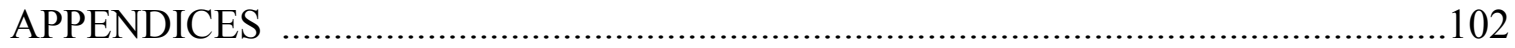

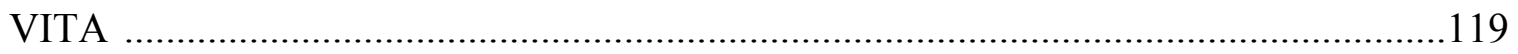




\section{LIST OF TABLES}

TABLE

PAGE

1. Athletic Training Educational Cognitive Competencies Related to the Prevention, Recognition, and Treatment of Heat Illnesses

2. Athletic Training Educational Psychomotor Skills Related to the Prevention, Recognition, and Treatment of Heat Illnesses

3. Athletic Training Educational Clinical Proficiencies Related to the Prevention, Recognition, and Treatment of Heat Illnesses

4. Questions Used to Identify AT Perceptions about the Causes, Treatment, and Success of Treatments and Prevention of EAMC (Stone et al., 2003)

5. January 2008 NATA ATs with Membership by District (NATA, 2008) . .58

6. January 2008 NATA Total Membership by Occupational Setting (NATA, 2008)

7. Demographic Characteristics of Sample $(n=103)$ Compared by Group

8. Perceived Knowledge Questionnaire (Modified from Flynn \&

Goldsmith, 1999)

9. Multiple Linear Regression Models to Analyze Relationship between Perceived Knowledge and Likelihood to Pursue Continuing Education .....

10. Multiple Linear Regression Models to Analyze Linear and Second Degree Relationship between Pre-test and Post-test Knowledge Gap .73

11. Multiple Linear Regression Models to Analyze Relationship between Knowledge Gap and Likelihood to Pursue Continuing Education

12. Multiple Linear Regression Models to Analyze Relationship between Linear and Second Degree Relationships and Likelihood to Pursue Continuing Education When Controlling for Selected Demographic Variables

13. Multiple Linear Regression Models to Analyze the Relationship between Actual Knowledge Gap and the Dependent Variables: Post-test Perceived Knowledge and Likelihood to Pursue Continuing Education

14. Model Summary for Relationships between Perceived Knowledge and Likelihood to Pursue Continuing Education 
15. Model Summary for Linear and Second Degree Relationships between Pre-test and Post-test Knowledge Gap

16. Model Summary for Relationships between Knowledge Gap and Likelihood to Pursue Continuing Education

17. Model Summary Analyzing Relationship between Linear and Second Degree Relationships and Likelihood to Pursue Continuing Education When Controlling for Selected Demographic Variables

18. Model Summary for Relationships between Actual Knowledge Gap and the Dependent Variables: Post-test Perceived Knowledge and Likelihood to Pursue Continuing Education

19. Actual Regression Models for Relationships between Perceived Knowledge and Likelihood to Pursue Continuing Education

20. Actual Regression Models for Relationships between Pre-test and Post-test Knowledge Gap

21. Actual Regression Models for Relationships between Knowledge Gap and Likelihood to Pursue Continuing Education

22. Actual Regression Models for Analyzing Effects of Demographic Variables on the Relationship between Knowledge Gap and Likelihood to Pursue Continuing Education

23. Actual Regression Models for Relationships between Actual Knowledge Gap and the Dependent Variables: Post-test Perceived Knowledge and Likelihood to Pursue Continuing Education 


\section{LIST OF FIGURES}

FIGURE

PAGE

1. Item-by-Item Performance Feedback ......................................................................70

2. 1F Model Summary and Table of Coefficients ..........................................................104

3. 2R Model Summary and Table of Coefficients .....................................................105

4. 3R Model Summary and Table of Coefficients ……….............................................106

5. 3F Model Summary and Table of Coefficients …………………….......................107

6. 5R Model Summary and Table of Coefficients ..........................................................108

7. 5F Model Summary and Table of Coefficients .......................................................109

8. 7R Model Summary and Table of Coefficients .......................................................110

9. 9R Model Summary and Table of Coefficients .....................................................112

10. 11R Model Summary and Table of Coefficients ....................................................113

11. 17R Model Summary and Table of Coefficients ..................................................116

12. 21R Model Summary and Table of Coefficients ..................................................117 


\section{CHAPTER I}

\section{INTRODUCTION}

Armed with the most accurate information, health care providers can afford patients the best possible health care. The dynamic nature of continuing education (CE) makes it an ideal platform to present health care providers with new knowledge that extends beyond entry-level education. Developments in medical research advance the depth and breadth of knowledge at a rate that often exceeds the capabilities of entry-level educators and texts. Therefore, $\mathrm{CE}$ is essential in providing practicing health care professionals with current methods of recognition and treatment of athletic injuries and illnesses. In the Athletic Training profession, CE provides skills that broaden the body of knowledge beyond the National Athletic Trainers' Association (NATA) Educational Competencies of entry-level education. Exertional heat illness and fluid replacement are topics for which research has yielded new knowledge beyond that of entry-level curricula; understanding such advanced clinical skills will help practitioners improve their ability to prevent, recognize, and treat exercise associated muscle cramps (EAMC).

Exercise associated muscle cramps occur most frequently when athletes are participating in extreme environmental conditions (Cooper, Ferrara, \& Broglio, 2006). Most cases of EAMC are benign, attributed to mineral deficiencies, and easily treated (Bergeron, 2003a). Exercise associated muscle cramps can be extremely painful, involve multiple muscle groups, and may be associated with more serious conditions, such as myopathy, rhabdomyolysis, and acute renal failure (Bergeron, 2003a). The NATA Educational Competencies regarding EAMC are limited and do not reflect new research 
regarding prevention, recognition, and treatment. Continuing education is necessary to inform practitioners of these new advances.

Practitioners must be motivated to seek out CE and gain new knowledge about EAMC and exertional heat illness in order for patients to benefit from current medical research. Adult learning theory suggests that the ideal learner is interested in the application of new knowledge and is intrinsically motivated or self-directed, and is therefore capable of directing his or her own learning (Knowles, 1968). Self-directed learners choose what to learn, taking into account both personal and professional experiences (Knowles). These experiences help self-directed learners set educational content, make education decisions, and set goals, which are the three critical steps of the adult learning process (Hewson, 1992). The self-directed learner initiates the educational process after reflecting on his or her own understanding of the topic and identifying a knowledge gap. Once aware of the knowledge gap, the self-directed learner then seeks methods, such as individual learning or CE to address the gap. Researchers measure such knowledge gaps by comparing perceived knowledge, defined as what the learner thinks he or she knows, with actual knowledge, what the learner actually knows. A poor relationship exists between perceived knowledge and actual knowledge (Clark, Jackson, \& Allen-Taylor, 2002; Drass, Muir-Nash, Boykin, Turek, \& Baker, 1989; El-Deirawi \& Zuraikat, 2001; van den Arend, Stolk, Rutten, \& Schrijvers, 2000), suggesting that most learners are unaware of their knowledge gap or are not self-directed and are therefore not likely to pursue CE. Without adequate professional or personal experiences, all learners, even self-directed learners, may require external feedback to identify the gap in their knowledge. Once a learner identifies a knowledge gap, the likelihood of pursuing CE 
may improve (Bandura, 1986; Gist, Schwoerer, \& Rosen, 1989; Hill, Smith \& Mann, 1987; Locke, Frederick, Lee, \& Bobko, 1984).

In formal education or clinical simulation an error can be easily identified and resolved in the next class session. Yet, the ideal, when health care professionals identify a knowledge gap before a professional experience revealed it, is not always realistic. External feedback is an effective means of initiating change and exploring CE opportunities in various professions (Bangert-Drowns, Kulik, Kulik, \& Morgan, 1991; Kulhavy \& Stock, 1989; Meyer, 1986). External feedback, which may be in the form of performance feedback, is necessary for learners in the medical professions to identify the knowledge gap. No research has identified the effects of performance feedback on Certified Athletic Trainers' (AT) perceived knowledge and likelihood to pursue CE. Therefore, the purpose of this study was to identify the effect of performance feedback on ATs' perceived knowledge and likelihood to pursue CE. Because of the risk of fatality and permanent injury related to exertional heat illnesses, ATs' perceived and actual knowledge of current standards for the prevention, recognition, and treatment of EAMC were assessed.

\section{Statement of the Problem}

Developments in medical research advance knowledge at a rate that often exceeds the capabilities of entry-level Athletic Training education. Without adequate professional experiences, all learners, even self-directed learners, may require performance feedback to identify the gap in their knowledge. The poor relationship between perceived knowledge and actual knowledge has been well established, yet the effect of performance feedback on perceived knowledge remains unclear. 


\section{Statement of the Purpose}

The purpose of this investigation was to assess the effect of performance feedback on ATs' perceived knowledge and likelihood to pursue CE regarding the current standards for the prevention, recognition, and treatment of EAMC. Further, the effects demographic variables (gender, occupational setting, occupational region, level of expertise, level of education) on the degree to which the knowledge gap predicts the likelihood to pursue $\mathrm{CE}$ was also examined.

\section{General Research Questions}

This investigation focused on the effect of performance feedback on perceived knowledge and likelihood to pursue $\mathrm{CE}$ as well as the relationship between the research variables.

1. What is the effect of performance feedback regarding actual knowledge on perceived knowledge?

2. What is the effect of performance feedback regarding actual knowledge on likelihood to pursue $\mathrm{CE}$ ?

3. What is the relationship between perceived knowledge and likelihood to pursue CE?

4. What is the relationship between pre-test and post-test knowledge gap?

5. What is the relationship between knowledge gap and likelihood to pursue CE?

6. What are the effects of demographic characteristics on the relationships between knowledge gap and likelihood to pursue CE?

7. What is the relationship between actual knowledge and the dependent variables in the experimental group? 


\section{Delimitations}

Participants were ATs in good standing with the NATA and capable of elementary computer processing skills. Participants were excluded if they did not complete all three parts of the investigation.

\section{Operational Definitions}

Actual Knowledge- Actual knowledge is a measurement of what a learner actually knows and can also be defined as the possession of information (Park, Gardener, \& Thukral, 1988). Actual knowledge was measured using the Actual Knowledge Assessment derived from current literature and standards of practice concerning EAMC (Binkley, Beckett, Casa, Kleiner, \& Plummer, 2002; Casa, Armstrong, Hillman, Montain, Reiff, \& Rich et al., 2000; NATA, 2003).

Continuing Education (CE)- Continuing education is the method of developing competencies for practitioners to meet the shifting expectations of clinical practice. In Athletic Training, requirements are intended to promote continued competence, the development of current knowledge and skills, and the enhancement of professional skills beyond those expected of an entry-level ATC (http://www.bocatc.org/).

Certified Athletic Trainer (AT) - Certified Athletic Trainers are health care professionals specialized in the prevention, recognition, and treatment of injuries and illnesses that result from physical activity (http://www.nata.org/about_AT/whatisat.htm).

Entry-Level Education- core knowledge necessary for competent practice Exercise Associated Muscle Cramps (EAMC) - Exercise associated muscle cramping often presents as intense pain (not associated with acute muscle strain) and 
persistent muscle contractions in working muscles during and after prolonged exercise and most often associated with exercise in heat. Cramping may be associated with "salty" sweating (those with high salt concentration in sweat), high sweat rate or heavy sweating, lack of heat acclimatization, insufficient sodium intake (during meals and practice), hypohydration or excessive thirst, irregular meals, increased fatigue and previous cramping history (NATA, 2003).

Knowledge Gap- Identifying knowledge gap occurs when a poor relationship is established between measurements of actual knowledge and perceived knowledge and often depicts a deficiency of knowledge in a content area. $\mathrm{Z}$ scores were calculated for the pre and post perceived knowledge and actual knowledge assessment variables. Difference scores were used to identify the knowledge gap between pre-test perceived knowledge and actual knowledge as well as post-test perceived knowledge and actual knowledge.

Perceived Knowledge- Perceived knowledge is a measurement of what a learner thinks he or she knows. Throughout the literature perceived knowledge has been termed the "illusion of knowing" (Glenberg, Wilkinson, \& Epstein, 1982) and the feeling of knowing information (Park et al., 1988). Perceived knowledge was measured using the Perceived Knowledge Questionnaire, a 16-item Likert-type assessment modified from Flynn and Goldsmith (1999).

Performance Feedback- Performance feedback is derived from an external source, like a teacher or computer, and is most often provided after a task is completed (Butler \& Winne, 1995). In this study, performance feedback was provided by the computer test-delivery system after the actual knowledge assessment. Summative 
and item-by-item feedback were provided immediately upon submission of the assessment.

\section{Organization of the Study}

This dissertation is organized in five chapters. In the first chapter, the theoretical rationale is presented. The statement of the problem and statement of the purpose, research questions, hypotheses, and operational definitions are presented in chapter one.

Chapter 2 presents an extensive review of the literature including an overview of athletic training education and EAMC. Further, the review of literature provides a critical analysis of research discussing factors that influence participation in continuing education as well as methods of identifying the knowledge gap. The third chapter describes the methods proposed for this investigation and includes sections on research questions, sampling procedures, variables, research design, instrumentation, procedures, limitations, delimitations, and statistical analysis. A comparison between the proposed methods and similar studies helps to establish the rationale for the design, sampling, and statistical decision making. The results, found in chapter 4 , provide an analysis of the data. Finally, chapter 5 provides a discussion and interpretation of the findings of this investigation as well as integration with previous research.

Summary

This chapter provided the rationale for this investigation based upon previous literature. A brief review of the pertinent literature helped to establish the need to understand the relationship between actual knowledge and perceived knowledge. Further, the role of performance feedback on perceived knowledge has not yet been investigated. In chapter 2 , a more thorough review of the literature is provided. A 
critical analysis of athletic training education, EAMC, factors that influence participation in $\mathrm{CE}$, and identifying the knowledge gap is included. 


\section{CHAPTER II}

\section{LITERATURE REVIEW}

The purpose of this critical analysis of the literature is to discuss the role of education, both entry-level and continuing, in maintaining and updating ATs' knowledge and practices. Because new research beyond the scope of entry-level education has been presented in the area of exertional heat illnesses, current research regarding EAMC are described. Finally, both the likelihood to pursue CE and methods of identifying the knowledge gap are discussed.

Certified Athletic Trainers are health care professionals responsible for the prevention, recognition, and treatment of athletic injuries and illnesses. Health care professionals have embraced the medical model of educating as the best method of transmitting problem-based, patient-based entry-level education. The medical model of educating incorporates balanced, rigorous didactic instruction and quality clinical experiences (Ford, 1978). Entry-level education creates the base of knowledge for early practitioners, yet we are continually seeking more effective and efficient treatment methods, especially in areas of active research. However, entry-level education often requires several years of study to delineate new curricula standards. Therefore, $\mathrm{CE}$ is often the best method of transmitting this new knowledge to practitioners. Pursuit of CE is strongly influenced by self-directed learning, but may often require performance feedback (Bangert-Drowns et al., 1991; Kulhavy \& Stock, 1989; Meyer, 1986).

All ATs and most health care professionals are required to participate in CE, but often practitioners choose to attend convenient sessions that pique their interest. Without an external mechanism, ATs and other health care professionals may lack the self- 
direction to recognize a knowledge gap. This investigation provided the performance feedback that may be necessary for ATs to recognize a gap in knowledge and subsequently pursue $\mathrm{CE}$.

\section{Education in Athletic Training}

\section{Medical Model of Educating}

Clinical education developed from "the natural method of teaching" in which students journey with the patient from diagnosis and treatment to the dissipation of the condition (Osler, 1928). With the emergence of formal training for medical professionals, clinical education was engrained in didactic performance. The combined direction of medical education changed with the development of the clerkship where the role of the student was to actively learn and practice within the hospital (Osler). When the clerkship was implemented, within the clinical-teaching paradigm, hospitals were not controlled by medical schools (Osler) and resisted formal teaching because of the stringent regulations set forth by the hospitals' boards of administration (Ludmerer, 1985). But as the clinical-teaching paradigm strengthened, medical schools built and governed their own hospitals and the clerkship prevailed (Lippard, 1974). Similar to the development of medical professional education, the curriculum of Athletic Training transformed from the internship perspective into the dual focused, didactic and clinical, educational design.

The Athletic Training profession has recently reshaped the entry-level curriculum to parallel the educational objectives of similar health care professions, such as Nursing and Physical Therapy. In 2004, the NATA and Board of Certification (BOC) embraced educational reform that sought to improve the professional preparation of entry-level ATs 
through the following objectives: building a healthy, reasonable, and financially tolerable clinical learning environment for students; integrating a clinical education model based on measurable, standardized, and referenced learning objectives; integrating competencies in education; integrating clinical-education objectives; improving clinical instruction; integrating the best elements of the internship and curriculum routes to form a single, better educational model; resolving disparities in the preparedness of entry-level ATs; and standardizing the route to certification (McMullen, 1997; Starkey, 1997). Educational reform in Athletic Training initiated competency-based education and created a system of accountability within the profession.

\section{Educational Reform in Athletic Training}

Competency-based education has emerged as the standard for the development and implementation of clinical education in health care professions (Ford, 1978). Clinical education of Athletic Training professionals has evolved from "by chance" learning experiences to structured and organized curriculum (Weidner \& Henning, 2002). Clinical education is the formal acquisition, practice, and evaluation of the entry-level Athletic Training Clinical Proficiencies through classroom, laboratory, and clinical education experiences under the direct supervision of an Approved Clinical Instructor (NATA, Education Council). Originally, the professional preparation of ATs (previously referred to as the "internship route" to certification) focused primarily on clinical experiences and less on formal, didactic instruction (Weidner \& Henning, 2002). Standards designed to homogenize the learning environments of Athletic Training Students (ATS) have already improved the quality of clinical education (Weidner \& Henning, 2002). In 2001, clinical education setting standards were proposed to 
normalize learning environments of entry-level ATs (Weidner \& Laurent, 2001). The standards outlined the essential personnel, administration, and environmental factors for the high quality clinical education experiences that learners need. Researchers have sought to evaluate these standards from the entry-level AT perspective (Laurent \& Weidner, 2002). A random sample of 500 ATs (261 respondents, $65.1 \%$ response rate) completed a 22-item questionnaire. Respondents were excluded if they were not employed or had not graduated from an Athletic Training education program (129 total questionnaires were available for analysis). Participants reported that $53.6 \%$ of perceived preparation was experienced through clinical education (Laurent \& Weidner), demonstrating a well executed balance between clinical and didactic instruction. The findings suggest equilibrium exists between clinical and didactic education; however, graduates who are not practicing as ATs were not surveyed and these respondents may have an important perspective on an imbalance between the clinical and didactic setting that led them away from AT. Their sample population may reveal more information regarding the influence of clinical education and should be investigated further. Without all possible respondents reporting in the investigation, the researchers could only suppose the balance between didactic and clinical education exists. The recent establishment of a standardized curriculum probably regulates the transmission of both didactic and clinical education (Craig, 2003) and has normalized learning environments.

The education of entry-level ATs is dependent upon the appropriate balance of clinical and didactic instruction. Just prior to education reform in Athletic Training, researchers asked ATSs, classroom and clinical instructors their perceptions about the relationship between didactic and clinical education (Carr \& Drummond, 2002). 
Participants completed a questionnaire that measured physical presence, cooperation, and communication between clinical and classroom instructors. Athletic Training students estimated the physical presence, cooperation, and communication between the clinical and classroom instructors. These students also rated the quantity or frequency of physical presence and the quality of cooperation and communication between clinical and classroom instructors. Classroom instructors perceived a significantly higher frequency of cooperation than clinical instructors. Athletic Training students reported significantly fewer communication occurrences than both clinical instructors and classroom instructors. Although, the findings suggest that an equal balance between didactic and clinical education was still not achieved (Carr \& Drummond), the investigation occurred before the final phases of educational reform, and therefore future evaluation of the reformation may better describe this crucial relationship.

Before the development of clinical competencies, students often felt they were part of a work-force and were lacking focused clinical instruction (Davis \& Misasi, 2001; Harris \& Naylor, 1992; Melia, 1987). Although no significant differences were identified among different athletic populations and settings, Weidner \& Pipkin (2002) reported that junior and senior students perceived that $75 \%$ of their planned clinical experience was unsupervised. Students may miss learning opportunities with the absence of instruction and continuous feedback in the clinical setting (Weidner \& Pipkin). The researchers suggested supervision and direction during clinical course work needed improvement and that the quantity of clinical experiences was not equal to the quality of clinical experiences (Weidner \& Pipkin). The accumulation of research, summarized by Craig 
(2003), in conjunction with leaders in Athletic Training helped shape educational reform within the profession.

The goals of Athletic Training clinical education reform are to build a healthy, reasonable, and financially tolerable clinical learning environment; integrate a clinicaleducation model based on measurable, standardized, and referenced learning objectives; integrate competencies and clinical-objectives; and to improve clinical instruction (Craig, 2003). These goals, as well as the motivation to compete among other health care professions, supported the transition to the modularized concept of Athletic Training education (Knight, 1990), which embraced educational competencies and proficiencies within the clinical education experiences. This began a focused and planned clinical education process in which fewer experiences occurred by chance and learning was facilitated through the clinical instructor.

Clinical education affords students opportunities to practice clinical proficiencies under the direct supervision of a clinical instructor. Approved Clinical Instructors provide the formal instruction and evaluation of clinical proficiencies to ATSs in classroom, laboratory, and/or in clinical education experiences (NATA, Education Council). Clinical education researchers developed clear and concise objectives for the roles and responsibilities of Approved Clinical Instructors (Weidner \& Henning, 2004). Developing standards was again another method of homogenizing educational experiences for ATSs and were designed for use in the selection, training, and evaluation of Approved Clinical Instructors in Athletic Training education programs. Weidner and Henning used a three round survey method, the Delphi technique, to find consensus on the standards. Sixteen panelists met the criteria for participation and completed all three 
rounds of the investigation. Results indicated consensus on seven standards (Legal and Ethical Behavior, Communication Skills, Interpersonal Relationships, Instructional Skills, Supervisory and Administrative Skills, Evaluation of Performance, and Clinical Skills and Knowledge) and 50 distinct criteria (Weidner \& Henning, 2004). That study created the standards and criteria for the selection, training, and evaluation of Approved Clinical Instructors; however implementation and execution within the profession are still necessary.

\section{Continuing Education}

Certified Athletic Trainers must continue to gather new knowledge beyond the scope of entry-level education. The BOC has established that all ATs must obtain a predetermined number of $\mathrm{CE}$ units within a 3 year reporting term (BOC, Continuing Education). Requirements for continued education facilitate that ATs stay current in the advancements in Athletic Training practice. The purposes of the CE requirements center on assuring that ATs continue to: obtain current professional development information, explore new knowledge in specific content areas, master new Athletic Training-related skills and techniques, expand approaches to effective Athletic Training, further develop professional judgment, and conduct professional practice in an ethical and appropriate manner (BOC, Continuing Education). Traditional methods of transferring knowledge through CE include the large, lecture-oriented conferences that are readily available to ATs; usually occurring annually at local, regional, and national levels. Yet, researchers propose that such opportunities do not incorporate the principles of adult learning theory and, therefore, may not have the expected outcomes desired (Davis, Thomson O'Brien, 
Freemantle, Wolf, Mazmanian, \& Taylor-Vaisey, 1999; Gristci \& Jacono, 2006; Pitney, 1998).

\section{Alternative Methods of Instruction in Athletic Training}

Although the medical profession led the way for other health care professions to initiate educational reform and embrace the principles of formal clinical education, problem-based learning and critical thinking instructional techniques have remained principal components to effective medical curricula and the development of sound clinical decision making.

Problem-based learning. Problem-based learning is an alternative form of instruction (Sonmez, 2003) that encourages students to take real life experiences from clinical application settings and allow these problems to evolve into solutions through discussion. Problem-based learning in medical curricula developed from the systematic approach a physician uses to definitively diagnose a patient's condition or injury revolutionized by (Barrows \& Tamblyn, 1980). In the first step, physicians gather information from the patient allowing a narrowing of the scope of the injury. Then, advantageous at this stage, the physician develops between two and five hypotheses, as multiple diagnoses. Physicians collect data further through the use of clinical and technical diagnostic testing. The fourth step involves a definitive diagnosis, and finally the fifth step involves a plan of action for the course of treatment for the patient (Barrows \& Tamblyn). The same steps apply to the concept of problem-based curricula, by allowing students to seek a problem, gather information, and while keeping a broad lens, realize that there is not always one right way for everything. This ambiguity is difficult for some students, especially in the early stages of problem-based curriculum 
implementation (Van den Hurk, Dolmans, Wolfhagan, \& Van der Vleuten, 2001); however, the long-term benefits outweigh the growing pains.

Student-directed learning is an important aspect of problem-based curricula, and along with critical thinking skills and lifelong learning skills are essential components of medical curricula by the Pew Health Professions Commission. The report stated that medical curricula should be redesigned to include "critical thinking and clinical judgment skills, effective organizational and team work skills, service orientation, cost awareness, accountability of clinical outcomes and quality care, and a commitment to continual learning and development" (Bellack \& O'Neil, 2000, p. 16). These recommendations initiated reform and provided the objectives for an improved medical based curriculum (Dowd, 1994; Jones, 2002).

Problem-based learning trained students are more frequent users of the library, use a more holistic approach, integrate new information or techniques more readily, adapt to change, and work as a team member (Smith, 1995). A problem-based curriculum stimulates thinking through the use of discussion. Often, instructors act as facilitators while small groups define, integrate, and solve problems. When issues in the classroom stem from real life situations, students are more likely to become involved and engaged and retain information to utilize in the clinical setting. Researchers observed and interviewed graduates $(n=3)$ from a physical therapist program with a problem-based learning curriculum and participants provided reflective journaling during the same period of observation (Wilson, Gallagher, Elbaum, \& Smith, 2001). The graduates believed that problem-based learning aided in problem solving and critical thinking skills, but that they were equal to their lecture-based educated peers (Wilson et al.). Although 
the researchers did not report differences between the two approaches to educating, their qualitative findings described student-assessment of their participation in a problembased curriculum.

Professionals and students in Athletic Training also shared perceptions about pedagogic strategies deemed effective in learning environments. Twenty-one students and 12 instructors were interviewed to examine perceptions about learning and teaching experiences (Mensch \& Ennis, 2002). Although this investigation did not isolate problem based learning, participants described classroom experiences deemed effective in enhancing students learning. A qualitative analysis of the interviews revealed three pedagogic strategies essential in the transfer of knowledge in Athletic Training. Participants reported that the use of scenarios and case studies as instructional tools in experiential learning, a problem-based approach, was effective in developing clinical decision making. Further, the use of authentic Athletic Training experiences as an effective teaching method also emerged from the interview data. Athletic Training students suggested that the most effective instructional tool was when clinical and classroom instructors encouraged them to share experiences and to discuss real patients. Scenarios and authentic experiences used in the classroom to facilitate discussion and improve clinical decision making are integral components of problem based learning and ATSs believed both were effective methods of enhancing knowledge in Athletic Training. Problem-based learning is an essential component for effective medical curricula because of its role in the development of appropriate clinical decision making. Teaching critical thinking skills helps to facilitate clinical decision making through prioritization, adaptation and reflection. 
Critical thinking skills. Critical thinking is essential in health professions because of the need to prioritize, anticipate change, troubleshoot, communicate, make sound and informed decisions, negotiate, and reflect on the outcomes of care (Goodfellow \& Valentine, 2002). Curricula should incorporate critical thinking skill development within the objectives. Because several specialists collaborate to make a successful sports medicine team, all health care professionals should be exposed to critical thinking teaching methods to advance clinical decision making. Critical skill development is transformational and improves with time and practice, so development of these skills early in the education process is most effective (Arnold \& Keller, 2002; Van den Hurk et al., 2001).

The development of critical thinking skills is a transformation and is often more difficult in beginner students, but as students mature critical thinking improves. High school students interested in entering medical professions participated in technology based learning (a pre-professional health science course) to develop critical thinking skills (Arnold \& Keller, 2002). The pre-professional health science course involved the use of four computer modules to promote discussions within small groups and within the whole class. Students wrote essays about problems in the clinical setting, which was complemented by direct observation. The researchers investigated the first year of the course, sought out flaws, and then reevaluated the second year of implementation. Using the Hounsell (1984) method of analyzing the nature of the essay, the researchers reviewed the essays placed each in one of three categories. Categories included essay as argument (students able to synthesize data into a single interpretation), essay as viewpoint (student expresses a clear point of view but lacks the appropriate organization 
of thoughts), and essay as arrangement (data is presented as discrete facts and no central theme emerges). In the first year of implementation, the researchers established that $43.33 \%(26 / 60)$ of students improved from the lowest level (essay of arrangement) to the essay of viewpoint level. In the second year of implementation, the students' essay writing improved to a level of essay as viewpoint in 50\% of students (30/60). The researchers concluded that critical thinking skills in conjunction with computer technology could improve over the course of a year. In the early stages of this project, the researchers described superficial discussions with few evidence-based responses from students. As the students progressed, they provided more elevated thoughts and responses which integrated previously shared perspectives and literature (Arnold \& Keller). Although no significance testing was performed, the researchers suggested that this curriculum integrating critical thinking and technology was successful in enhancing student discussion and essay writing. Success was also connected to level of experience with the instructional method, and therefore future research should compare different groups of experienced and novice students with critical thinking pedagogy. With time and comfort, implementation of this type of curricular technique in secondary school education should further improve students' critical thinking skills and transform young learners into evidence-based decision makers.

Critical thinking is required of health care professionals who must continuously think in terms of prioritization, anticipation, troubleshooting, communication, negotiation, reflection, and decision making. Respiratory therapists assessed their own critical thinking behaviors in order to create a typography of the profession (Goodfellow \& Valentine, 2002). The researchers identified three types of respiratory therapists. 
Type I $(43.4 \%, 377 / 868)$ respondents were mostly experienced female professionals working in hospitals and perceived that their strengths were in both problem solving and skilled communication. Alternatively, Type II $(29.0 \%$; $252 / 868)$ respiratory therapists were also mostly female, but worked in alternative settings and scored themselves low in both situated problem solving and low in skilled communication. Type III (27.6\%; 239/868) respiratory therapists, primarily males working in hospitals with weak interpersonal skills, scored themselves low in skilled communication but high in situated problem solving. The researchers concluded that respiratory therapy professionals require more pre-service teaching and on- the-job learning experiences to develop problem solving and critical thinking. Pre-service education should emphasize experience, expertise, and reflection to facilitate critical thinking (Goodfellow \& Valentine). These researchers proposed that integrating more ambiguity in the classroom will allow for more problem-based learning and the development of critical thinking skills (Goodfellow \& Valentine). Ambiguity in the classroom will legitimize reasoning and improve coping skills by forcing students to confront multiple points of view and build solid and grounded arguments using higher levels of critical thinking. Incorporating critical thinking skills curricula into clinical education seminars may be an appropriate method of improving clinical decision making in pre-service education.

Critical thinking skills and problem-based learning instruction are both integral aspects of the medical education model. As such, critical thinking teaching methods in conjunction with problem-based learning in didactic education can help facilitate more advanced and quality clinical experiences. Medical education is constantly changing to incorporate new, more effective teaching methods to best provide entry-level ATs with 
current information, yet the competencies and proficiencies may not always reflect current literature. The role of CE in disseminating current research is influential in maintaining AT knowledge and best-practice.

\section{Exercise Associated Muscle Cramping}

Exercise-associated muscle cramping is a condition commonly experienced by athletes limiting participation and hindering performance, and is an area of flourishing research. Several professional organizations and collaborative task-forces have worked to best define and prescribe an appropriate rationale for the recognition and treatment of EAMC (Binkley et al., 2002; Casa et al., 2000; NATA, 2003). Exercise-associated muscle cramping is one of the most common exertional heat illnesses occurring when athletes are participating in extreme environmental conditions. In a recent epidemiological study, 70\% (6.31 incidents/1000 athlete exposures) of total heat illnesses occurring in August (mean wet bulb globe temperature $=28.98^{\circ} \pm 4.67^{\circ} \mathrm{C}$ for practice session 1 and $27.14^{\circ} \pm 2.70^{\circ} \mathrm{C}$ for practice session 2 ) at five southeastern US universities (Cooper et al., 2006). Most cases of cramping are benign, attributed to mineral deficiencies, and easily treated (Binkley et al. 2002). However, EAMC can be extremely painful, involve multiple muscle groups, and may be associated with more serious conditions, such as myopathy, rhabdomyolysis, and acute renal failure (Bergeron, 2003b). Several recent investigations have provided theories to explain the exact etiology of EAMC including fatigue and the resultant abnormal control of motor neuron activity, fluid/electrolyte imbalance, hypohydration, and hyperthermia (Jung, Bishop, AlNawwas, \& Dale, 2005; Stofan, Zachwieja, Horswill, Murray, Anderson, \& Eichner, 2005; Sulzer, Schwellnus, \& Noakes, 2005). Other investigations (Dombek, Casa, 
Yeargin, Mazzerole, Ganio, \& Armstrong et al., 2006; Stone, Edwards, Stemmans, Ingersoll, Palmieri, \& Krause, 2003) attempted to identify perceived knowledge and selfreported behaviors regarding EAMC and exertional heat stroke. These investigations provide the initial information necessary in identifying a knowledge gap, but fail to provide ATs with subsequent feedback to initiate necessary changes in professional practice. The purpose of this investigation is to identify both the knowledge and perceptions and provide performance feedback about the prevention, recognition, and treatment of EAMC.

Possible Mechanisms Contributing to EAMC

Fatigue. Muscle fatigue is widely accepted as a factor in EAMC, although difficulty arises in attempting to rule out dehydration and sodium depletion as possible causes (Schwellnus, Nicol, Laubscher, \& Noakes, 2004; Sulzer et al., 2005). Some research suggests that EAMC is singularly caused by a neuromuscular origin, specifically with altered motor neuron activity secondary to a muscle spindle and golgi-tendon organ imbalance (Bentley, 1996; Schwellnus, Derman, \& Noakes, 1997). Endurance athletes experienced cramping due to fatigue although the participants also suffered from diminished plasma sodium concentrations (Schwellnus et al., 2004). The theory that fatigue is the cause of EAMC suggests that neurological hyperexcitability and adenosine triphosphate depletion may cause an inability for muscles to relax following contraction. Cramps occurring after prolonged exercise or causing premature cessation of prolonged exercise bouts support the fatigue theory (Schwellnus et al., 2004). EAMC did not occur in marathon runners before $28 \mathrm{~km}$ of a $42.2 \mathrm{~km}$ race and $76 \%$ of the athletes experiencing the cramps relieved the pain and spasm by slowing their running pace (Schwellnus et al., 
2004). Although the relationship between the subjects' pace and lactate threshold is unknown, the researchers theorized that the runners were slowing down to an oxygen consumption level less than their lactate threshold. Neither of these investigations provided blood-lactate measures and therefore further research is necessary to identify fatigue as the primary causal factor in the development of EAMC.

Sodium depletion. Increased sweat rate causes water and electrolyte losses, which leads to both dehydration and sodium depletion (Wexler, 2002). The primary concern with sodium losses in athletes is the resultant hyperexcitability of specific motor nerve endings due to mechanical stress and changes in surrounding electrolyte concentrations (Jansen, Joosten, \& Vingerhoets, 1990; Layzer, 1994). Serum sodium concentrations were decreased in tennis (Bergeron, 2003a; Bergeron, 1996) and football players (Stofan et al., 2005) after exercising in the heat. Plasma sodium concentrations were statistically diminished in both cramping and non-cramping endurance athletes however the loss of sodium depletion was not indicative of clinical ( $<136 \mathrm{mmol} / \mathrm{L}$ : diagnostic criterion for hyponatremia) sodium depletion (Schwellnus et al., 2004; Sulzer et al., 2005). Since endurance athletes who experience hyponatremia do not necessarily cramp, the link between sodium depletion and EAMC may be related to rate of sodium loss rather than the plasma sodium concentrations measured following activity. Division I football players who cramped lost greater amounts of sodium than non-crampers (Stofan et al.); however, gross individual differences in sweat rate made it impossible to establish statistical significance. The current literature has not established a causal relationship between sodium depletion and EAMC; however, the role of sweat rate in the development of EAMC has yet to be thoroughly investigated. 
Hypohydration. Excessive water loss (hypohydration) has been mentioned as a possible cause of EAMC (Wexler, 2002). Because of the relationship between water loss and sodium depletion, researchers have failed to separate the two in identifying the cause of EAMC. Fluid loss results in sodium depletion through sweat loss and negatively impacts the ability of skeletal muscle to contract. Dehydration diminishes performance by decreasing the time to onset of fatigue by $15 \%$ (Montain, Smith, Mattot, Zientara, Jolesz, \& Sawka, 1998) and prolonging "suicide" sprint times by $3 \mathrm{~s}$ in adolescent male basketball players (Dougherty, Baker, Chow, \& Kenney, 2006). Dehydration results in a $23 \%$ decrease in endurance time of contraction ( $25 \%$ of maximal contraction) and failure to resist fatigue in skeletal muscles (Bigard, Sanchez, Claveyrolas, Martin, Thimonier, \& Arnaud, 2001). On the contrary, no decrements in muscle output have been reported with dehydration only (Gonzalez-Alonso, Calbet, \& Nielsen, 1999), suggesting that hyperthermia, and not dehydration, may be the cause of strength deficits in skeletal muscle following exercise in the heat. Little empirical evidence exists supporting the link between hypohydration and EAMC, and further, the inherent connection between dehydration and sodium depletion has made researching the condition increasingly difficult.

Hyperthermia. The role of hyperthermia (elevated core body temperature) in the development of EAMC has not yet been established in controlled laboratory experiments. Observational research and clinical case reports have demonstrated that prolonged exercise in hot, humid environments exposes athletes to hyperthermia and at times subsequent EAMC (Bergeron, 1996; Schwellnus et al., 2004; Stofan et al., 2005; Sulzer et al., 2005). When athletes have developed EAMC due to muscle fatigue alone 
(Schwellnus et al., 2004; Sulzer et al.), ambient conditions reported were not extreme (ambient temperature: $14.3-23.8^{\circ} \mathrm{C}$ and relative humidity: $47 \%$ [Schwellnus et al., 2004]; ambient temperature: $20.5^{\circ} \mathrm{C}$ and relative humidity: $68 \%$ [Sulzer et al.]). Other researchers have reported the development of EAMC in more extreme conditions both in the mornings (ambient temperature: $22.8-27 .{ }^{\circ} \mathrm{C}$, and relative humidity: $72-93 \%$ ) and in the evenings (ambient temperature: $30.8-28.2{ }^{\circ} \mathrm{C}$, and relative humidity $51-72 \%$ in [Stofan et al.]). Hot, humid environments and the increased metabolic rate associated with exercise causes an increase in core body temperature and subsequently increased sweating as a thermoregulatory response (Wexler, 2002). Although the hyperthermia theory as a cause of EAMC remains unclear, the varied environmental conditions demonstrated among these investigations may suggest a possible relationship between environmental conditions, subsequent hyperthermia and the development of EAMC. Education and Guidelines for the Prevention, Recognition, and Treatment of EAMC

The NATA Education Council has established educational cognitive competencies (Table 1), psychomotor skills (Table 2) and clinical proficiencies (Table 3) to provide guidelines to increase safety and performance of physically active individuals participating in hot, humid environments (NATA, Education Council). 
Table 1

Athletic Training Educational Cognitive Competencies Related to the Prevention, Recognition, and Treatment of Heat Illnesses Cognitive

Competency Description

1 Describe pathological signs of acute/traumatic injury and illness including, but not limited to, skin temperature, skin color, skin moisture, pupil reaction, and neurovascular function.

Identify the signs, symptoms, and treatment of patients suffering from adverse reactions to environmental conditions.

Identify information obtained during the examination to determine when to refer an injury or illness for further or immediate medical attention.

Explain the importance and proper procedures for measuring body temperature (e.g., oral, axillary, rectal). Explain normal and abnormal circulation and fluid homeostasis.

5 Identify and explain the epidemiology data related to the risk of injury and illness related to participation in physical activity. 
Table 1

Athletic Training Educational Cognitive Competencies Related to the Prevention, Recognition, and Treatment of Heat Illnesses (cont.)

Cognitive

Competency

Description

6

Explain the principles of effective heat loss and heat illness prevention programs. Principles include, but are

not limited to, knowledge of the body's thermoregulatory mechanisms, acclimation and conditioning, fluid

and electrolyte replacement requirements, proper practice and competition attire, and weight loss.

Explain the accepted guidelines, recommendations, and policy and position statements of applicable

governing agencies related to activity during extreme weather conditions.

Interpret data obtained form a wet bulb globe temperature (WBGT) or other similar device that measures heat and humidity to determine the scheduling, type, and duration of activity.

Recognize the clinical signs and symptoms of environmental stress.

Describe the clinical signs and symptoms of environmental stress. 
Table 2

Athletic Training Educational Psychomotor Skills Related to the Prevention, Recognition, and Treatment of Heat Illnesses Psychomotor

Skill Description

$1 \quad$ Implement appropriate emergency treatment strategies including, but not limited to: normalize body temperature in situations of sever/life-threatening heat or cold stress.

Perform a secondary assessment and employ the appropriate management techniques for non-life-threatening situations, including but not limited to: environmental illness.

Apply commonly used special tests and instruments (e.g., otoscope, stethoscope, ophthalmoscope, peak flow meter, chemical "dipsticks" [or similar devices], and document the results for the assessment of: (a) Vital signs including respiration (including asthma), pulse and circulation, and blood pressure, (b) Heart, lung, and bowel sounds, (c) Pupil response, size and shape, and ocular motor function, (d) Body temperature, and (e) Urinalysis.

4 Obtain, interpret, and make decisions regarding environmental data. This includes, but is not limited to: (a) Operate a sling psychrometer and/or wet bulb globe index, (b) Access local weather/environmental information, and (c) Assess hydration status using weight charts, urine color charts, or specific gravity. 
Table 3

Athletic Training Educational Clinical Proficiencies Related to the Prevention, Recognition, and Treatment of Heat Illnesses Clinical

Proficiency

Description

Demonstrate the ability to manage acute injuries and illnesses. This will include surveying the scene, conducting an initial assessment, utilizing universal precautions, activating the emergency action plan, implementing appropriate emergency techniques and procedures, conducting a secondary assessment and implementing appropriate first aid techniques and procedures for non-life-threatening situations. Effective lines of communication should be established and the results of the assessment, management, and treatment should be documented.

Demonstrate a general and specific (e.g., head, torso and abdomen) assessment for the purpose of (a) screening and referral of common medical conditions, (b) treating those conditions as appropriate, and (c) when appropriate, determining a patient's readiness for physical activity. Effective lines of communication should be established to elicit and convey information about the patient's status and the treatment program. While maintaining confidentiality, all aspects of the assessment, treatment, and determination for activity should be documented using standardized record-keeping methods. 
Table 3

Athletic Training Educational Clinical Proficiencies Related to the Prevention, Recognition, and Treatment of Heat Illnesses (cont.)

Clinical

Proficiency

Description

3 Demonstrate the ability to develop, implement, and communicate effective policies and procedures to allow safe and efficient physical activity in a variety of environmental conditions. This will include obtaining, interpreting, and recognizing potentially hazardous environmental conditions and making the appropriate recommendations for the patient and/or activity. Effective lines of communication shall be established with the patient, coaches, and/or appropriate officials to elicit and convey information about the potential hazard of the environmental condition and the importance of implementing appropriate strategies to prevent injury.

Beyond the educational competencies, the Inter-association Task Force and the NATA task forces identified strategies to optimize proper care of dehydration, exertional heat stroke, heat exhaustion, heat cramps and exertional hyponatremia (Binkley et al., 2002; Casa et al., 2000; NATA, 2003). The risks associated with exercise in the heat are well documented, and although the literature about EAMC continues to grow, policies and procedures to prevent, recognize and treat "heat cramps" (common misnomer for EAMC) are available. 
Prevention of EAMC. Additional sodium (.5 g of sodium dissolved in about 1.0 L) may be necessary prior to activity and is best administered by diluting the salt into a carbohydrate-electrolyte beverage (especially in athletes with history of heat cramps). This sodium-infused beverage consumed prior to exercise may help to provide ample fluids and sodium, and the flavor (while certainly saltier) is still very palatable. In cases of recurrent cramping, diet, rehydration practices, electrolyte consumption, fitness status, level of acclimatization, and use of dietary supplements should be reviewed and modified (NATA, 2003). The competencies and proficiencies fail to provide detailed recommendations about prevention, especially in regards to fluid and sodium replacement strategies. Current literature reaches beyond the scope of entry-level education and reflects best-clinical practice.

Recognition of EAMC. Practitioners can best recognize patients with EAMC complaining of (a) intense pain (not associated with acute muscle strain) and (b) persistent muscle contractions in working muscles during and after prolonged exercise and most often associated with exercise in heat. Additionally, athletes complaining of persistent cramping are also associated with (a) "salty" sweating (those with high salt concentration in sweat), (b) high sweat rate or heavy sweating, (c) lack of heat acclimatization, (d) insufficient sodium intake (during meals and practice), (e) hypohydration or excessive thirst, (f) irregular meals, (g) increased fatigue, and (h) previous cramping history (NATA, 2003). The competencies and proficiencies call upon the NATA position statements to appropriately define EAMC (Binkley et al., 2002; Casa et al. 2000). 
Treatment of EAMC. Athletes suffering from EAMC should re-establish normal hydration status and replace some sodium losses with a carbohydrate-electrolyte beverage or other sodium source. Light stretching, relaxation and massage of the involved muscle may help resolve the acute pain of a muscle cramp. When considering return-to-play the athlete should determine if they can perform at the level needed for successful participation (NATA, 2003). Again, the current competencies and proficiencies provide vague suggestions for treatment of EAMC and therefore the position statements provide the most appropriate guidelines (Binkley et al., 2002; Casa et al., 2000; NATA, 2003). Knowledge and Behaviors of Certified Athletic Trainers on EAMC

The NATA position statements and the Inter-Association Task Force consensus statement provide the best and most appropriate guidelines (Binkley et al., 2002; Casa et al., 2000; NATA, 2003); however, subsequent investigations have provided information about ATs' self-reported behavior and knowledge about exertional heat illnesses. ATs have described their knowledge about the prevention, causes, and treatment of EAMC, yet the researchers may have biased the participants because of their belief that EAMC is solely the result of fatigue (Stone et al., 2003). ATs identified perceptions about the causes, treatment, and their success in treatments and prevention of EAMC using Likerttype (4-point: Very Important, Somewhat Important, Important, Not Important) and open-ended questions (Table 4).

The inconsistency among participant responses demonstrated confusion among ATs about the most appropriate methods for the prevention, recognition and treatment of EAMC and as such, there was insufficient evidence to support the researchers' belief that EAMC is solely a result of fatigue (Stone et al., 2003). The questionnaire and methods 
utilized in this investigation may have contributed to the confusion among responses. Further research with rigorous instrumentation may provide a clearer representation of AT knowledge and behavior regarding the prevention, recognition, and treatment of EAMC.

Table 4

Questions Used to Identify AT Perceptions about the Causes, Treatment, and Success of Treatments and Prevention of EAMC (Stone et al., 2003)

Type Question

Likert How important are the following factors as causes of EAMC?

How successful are the following treatments for managing EAMC?

Rate your success in treating EAMC

How successful are the following methods for preventing EAMC?

Open-Ended What is the most common cause of EAMC?

How do you treat EAMC?

What is the best method for preventing EAMC?

Recently, researchers investigated the current practices of ATs regarding the prevention, recognition, treatment, and return-to-play guidelines of exertional heat stroke in high school athletics (Dombek et al., 2006). The researchers suggested that ATs possess adequate knowledge regarding exertional heat stroke, but do not implement evidence-based best clinical practice. Based upon this pilot investigation, educational competencies should be revised to include factors that cause exertional heat stroke, the utilization of a valid temperature device for assessment, the preferable cooling modality for treatment, and guidelines for return to play. 
There exists a disconnect between entry-level, competency-based education and practitioner implementation with regard to heat illness (Dombek et al., 2006; Stone et al., 2003). The most recent membership information indicates that approximately $60 \%$ of ATs have a master's degree and $6 \%$ a doctorate, suggesting the profession acknowledges the value of post-professional education (NATA Membership Statistics, 2008). Further, AT leadership calls for more advanced Athletic Training-specific education (NATA, Education Council), which may be available in the form of advanced degrees in AT or CE. Continuing education is required both by the NATA and most state credentialing agencies to maintain certification and licensure. Because CE is required of all ATs, this may be the most effective method of providing information to ATs to the evolving information regarding EAMC, but several other factors influence the likelihood to pursue CE.

\section{Likelihood to Pursue Continuing Education}

Because Athletic Training lends itself to problem-based learning, rich experiential education, and immediate application of knowledge, workplace continued education proves to be a viable self-directed learning environment where individualized achievement goals are attainable (Pitney, 1998). The adult learning approach to CE involves preparing an optimal learning environment, identifying learning needs, allowing the learner to set goals and organize learning, implementing specific learning strategies, assessing the extent of learning, and reflection (Pitney). Facilitators of CE encourage learners to identify and challenge their educational and professional goals (Brookfield, 1986). To be an effective facilitator of self-directed learning it is important to create an environment that expects new and fresh ideas, establishes goals, hold professional 
discussions, encourages different styles of practice, and promotes role models (Pitney). Self-directed learning environments are student-driven and therefore the needs and reflection of adult learners are essential for success.

Adult learners must choose what to learn by taking from their personal and professional experiences, motivating and aligning themselves with the agenda of $\mathrm{CE}$ programming. Adult learning theory was established on the pillar that learners must be motivated to learn. Setting educational content, participating in education decisions, and setting goals is a critical step in the learning process (Hewson, 1992). Further, adult learning is initiated when students reflect, assess a deficit, and seek methods to meet the inadequacy. Immediate application of new knowledge is most likely the result of this deficit based knowledge acquisition (Hewson). When ATs and other adult learners are reflective about their practice and clearly understand the role of CE in improving clinical practice, they are embracing adult education theory.

\section{AT Perceptions about Continuing Education}

Self-perception and reflection influence on self-directed learning and therefore play an important role in $\mathrm{CE}$ effectiveness. Although $\mathrm{CE}$ is required, several researchers have sought to identify AT perceptions on needs (Cuppett, 2001) and deterring factors (Hughes, 2005). The 3rd edition of the role delineation study was used to identify selfperceived CE needs of ATs (Cuppett). Results suggested that attendance at the annual symposia was the primary method of obtaining CE units, while district meetings and conferences were also popular. The least popular methods were college courses, publications, and home study. ATs felt they needed the most CE in rehabilitation and reconditioning of athletic injuries and illnesses. When responding to open-ended 
questions, ATs suggested the following areas in Athletic Training required improvement: personnel management, business management, third party providers, outcome studies, and legal issues; eating disorders and dermatology; tenure and promotion issues, public relations ideas, and sensitivity training. The researcher concluded that ATs perceive a moderate need for CE within all domains (Cuppett).

Although participation in $\mathrm{CE}$ is a requirement for most health care professions, the attitudes about obtaining $\mathrm{CE}$ units may be helpful in understanding perceptions and learning preferences among professionals. Learner attitude and motivation play an essential role in obtaining CE units. A recent investigation revealed the attitudes and deterrents to ATs obtaining CE units (Hughes, 2005). The Adult Attitudes Toward Continuing Education Scale (AATCES) and the Deterrents to Participation Scale-General (DPS-G) was used to detect perceived attitudes and measure deterrents to participation in CE. An analysis of the AATCES instrument revealed that ATs perceived CE as an important function in their professional livelihood and that ATs reported few deterrents toward CE. The researchers identified three distinct groups of ATs separated by their perceptions about lack of course relevance. An "eager beaver" group (younger, less experienced, attended fewer conferences) felt course relevance was not that important. The "cautiously-eager" group (slightly older, more experienced) felt course relevance played an important role in CE selection. The "mellow" group (oldest and most experienced) placed the greatest importance on course relevance. The researcher concluded that practical program planning can improve knowledge acquisition and retention by including a range of activities and experiences that learners really want. 


\section{Identifying the Knowledge Gap}

Few investigations have described ATs' knowledge regarding EAMC and exertional heat illness (Dombek et al., 2006; Stone et al., 2003), but neither investigation measured perceived knowledge or compared self-reported behaviors with knowledge assessment scores. Therefore, there is a need to look outside the scope of Athletic Training to find methods of measuring and evaluating perceived knowledge and actual knowledge. Although several researchers have failed to provide instrument validation information (Clark et al., 2002; Haywood, Goldenberg, Bronstein, Nelson, \& Carlo, 1994; Wallace, Wu, Weinstein, Gorenflo, \& Fetters, 2004), other investigators have demonstrated ideal strategies for validation and implementation of perception and knowledge assessment methods (Flynn \& Goldsmith, 1999; Khan, Awonuga, Dwarakanath, \& Taylor, 2001; van den Arend et al., 2000).

Self-assessment and of perceived knowledge are not effective measurements of actual knowledge. In an assessment of evidence-based medical workshops, researchers asked participants ( $\mathrm{n}=55)$ to complete two questionnaires: one rated participant subjective knowledge and the other examined the objective knowledge after participating in an education workshop (Khan et al., 2001). The researchers found there was a poor relationship between perceived knowledge and actual knowledge of literature appraisal skills. The researchers concluded that self-assessment in continuing education is an insufficient measurement technique.

Beyond the practitioner, patients' knowledge has also been measured and compared to perceived knowledge. Again, the relationship between actual knowledge indicators and perceived knowledge indicators are poorly related. In an investigation 
about patient knowledge about diabetes self-care, participants $(\mathrm{n}=243)$ completed a validated multipart questionnaire (van den Arend et al., 2000). Researchers measured knowledge, self-care behavior and disease perceptions before and after (6 months and 12 months) participation in a patient care course. The patients improved knowledge immediately following the implementation, yet failed to retain the knowledge over time. Further, patients' disease perception did not change with participation in the investigation. When knowledge and self-care behavior where compared, the researchers found that baseline disease knowledge and self-care behavior were positively related and improved knowledge correlated with self-care behavior.

Other investigations, not as rigorous as those previously described, also provide a clear picture that actual knowledge and perceived knowledge often fail to have a strong positive relationship. Researchers have measured physicians' ( $\mathrm{n}=224)$ perceived and actual rates of survival and freedom from disability in premature infants (Haywood et al., 1994) and found that physicians significantly underestimate survival rates and freedom from disability. Clark and associates (2002) measured patient $(\mathrm{n}=33)$ perceived knowledge and actual knowledge of sexually transmitted diseases and found that perceived knowledge was poorly correlated with total knowledge scores. Wallace and colleagues (2004) measured perceived and actual knowledge of family medicine providers $(\mathrm{n}=78)$ on emergency contraceptives. The investigation was limited to one hospital, but the practitioners believed they were familiar with indications (96\%) and protocols (78\%) for the administration of emergency contraceptives. Participants demonstrated slightly above average knowledge about the administration of emergency contraceptives $(3.7 \pm 1.7 / 6$ items). 


\section{Feedback as a Means of Identifying the Knowledge Gap}

To date, no researchers have incorporated the theory of external or performance feedback in investigations comparing actual and perceived knowledge across disciplines. However, forms of feedback, particularly external feedback, have been thoroughly discussed and theorized in the educational literature (Bangert-Drowns et al., 1991; Butler \& Winne, 1995; Carver \& Scheier, 1990; Kulhavy \& Stock, 1989; Meyer, 1986). Research suggests that learners are more effective when responding to externally provided feedback, (Bangert-Drowns et al.; Kulhavy \& Stock; Meyer) like that provided through peer evaluation, teacher remarks on class work, or answer sections of a textbook (Butler \& Winne). This external feedback is most often provided after a task is completed and is therefore feedback about performance directed toward improving student scores on the task (Butler \& Winne).

Performance feedback may also serve an alternative purpose, especially in selfdirected or adult learners. Carver and Scheier (1990) suggest that self-directed learners who experience an impediment to learning, which may come in the form of negative performance feedback, this interruption triggers reassessment of the educational goal. This would then suggest that once a learner identifies a knowledge gap or experiences an interruption, he or she will estimate how probable it is to achieve the goal and will assess if they should invest further effort, modify their plan or both. Researchers theorize that performance feedback that identifies a knowledge gap may trigger a learner to reassess and identify the need for CE, improving the likelihood of engaging in CE opportunities (Bandura, 1986; Gist et al., 1989; Hill et al., 1987; Locke et al., 1984). 
Understanding the relationship between actual knowledge and perceived knowledge ("the illusion of knowing") is not a new concept in health science literature. However, understanding the subsequent behavior resulting from perceived knowledge is rather limited. Some recent theorists have relied upon W.I. Thomas who describes "the definition of the situation" where one's perceptions shape behaviors (Thomas \& Thomas, 1928). Further, cognitive psychologists suggest the discrepancy between actual knowledge and perceived knowledge significantly contributes to learning (Getner \& Collins, 1981; Glenberg et al., 1982; Park et al., 1988; Radecki \& Jaccard, 1995) because individuals often overestimate actual knowledge and therefore create a barrier to acquiring new information (Glenberg et al.). This investigation is grounded in the theories of "the definition of the situation" (Thomas \& Thomas) and the "illusion of knowing," (Glenberg et al.) both of which suggest that perceived knowledge drives behavior. This investigation is intended to use performance feedback to identify the knowledge gap, change perceived knowledge, and subsequently change CE seeking behavior.

\section{Measurement Methods and Statistical Analysis}

Sampling. Based upon sampling strategies used in similar investigations, response rates range between 11.5 and 52\% (mean=28.38 \pm 17.16 ) (Cuppett, 2001; Dombek et al., 2006; Hughes, 2005; Stone et al., 2003). However, the standard response rate for survey-type research in Athletic Training is $60-80 \%$ (Turocy, 2002). The most successful sampling method used among similar investigations was a stratified random sample; although, the sample was representative of NATA district, but occupational setting was skewed (Cuppett). 
Survey researchers have employed several sampling techniques to best acquire a representative sample of the NATA membership. Researchers surveyed ATs $(1040 / 2000$; response rate $=52 \%)$ about their perceived CE needs using a stratified random selection of ATs by each NATA district (Cuppett, 2001). Although the sample was representative of the NATA district, employment setting skewed the sample towards the college and university setting, and the researchers failed to report descriptive data on gender (Cuppett). Other investigators also asked ATs about their attitudes and deterrents to obtaining CE units (Hughes, 2005). Of 1200 ATs sampled, 268 respondents (22\% response rate) participated in this investigation, likely because the sampling procedures (electronic recruitment three times in a 6-week period using two university alumni listserves) provided a sample that poorly represented NATA membership. The population skewed toward the perceptions of Caucasian, slightly more educated ATs working predominantly in the college or university setting.

The investigations that identified actual knowledge of ATs regarding exertional heat stroke and EAMC also used various sampling procedures. Secondary school ATs responded to questions about their current practices in the prevention, recognition, treatment, and return-to-play guidelines of EHS (Dombek et al., 2006). The researchers selected 500 high school ATs using a stratified random selection and received responses from 136 ATs (28\% response rate), but only 84 [50 males (60\%), 34 females (40\%), age $35 \pm 9 y, A T$ experience $11 \pm 8 y$ ] questionnaires were viable for statistical analyses. In a separate investigation, ATs responded to a questionnaire about the prevention, causes, and treatment of EAMC (Stone et al., 2003). Stone et al. recruited all retired and 
practicing (including certified students) ATs via email to participate in the investigation. With only nine days of data collection, 11.5\% (997/8649) participants responded.

Demographic considerations. The role of gender, occupational setting, occupational region, level of expertise, and level of education often skew samples of recruited participants in Athletic Training survey research. Yet researchers often fail to address the role of these demographic characteristics in outcomes in their investigations. As previously mentioned, previous investigations have yielded samples skewed by employment setting (Cuppett, 2001; Hughes, 2005), ethnicity, and level of education (Hughes).

Two investigations have analyzed the roles of demographic characteristics in regards to CE. As previously discussed, Cuppett (2001) investigated self-perceived needs of CE using multiple linear regression and identified to determine the influence of gender, employment setting (occupational setting), years of experience (level of expertise), environment, employer support, age, professional isolation, and education (level of education) on the perceived need for CE in each of the domains of knowledge in Athletic Training. Gender, years of experience, and professional isolation played a significant role in Prevention of Injuries CE needs. Gender also played a significant role in the domains of Recognition, Evaluation, and Immediate Care of Athletic Injuries and Health Care Administration where women tend to want more CE in this area. Gender and employment setting were significant predictors in the Rehabilitation and Reconditioning of Athletic Injuries domain of Athletic Training. Gender is rarely investigated related to $\mathrm{CE}$, yet appears to have a great influence on the CE needs of ATs. Little research has been conducted on differences in professional practice and 
professional career patterns by gender. Although employment setting and years of experience also played a statistically significant role as a predictor, the researcher found that these facts accounted for very little variance in the investigation (Cuppett).

Hughes (2005) identified that gender influenced attitudes and deterring factors toward CE in Athletic Training. Females in the investigation demonstrated a more positive attitude toward $\mathrm{CE}$ as well as felt that cost and time were both deterrents to obtaining CE credits as compared to their male counterparts. Although the role of gender was identified as a significant predictor in CE content needs and deterrents (Cuppett, 2001; Hughes), occupational setting, level of expertise, and level of education were briefly only evaluated (Cuppett). Occupational region has not yet been evaluated as a predictor in Athletic Training research in regards to CE or knowledge.

Instrument development. Flynn and Goldsmith (1999) suggest that several implementations are required to establish internal and external consistency. In the first of five implementations to validate a questionnaire for consumer knowledge, the researchers established content; study 2 utilized a factor analysis to determine dimensionality, testretest reliability, and construct validity; study 3 further established validity using a known group, reestablished the scale's psychometric properties, and tested the scale's generalizability; study 4 provided evidence of convergent, criterion, and nomologic validity (defined as the extent to which scale scores relate to other variables as would be predicted theoretically); study 5 further demonstrated generalizability. This investigation clearly illustrates the rigor required for validation of an instrument and further provides and excellent example of a subjective knowledge instrument. 
In the actual knowledge assessment implemented among high school ATs, Dombek and associates (2006) developed a questionnaire which was reviewed by a panel of experts $(n=6)$ and pilot-tested on a sample of high school and collegiate ATs $(n=10)$. Previous researchers have adapted instruments to meet the needs of diabetes mellitus knowledge among nurses, (Drass et al., 1989; El-Deirawi \& Zuraikat, 2001) but none have created an instrument related to patient care in Athletic Training.

Entry-level education creates the base of knowledge for early practitioners, yet we are continually seeking more knowledge through areas of active research. However, entry-level education often requires several years of study to delineate new curricula standards. Therefore, $\mathrm{CE}$ is often the best method of transmitting new knowledge to practitioners. Pursuit of CE is strongly influenced by self-directed learning, but may often require performance feedback (Bangert-Drowns et al., 1991; Kulhavy \& Stock, 1989; Meyer, 1986). A poor relationship exists between perceived knowledge and actual knowledge (Clark et al., 2002; Drass et al., 1989; El-Deirawi \& Zuraikat, 2001; van den Arend et al., 2000), suggesting that most learners are unaware of their knowledge gap or are not self-directed and are therefore are not likely to pursue CE. Without adequate professional experiences, all learners, even self-directed learners, may require performance feedback to identify the gap in their knowledge. Although adult learning theory develops the entry-level education model for Athletic Training, performance feedback is may be necessary because the personal and professional experiences that drive adult learning theory can be fatal in the health professions. 


\section{Summary}

This review of literature provided an overview to education in Athletic Training. This section helped to provide a foundation to understanding how ATs are educated. The analysis of EAMC literature established a basis for understanding the importance of this content area in Athletic Training. Without appropriate knowledge and application of the measures to prevent, recognize, and treat EAMC, this condition can lead to irreversible kidney failure and as such ATs need to be well versed in these treatment strategies. The critical analysis of factors that influence the likelihood to pursue $\mathrm{CE}$ and recognizing the knowledge gap clearly identified the failures of previous literature. The following chapter describes the methods employed to resolve this gap in the literature. 


\section{CHAPTER III}

\section{METHODS}

This chapter describes the methods used to answer the following research questions. The chapter includes research questions, sampling procedures, variables, research design, instrumentation, procedures, and statistical analysis.

General Research Questions

This investigation focused on the effect of performance feedback on perceived knowledge and likelihood to pursue CE as well as the relationship between the research variables.

1. What is the effect of performance feedback regarding actual knowledge on perceived knowledge?

2. What is the effect of performance feedback regarding actual knowledge on likelihood to pursue CE?

3. What is the relationship between perceived knowledge and likelihood to pursue CE?

4. What is the relationship between pre-test and post-test knowledge gap?

5. What is the relationship between knowledge gap and likelihood to pursue CE?

6. What are the effects of demographic characteristics on the relationships between knowledge gap and likelihood to pursue CE?

7. What is the relationship between actual knowledge and the dependent variables in the experimental group?

\section{Alternative Hypotheses}

The following alternative hypotheses were potential outcomes to the research questions: 
1. Performance feedback regarding actual knowledge will significantly decrease perceived knowledge.

2. Performance feedback regarding actual knowledge will increase likelihood to pursue CE.

3. Perceived knowledge will account for a significant amount of variance in predicting likelihood to pursue $\mathrm{CE}$.

a. Regression model 1F tested the hypothesis: Pre-test perceived knowledge will account for a significant amount of variance in predicting pre-test likelihood to pursue CE.

b. Regression model 2R tested the hypothesis: Pre-test perceived knowledge will account for a significant amount of variance in predicting post-test likelihood to pursue CE.

c. Regression model 2F tested the hypothesis: Group allocation, or exposure to performance feedback, will account for a significant amount of unique variance in predicting post-test likelihood to pursue $\mathrm{CE}$ when pre-test perceived knowledge is held constant.

d. Regression model 3R tested the hypothesis: Pre-test likelihood to pursue CE will account for a significant amount of variance in predicting post-test likelihood to pursue CE.

e. Regression model 3F tested the hypothesis: Group allocation, or exposure to performance feedback, will account for a significant amount of unique variance in predicting post-test likelihood to pursue $\mathrm{CE}$ when pre-test likelihood to pursue $\mathrm{CE}$ is held constant. 
f. Regression model 4R tested the hypothesis: Post-test perceived knowledge will account for a significant amount of variance in predicting post-test likelihood to pursue CE.

g. Regression model 4F tested the hypothesis: Group allocation, or exposure to performance feedback, will account for a significant amount of unique variance in predicting post-test likelihood to pursue $\mathrm{CE}$ when post-test perceived knowledge is held constant.

h. Regression model 5R tested the hypothesis: Pre-test perceived knowledge and pre-test likelihood to pursue CE will account for a significant amount of unique variance in predicting post-test likelihood to pursue CE.

i. Regression model 5F tested the hypothesis: Group allocation, or exposure to performance feedback, will account for a significant amount of unique variance in predicting post-test likelihood to pursue $\mathrm{CE}$ when all other variables are held constant (pre-test perceived knowledge, pre-test likelihood to pursue CE).

j. Regression model 6R tested the hypothesis: Pre-test perceived knowledge, posttest perceived knowledge, and pre-test likelihood to pursue CE will account for a significant amount of unique variance in predicting post-test likelihood to pursue CE.

k. Regression model 6F tested the hypothesis: Group allocation, or exposure to performance feedback, will account for a significant amount of unique variance in predicting post-test likelihood to pursue CE when all other variables are held constant (pre-test perceived knowledge, post-test perceived knowledge, pre-test likelihood to pursue $\mathrm{CE}$ ). 
4. Pre-test knowledge gap will account for a significant amount of unique variance in predicting post-test knowledge gap.

a. Regression model 7R tested the hypothesis: Pre-test knowledge gap will account for a significant amount of variance in predicting post-test knowledge gap.

b. Regression model 7F tested the hypothesis: Group allocation, or exposure to performance feedback, will account for a significant amount of unique variance in predicting post-test knowledge gap when pre-test knowledge gap is held constant.

c. Regression model $8 \mathrm{R}$ tested the hypothesis: There will be a second degree curvilinear relationship for pre-test knowledge gap that accounts for a significant amount of unique variance in predicting post-test knowledge gap.

d. Regression model 8F tested the hypothesis: Group allocation, or exposure to performance feedback, will account for a significant amount of unique variance in predicting post-test knowledge gap when all other variables are held constant (curvilinear pre-test knowledge gap, linear pre-test knowledge gap).

5. Knowledge gap will account for a significant amount of variance in predicting likelihood to pursue $\mathrm{CE}$.

a. Regression model 9R tested the hypothesis: Pre-test knowledge gap will account for a significant amount of variance in predicting post-test likelihood to pursue CE.

b. Regression model 9F tested the hypothesis: Group allocation, or exposure to performance feedback, will account for a significant amount of unique variance in predicting post-test likelihood to pursue CE when pre-test knowledge gap is held constant. 
c. Regression model 10R tested the hypothesis: There will be a second degree curvilinear relationship for pre-test knowledge gap that accounts for a significant amount of unique variance in predicting post-test likelihood to pursue CE.

d. Regression model $10 \mathrm{~F}$ tested the hypothesis: Group allocation, or exposure to performance feedback, will account for a significant amount of unique variance in predicting post-test likelihood to pursue CE when all other variables are held constant (curvilinear pre-test knowledge gap, linear pre-test knowledge gap).

e. Regression model $11 \mathrm{R}$ tested the hypothesis: Post-test knowledge gap will account for a significant amount of variance in predicting post-test likelihood to pursue CE.

f. Regression model $11 \mathrm{~F}$ tested the hypothesis: Group allocation, or exposure to performance feedback, will account for a significant amount of unique variance in predicting post-test likelihood to pursue CE when post-test knowledge gap is held constant.

g. Regression model $12 \mathrm{R}$ tested the hypothesis: There will be a second degree curvilinear relationship for post-test knowledge gap that accounts for a significant amount of unique variance in predicting post-test likelihood to pursue CE.

h. Regression model $12 \mathrm{~F}$ tested the hypothesis: Group allocation, or exposure to performance feedback, will account for a significant amount of unique variance in predicting post-test likelihood to pursue $\mathrm{CE}$ when all other variables are held constant (curvilinear post-test knowledge gap, linear post-test knowledge gap). 
i. Regression model 13R tested the hypothesis: Knowledge gap (pre-test and posttest variables) will account for a significant amount of unique variance in predicting post-test likelihood to pursue $\mathrm{CE}$.

j. Regression model 13F tested the hypothesis: Group allocation, or exposure to performance feedback, will account for a significant amount of unique variance in predicting post-test likelihood to pursue CE when all other variables are held constant (pre-test knowledge gap, post-test knowledge gap).

k. Regression model 14R tested the hypothesis: There will be a second degree curvilinear relationship for pre-test knowledge gap that accounts for a significant amount of unique variance in predicting post-test likelihood to pursue $\mathrm{CE}$ when all other variables are held constant (pre-test knowledge gap, post-test knowledge gap).

1. Regression model $14 \mathrm{~F}$ tested the hypothesis: Group allocation, or exposure to performance feedback, will account for a significant amount of unique variance in predicting post-test likelihood to pursue CE when all other variables are held constant (curvilinear pre-test knowledge gap, linear pre-test knowledge gap, linear post-test knowledge gap).

m. Regression model 15R tested the hypothesis: There will be a second degree curvilinear relationship for post-test knowledge gap that accounts for a significant amount of unique variance in predicting post-test likelihood to pursue $\mathrm{CE}$ when all other variables are held constant (pre-test knowledge gap, post-test knowledge gap). 
n. Regression model $15 \mathrm{~F}$ tested the hypothesis: Group allocation, or exposure to performance feedback, will account for a significant amount of unique variance in predicting post-test likelihood to pursue CE when all other variables are held constant (curvilinear post-test knowledge gap, linear pre-test knowledge gap, linear post-test knowledge gap).

o. Regression model 16R tested the hypothesis: There will be a second degree curvilinear relationship for knowledge gap (pre-test and post-test variables) that accounts for a significant amount of unique variance in predicting post-test likelihood to pursue CE.

p. Regression model $16 \mathrm{~F}$ tested the hypothesis: Group allocation, or exposure to performance feedback, will account for a significant amount of unique variance in predicting post-test likelihood to pursue CE when all other variables are held constant (linear pre-test knowledge gap, linear post-test knowledge gap, curvilinear pre-test knowledge gap, curvilinear post-test knowledge gap).

6. Demographic characteristics will account for a significant amount of unique variance in predicting likelihood to pursue CE.

a. Regression model 17R tested the hypothesis: Demographic characteristics will account for a significant amount of unique variance in predicting post-test likelihood to pursue CE when pre-test knowledge gap is held constant.

b. Regression model $17 \mathrm{~F}$ tested the hypothesis: Group allocation, or exposure to performance feedback, will account for a significant amount of unique variance in predicting post-test likelihood to pursue CE when all other variables are held constant (pre-test knowledge, demographic characteristics). 
c. Regression model 18R tested the hypothesis: Demographic characteristics will account for a significant amount of unique variance in predicting post-test likelihood to pursue CE when all other variables are held constant (curvilinear pre-test knowledge gap, linear pre-test knowledge gap).

d. Regression model $18 \mathrm{~F}$ tested the hypothesis: Group allocation, or exposure to performance feedback, will account for a significant amount of unique variance in predicting post-test likelihood to pursue $\mathrm{CE}$ when all other variables are held constant (curvilinear pre-test knowledge gap, linear pre-test knowledge gap, demographic characteristics).

e. Regression model 19R tested the hypothesis: Demographic characteristics will account for a significant amount of unique variance in predicting post-test likelihood to pursue CE when post-test knowledge gap is held constant.

f. Regression model $19 \mathrm{~F}$ tested the hypothesis: Group allocation, or exposure to performance feedback, will account for a significant amount of unique variance in predicting post-test likelihood to pursue CE when all other variables are held constant (post-test knowledge, demographic characteristics).

g. Regression model 20R tested the hypothesis: Demographic characteristics will account for a significant amount of unique variance in predicting post-test likelihood to pursue $\mathrm{CE}$ when all other variables are held constant (curvilinear post-test knowledge gap, linear post-test knowledge gap).

h. Regression model 20F tested the hypothesis: Group allocation, or exposure to performance feedback, will account for a significant amount of unique variance in predicting post-test likelihood to pursue $\mathrm{CE}$ when all other variables are held 
constant (curvilinear post-test knowledge gap, linear post-test knowledge gap, demographic characteristics).

i. Regression model 21R tested the hypothesis: Demographic characteristics will account for a significant amount of unique variance in predicting post-test likelihood to pursue $\mathrm{CE}$ when all other variables are held constant knowledge gap (pre-test knowledge gap, post-test knowledge gap).

j. Regression model 21F tested the hypothesis: Group allocation, or exposure to performance feedback, will account for a significant amount of unique variance in predicting post-test likelihood to pursue $\mathrm{CE}$ when all other variables are held constant (pre-test knowledge gap, post-test knowledge, demographic characteristics).

k. Regression model 22R tested the hypothesis: Demographic characteristics will account for a significant amount of unique variance in predicting post-test likelihood to pursue $\mathrm{CE}$ when all other variables are held constant (curvilinear pre-test knowledge gap, linear pre-test knowledge gap, linear post-test knowledge gap).

1. Regression model $22 \mathrm{~F}$ tested the hypothesis: Group allocation, or exposure to performance feedback, will account for a significant amount of unique variance in predicting post-test likelihood to pursue $\mathrm{CE}$ when all other variables are held constant (curvilinear pre-test knowledge gap, linear pre-test knowledge gap, linear post-test knowledge gap demographic characteristics).

m. Regression model 23R tested the hypothesis: Demographic characteristics will account for a significant amount of unique variance in predicting post-test 
likelihood to pursue $\mathrm{CE}$ when all other variables are held constant (curvilinear post-test knowledge gap, linear pre-test knowledge gap, linear post-test knowledge gap).

n. Regression model 23F tested the hypothesis: Group allocation, or exposure to performance feedback, will account for a significant amount of unique variance in predicting post-test likelihood to pursue $\mathrm{CE}$ when all other variables are held constant (curvilinear post-test knowledge gap, linear pre-test knowledge gap, linear post-test knowledge gap demographic characteristics).

o. Regression model 24R tested the hypothesis: Demographic characteristics will account for a significant amount of unique variance in predicting post-test likelihood to pursue $\mathrm{CE}$ when all other variables are held constant (curvilinear pre-test knowledge gap, curvilinear post-test knowledge gap, linear pre-test knowledge gap, linear post-test knowledge gap).

p. Regression model 24F tested the hypothesis: Group allocation, or exposure to performance feedback, will account for a significant amount of unique variance in predicting post-test likelihood to pursue $\mathrm{CE}$ when all other variables are held constant (curvilinear pre-test knowledge gap, curvilinear post-test knowledge gap, linear pre-test knowledge gap, linear post-test knowledge gap, demographic characteristics).

7. Actual knowledge will account for a significant amount of variance in predicting dependent variables in the experimental group. 
a. Regression model $25 \mathrm{R}$ tested the hypothesis: Actual knowledge will account for a significant amount of variance in predicting post-test perceived knowledge in the experimental group.

b. Regression model $25 \mathrm{~F}$ tested the hypothesis: There will be a second degree curvilinear relationship for actual knowledge that accounts for a significant amount of unique variance in predicting post-test perceived knowledge in the experimental group.

c. Regression model 26R tested the hypothesis: Actual knowledge will account for a significant amount of variance in predicting post-test likelihood to pursue CE in the experimental group.

d. Regression model $26 \mathrm{~F}$ tested the hypothesis: There will be a second degree curvilinear relationship for actual knowledge that accounts for a significant amount of unique variance in predicting post-test likelihood to pursue $\mathrm{CE}$ in the experimental group.

\section{Sampling Procedures}

ATs were randomly sampled using the NATA membership directory and were randomly assigned to the experimental and comparison groups. Random assignment creates a theoretical equality between groups and is the most rigorous method of controlling against threats to internal validity (Arnold, Gansneder, \& Perrin, 2005). Because self-selection is likely to affect sampling procedures, a planned comparison of participant demographics was performed to compare equality between the groups and the national membership on geographical location by NATA district (Table 5: does not equal $100 \%$ because not all members of NATA are ATs) and occupational setting (Table 6). 
Table 5 delineates both Certified Regular and Student Certified ATs. Both groups of individuals have met the expectations of entry-level education; however Student Certified ATs are currently enrolled in higher education. The delineation is created to aid students in membership costs, but the level of preparation is the same between both groups.

Table 5

January 2008 NATA ATs with Membership by District (NATA, 2008)

$$
\text { Percentage of Total Certified }
$$

\begin{tabular}{ccc} 
District & Certified Members & Members \\
\hline 1 & 1632 & $5.02 \%$ \\
3 & 3683 & $11.34 \%$ \\
4 & 2862 & $8.81 \%$ \\
5 & 5520 & $16.99 \%$ \\
6 & 2073 & $6.38 \%$ \\
7 & 1298 & $4.00 \%$ \\
8 & 1480 & $4.56 \%$ \\
9 & 2126 & $6.54 \%$ \\
10 & 3671 & $11.30 \%$ \\
\hline Total Certified Members & 1096 & $3.37 \%$ \\
\hline
\end{tabular}


Table 6

January 2008 NATA Total Membership by Occupational Setting (NATA, 2008)

Percentage of Total

\begin{tabular}{lrr}
\multicolumn{1}{c}{ Occupational Setting } & Setting Totals & Membership \\
\hline Professional athletics & 809 & $2.59 \%$ \\
Collegiate athletics & 5934 & $18.98 \%$ \\
Secondary and intermediate schools & 4608 & $14.74 \%$ \\
Sports medicine clinics & 7427 & $23.75 \%$ \\
Occupational/Industrial settings & 312 & $1.00 \%$ \\
Hospital/Physician Office & 667 & $2.13 \%$ \\
Other & 11515 & $36.81 \%$ \\
\hline Total & 31272 & $100.00 \%$
\end{tabular}

Based upon sampling strategies used in similar investigations, response rates range between $11.5 \%$ and 52\% (mean= 28.38 \pm 17.16$)$ (Cuppett, 2001; Dombek et al., 2006; Hughes, 2005; Stone et al., 2003). However, the standard response rate for surveytype research in Athletic Training is 60-80\% (Turocy, 2002). No previous investigations have used the rigorous pretest-posttest control group design and as such have not used random sampling or random assignment. The most successful sampling method used among other investigations was a stratified random sample; although the sample was representative of NATA district, occupational setting was skewed (Cuppett).

Survey researchers have employed several sampling techniques to best acquire a representative sample of the NATA membership. Researchers surveyed ATs $(1040 / 2000$; response rate $=52 \%)$ about their perceived CE needs using a stratified 
random selection of ATs by each NATA district (Cuppett, 2001). Although the sample was representative of the NATA district, employment setting skewed the sample towards the college and university setting, and the researchers failed to report descriptive data on gender (Cuppett). Other investigators also asked ATs about their attitudes and deterrents to obtaining CE units (Hughes, 2005). Of 1200 ATs sampled, 268 respondents (22\% response rate) participated in this investigation; however, the sampling procedures (electronic recruitment three times in a six-week period using two university alumni listserves) provided a sample that poorly represented NATA membership. The population skewed toward the perceptions of Caucasian, slightly more educated ATs working predominantly in the college or university setting.

Similar investigations that identified actual knowledge of ATs regarding EHS and EAMC also used various sampling procedures. Secondary school ATs responded to questions about their current practices in the prevention, recognition, treatment, and return-to-play guidelines of EHS (Dombek et al., 2006). The researchers selected 500 high school ATs using a stratified random selection and received responses from 136

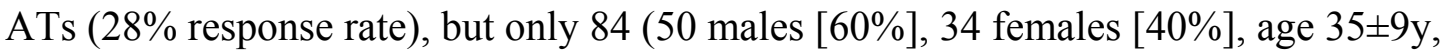
AT experience $11 \pm 8 \mathrm{y})$ questionnaires were viable for statistical analyses. In a separate investigation, ATs responded to a questionnaire about the prevention, causes, and treatment of EAMC (Stone, et al., 2003). The researchers recruited all retired and practicing (including certified students) ATs via email to participate in the investigation (Stone, et al.). With only 9 days of data collection, 997 of the 8649 participants solicited responded, indicating an $11.5 \%$ response rate (Stone et al.). The sampling procedures in this investigation were designed to use the most effective sampling methods and to 
provide adequate time for respondents to complete the investigation so as to avoid errors made by previous researchers.

A stratified random sample $(\mathrm{n}=2000)$ was selected by geographical location by NATA district to obtain a representative sample of the NATA membership. The response rate was $5.15 \%(\mathrm{n}=103 / 2000)$ and the control $(\mathrm{n}=58)$ and experimental group $(\mathrm{n}=45)$ were similar $($ Table 7$)$.

Levene's statistic indicated that the groups were heterogeneous $(p>.05)$ on three of the five demographic variables, therefore the groups were compared using parametric independent t-tests and one-way analyses of variance. The groups were not significantly different in regards to occupational region, occupational setting, and level of expertise. The groups were significantly different in regards to gender $\left(\mathrm{t}_{101}=2.45, p=.02, \mathrm{ES}=0.12\right.$ [small]) and level of education $\left(\mathrm{F}_{1,101}=5.48, p=0.02, \mathrm{ES}=0.04\right.$ [small]).

\section{Variables}

The dependent variables were perceived knowledge and likelihood to pursue CE regarding the prevention, recognition, and treatment of EAMC. The independent variable was performance feedback. Knowledge gap was calculated as a difference between perceived knowledge and actual knowledge. The relationship of gender, occupational setting, occupational location, level of expertise, and level of education were also examined. 
Table 7

Demographic Characteristics of Sample (n=103) Compared by Group

\begin{tabular}{|c|c|c|c|c|c|}
\hline \multirow[b]{2}{*}{ Characteristic } & & \multicolumn{2}{|c|}{ Experimental } & \multicolumn{2}{|c|}{ Control } \\
\hline & & $\mathrm{n}=$ & $\%$ & $\mathrm{n}=$ & $\%$ \\
\hline \multirow[t]{2}{*}{ Gender } & Male & 18 & 40.0 & 37 & 63.8 \\
\hline & Female & 27 & 60.0 & 21 & 36.2 \\
\hline \multirow[t]{10}{*}{ Occupational Region } & District 1 & 0 & 0.0 & 1 & 1.7 \\
\hline & District 2 & 7 & 15.6 & 4 & 6.9 \\
\hline & District 3 & 4 & 8.9 & 9 & 15.5 \\
\hline & District 4 & 11 & 24.4 & 12 & 20.7 \\
\hline & District 5 & 3 & 6.7 & 7 & 12.1 \\
\hline & District 6 & 5 & 11.1 & 6 & 10.3 \\
\hline & District 7 & 3 & 6.7 & 3 & 5.2 \\
\hline & District 8 & 5 & 11.1 & 2 & 3.4 \\
\hline & District 9 & 5 & 11.1 & 11 & 19 \\
\hline & District 10 & 2 & 4.4 & 3 & 5.2 \\
\hline
\end{tabular}


Table 7

Demographic Characteristics of Sample (n=103) Compared by Group (cont.)

\begin{tabular}{|c|c|c|c|c|c|}
\hline \multirow[b]{2}{*}{ Characteristic } & & \multicolumn{2}{|c|}{ Experimental } & \multicolumn{2}{|c|}{ Control } \\
\hline & & $\mathrm{n}=$ & $\%$ & $\mathrm{n}=$ & $\%$ \\
\hline \multirow[t]{7}{*}{ Occupational Setting } & Professional Sports & 0 & 0.0 & 3 & 5.2 \\
\hline & College/University & 20 & 44.4 & 25 & 43.1 \\
\hline & Secondary/Intermediate School & 11 & 24.4 & 18 & 31 \\
\hline & Sports Medicine Clinics & 5 & 11.1 & 1 & 1.7 \\
\hline & Industrial/Occupational Setting & 1 & 2.2 & 1 & 1.7 \\
\hline & Physician's Office/Hospital & 1 & 2.2 & 1 & 1.7 \\
\hline & Other & 7 & 15.6 & 9 & 15.5 \\
\hline \multirow[t]{3}{*}{ Level of Education } & Doctoral & 2 & 4.4 & 5 & 8.6 \\
\hline & Masters & 25 & 55.6 & 42 & 72.4 \\
\hline & Bachelors & 18 & 40.0 & 11 & 19 \\
\hline \multirow[t]{2}{*}{ Level of Expertise } & More than 5 years of working experience & 26 & 57.8 & 33 & 56.9 \\
\hline & 5 years or less of working experience & 19 & 42.2 & 25 & 43.1 \\
\hline
\end{tabular}




\section{Research Design}

The effect of performance feedback on perceived knowledge and likelihood to pursue CE was measured using a pre-test post-test control-group design. Perceived knowledge and likelihood to pursue CE were measured prior to and after assessing participants' actual knowledge. The experimental group was provided with item-by-item and summative performance feedback immediately following a knowledge assessment. The control group received no form of external performance feedback.

\section{Instrumentation}

Two instruments were used in this investigation: the Perceived Knowledge Questionnaire (PKQ) and the Actual Knowledge Assessment (AKA).

\section{Perceived Knowledge Questionnaire}

Investigators have measured subjective or perceived knowledge (Flynn \& Goldsmith, 1999; Khan et al., 2001; van den Arend et al., 2000), yet most researchers failed to provide rigorous validation of their instruments (Clark et al., 2002; Haywood et al., 1994; Wallace et al., 2004). The PKQ is a 16-item questionnaire (Table 8) modified from a validated subjective knowledge five item assessment tool developed by Flynn and Goldsmith (1999). The original subjective knowledge instrument was developed from five implementations to estimate internal and external consistency (Flynn \& Goldsmith). In the first of five implementations to validate the subjective knowledge questionnaire for consumer knowledge, the researchers estimated content validity (Flynn \& Goldsmith). In the second study, the researchers used a factor analysis to examine dimensionality and test-retest reliability to estimate construct validity (Flynn \& Goldsmith). The researchers then used a third implementation to further estimate validity using a known group, 
reestablish the scale's psychometric properties, and test the scale's generalizability (Flynn \& Goldsmith). The fourth study evaluated convergent, criterion, and nomologic validity, the extent to which scale scores related to variables would be theoretically predicted (Flynn \& Goldsmith). The researchers used the fifth and final implementation to demonstrate generalizability (Flynn \& Goldsmith). The five original items were applied to three constructs of EAMC; recognition, prevention, and treatment.

The instrument was intended to be implemented with a 7-point Likert-scale, (Flynn \& Goldsmith, 1999) which provides participants a centralized option (Osgood, Suci, \& Tannenbaum, 1957). A pilot study was used to compare a 6-point Likert scale to the suggested 7-point scale. Eighteen ATs and ATSs participated in a test-retest crossover design to evaluate the two scales of the PKQ. All but two of the items and the mean of all the item correlations demonstrated strong (0.50-1.00) reliability (Cohen, 1988) based on Spearman's rho correlation coefficient. The variance provided by a 6point scale paired with the strong correlation provided a strong rationale to implement the PKQ with a 6-point Likert-scale ranging from $1-6$ where $1=$ Strongly Disagree and $6=$ Strongly Agree.

Although two previous investigations have identified the self-perceived CE needs of ATs (Cuppett, 2001) and deterrents to obtaining CE units (Hughes, 2005), neither provided an item to reflect the participants' likelihood to pursue CE. Therefore, the $16^{\text {th }}$ item was created to determine the participants' likelihood to pursue $\mathrm{CE}$ to improve knowledge of EAMC graded with the same 6-point Likert-scale. 
Table 8

Perceived Knowledge Questionnaire (Modified from Flynn \& Goldsmith, 1999)

Spearman's

rho

Item Description Correlation $p$ value

\begin{tabular}{|c|c|c|c|}
\hline 1 & I know pretty much about preventing EAMC. & 0.85 & $\mathrm{p}<0.001$ \\
\hline \multirow[t]{2}{*}{2} & I do not feel very knowledgeable about & & \\
\hline & preventing EAMC. (reverse scored) & 0.94 & $\mathrm{p}<0.001$ \\
\hline \multirow[t]{2}{*}{3} & Among my colleagues, I'm one of the & & \\
\hline & "experts" on preventing EAMC. & 0.82 & $\mathrm{p}<0.001$ \\
\hline \multirow[t]{2}{*}{4} & Compared to most other ATs, I know less & & \\
\hline & about preventing EAMC. (reverse scored) & 0.64 & $\mathrm{p}=0.005$ \\
\hline \multirow[t]{2}{*}{5} & When it comes to preventing EAMC, I really & & \\
\hline & don't know a lot. (reverse scored) & 0.67 & $\mathrm{p}=0.003$ \\
\hline \multirow[t]{2}{*}{6} & I know pretty much about recognizing & & \\
\hline & EAMC. & 0.78 & $\mathrm{p}<0.001$ \\
\hline \multirow[t]{2}{*}{7} & I do not feel very knowledgeable about & & \\
\hline & recognizing EAMC. (reverse scored) & 0.88 & $\mathrm{p}<0.001$ \\
\hline \multirow[t]{2}{*}{8} & Among my colleagues, I'm one of the & & \\
\hline & "experts" on recognizing EAMC. & 0.90 & $\mathrm{p}<0.001$ \\
\hline \multirow[t]{2}{*}{9} & Compared to most other ATs, I know less & & \\
\hline & about recognizing EAMC. (reverse scored) & 0.39 & $\mathrm{p}=0.11$ \\
\hline
\end{tabular}


Table 8

Perceived Knowledge Questionnaire (Modified from Flynn \& Goldsmith, 1999) [cont.]

Spearman's

rho

Item Description Correlation $p$ value

10 When it comes to recognizing EAMC, I really

don't know a lot. (reverse scored) $\quad 0.94 \quad \mathrm{p}<0.001$

11 I know pretty much about treating EAMC. $\quad 0.83 \quad \mathrm{p}<0.001$

12 I do not feel very knowledgeable about

treating EAMC. (reverse scored) $\quad 0.85 \quad \mathrm{p}<0.001$

13 Among my colleagues, I'm one of the

“experts” on treating EAMC. $\quad 0.84 \quad \mathrm{p}<0.001$

14 Compared to most other ATs, I know less

about treating EAMC. (reverse scored) $\quad 0.35 \mathrm{p}=0.15$

15 When it comes to treating EAMC, I really

don't know a lot. (reverse scored) $\quad 0.79 \quad \mathrm{p}<0.001$

16 I am likely to pursue continuing education to

improve my knowledge of EAMC. $\quad 1.00 \quad \mathrm{p}<0.001$

$\begin{array}{cc}\text { Mean }= & 0.78 \\ \mathrm{SD}= & 0.19\end{array}$

Actual Knowledge Assessment

The AKA is a 25-item examination derived from the Inter-Association Task Force and NATA position statements on Exertional Heat Illness and Fluid Replacement 
(Binkley et al., 2002; Casa et al., 2000; NATA 2003), which are the professional standards for ATs. The AKA was reviewed by experts for clarity, accuracy, and reflection of current knowledge regarding exertional heat illnesses and fluid replacement using a questionnaire. The expert panelists are researchers who have or are currently employed to lead or act as members on EHI and Fluid Replacement Task Forces for the NATA. These Task Forces act to formulate the standard of care for the prevention, recognition, and treatment of EHI. The panel scored each item's level of clarity (4-point Likert scale), accuracy (dichotomous: Yes or No), and level of agreement (4-point Likert scale) that the item reflects current knowledge. An analysis of the panel's agreement with the AKA revealed strong clarity (mean $=4 \pm 0$ ), strong accuracy ( 3 items deemed inaccurate by 2 or more panelists), and strong agreement on reflection of current knowledge (mean $=4 \pm 0$ ). More importantly, the experts provided comments for item improvement that were incorporated into the instrument. For instance, one of the experts suggested more variance in the answers and another expert suggested using both English and metric measurements within the responses. Previous research has failed to gather more than descriptive information about ATs' knowledge of EHI. Therefore, the role of the AKA was to assess knowledge, but moreover to provide participants with feedback regarding their performance.

Assessment of the self-reported behavior and knowledge of ATs concerning the facets of EHI has provided information about the basic knowledge of ATs. Researchers sought to evaluate the knowledge of ATs on the prevention, causes, and treatment of EAMC (Stone et al., 2003). Twelve ATs estimated the face validity of the instrument prior to distribution. Four Likert-type questions and three open-ended questions 
identified perceptions about the causes, treatment, success of treatment, and prevention of EAMC. The inconsistency among participant responses demonstrated confusion about the most appropriate methods for the prevention, recognition, and treatment of EAMC and as such, there was insufficient evidence to support the researchers' belief that ATs perceived EAMC is solely a result of fatigue (Stone et al.). Further research with more rigorous instrumentation, including the research design and instrumentation used in this study, may provide a better representation of AT knowledge and behavior regarding the prevention, recognition, and treatment of EAMC.

Recently ATs employed in the high school setting responded to a questionnaire about the current practices regarding the prevention, recognition, treatment, and returnto-play guidelines of EHS (Dombek et al., 2006). The researchers used a 16-item questionnaire based on current literature and recommendations with specific questions related to the prevention, recognition, treatment, and return-to-play of EHS in high school athletes. A panel of experts $(n=6)$ reviewed and pilot-tested the questionnaire on a sample of high school and collegiate ATs $(\mathrm{n}=10)$. The researchers suggested that ATs possess adequate knowledge regarding EHS, but do not implement evidence-based best clinical practice. This pilot investigation provided information about ATs' knowledge but did not investigate recognition of a knowledge gap, as was the purpose of our investigation.

\section{Procedures}

Participants were solicited via electronic mail using a Contact Cover Letter. The participants received instructions and individualized access information for admittance to the secure testing site (Campus Edition 6; Blackboard Inc.), which was available for 
approximately 6 weeks. The first questions $(\mathrm{n}=6)$ of the pre-test PKQ requested participant demographics. Subsequently, the test delivery system prompted the participants to complete the pre-test PKQ. Following the PKQ participants completed the AKA. Upon completion of the AKA in the experimental group, the computer-based testdelivery system provided each participant with item-by-item feedback regarding every question in the AKA (Figure 1).

The item-by-item feedback included the question and the list of responses, the participant's response, the correct response, and then the correct response included in sentence format. Participants also received a total score with the number correct, the total number of questions, and a percentage (i.e., 22 correct $/ 25=88 \%$ ). No feedback was provided to participants in the comparison group. The participants then completed the post-test PKQ. Completion of the assessment did not exceed 30 minutes.

Sweat rate generally increases after a period of acclimatization, typical after of heat exposure, requiring a greater fluid intake for a similar bout of exercise.

\begin{tabular}{|clll|}
\hline Student Response & Value & $\begin{array}{c}\text { Correct } \\
\text { Answer }\end{array}$ & Feedback \\
\hline A. 0 to 5 days & $0 \%$ & & \\
\hline B. 7 to 12 days & $0 \%$ & & \\
\hline C. 10 to 14 days & $100 \%$ & \\
\hline D. 15 to 20 days & $0 \%$ & \\
\hline & $0 \%$ & \\
\hline
\end{tabular}

General Sweat rate generally increases after a period of acclimatization, typical after Feedback: 10 to 14 days of heat exposure, requiring a greater fluid intake for a similar bout of exercise.

Figure 1.Item-by-item performance feedback. 


\section{Assumptions}

Although one of the primary limitations of this investigation was that participants self-selected, this practice is grounded in adult-learning theory and the assumption that practitioners are self-directed learners. Also, the pre-test perceived knowledge questionnaire identified self-directed learners and the random assignment to the groups helped maintain internal validity.

The PKQ has not been used in Athletic Training. However, the tool has been used across various content areas (Flynn \& Goldsmith, 1999), and the assumption is that the tool is applicable for EAMC and Athletic Training.

\section{Statistical Analysis}

Data were imported from the test delivery system into SPSS Statistical Package for Windows (Version 15.0) for statistical analysis. Descriptive statistics were calculated for dependent measures and all demographic data. Difference scores were calculated between pre and post PKQ (mean scores) and between pre and post likelihood to pursue CE. Two independent samples t-tests were used to compare groups on the difference scores.

Multiple linear regression (MLR; McNeil, Newman, \& Kelly, 1996) was used in analyzing the variance in predicting one variable to another and in co-varying some of the variables to test the alternative hypotheses. This method of analysis was chosen because it is more flexible than a traditional ANOVA. The use of MLR allows models to be written that reflect the specific research questions being asked. Further, MLR can allow relationships to be tested between categorical variables, between categorical and continuous variables, or between continuous variables (Arnold et al., 2005). The 
relationship between the dependent variables, post-test perceived knowledge and likelihood to pursue continuing education, were analyzed using MLR. Models for these relationships are listed in Table 9.

Table 9

Multiple Linear Regression Models to Analyze Relationship between Perceived Knowledge and Likelihood to Pursue Continuing Education

\section{Model}

Number

\section{Regression Model}

\begin{tabular}{|c|c|}
\hline $1 \mathrm{~F}$ & $\mathrm{Y}_{\mathrm{CEpre}}=\mathrm{b}_{1} \mathrm{X}_{\mathrm{PKpre}}+\mathrm{a}+\mathrm{E}$ \\
\hline 2R & $\mathrm{Y}_{\text {CEpost }}=\mathrm{b}_{1} \mathrm{X}_{\mathrm{PKpre}}+\mathrm{a}+\mathrm{E}$ \\
\hline $2 \mathrm{~F}$ & $\mathrm{Y}_{\text {CEpost }}=\mathrm{b}_{1} \mathrm{X}_{\mathrm{PKpre}}+\mathrm{b}_{2} \mathrm{X}_{\text {group }}+\mathrm{a}+\mathrm{E}$ \\
\hline $3 \mathrm{R}$ & $\mathrm{Y}_{\text {CEpost }}=\mathrm{b}_{1} \mathrm{X}_{\text {CEpre }}+\mathrm{a}+\mathrm{E}$ \\
\hline $3 \mathrm{~F}$ & $\mathrm{Y}_{\text {CEpost }}=\mathrm{b}_{1} \mathrm{X}_{\mathrm{CEpre}}+\mathrm{b}_{2} \mathrm{X}_{\text {group }}+\mathrm{a}+\mathrm{E}$ \\
\hline $4 \mathrm{R}$ & $\mathrm{Y}_{\mathrm{CEpost}}=\mathrm{b}_{1} \mathrm{X}_{\text {PKpost }}+\mathrm{a}+\mathrm{E}$ \\
\hline $4 \mathrm{~F}$ & $\mathrm{Y}_{\text {CEpost }}=\mathrm{b}_{1} \mathrm{X}_{\text {PKpost }}+\mathrm{b}_{2} \mathrm{X}_{\text {group }}+\mathrm{a}+\mathrm{E}$ \\
\hline $5 \mathrm{R}$ & $\mathrm{Y}_{\text {CEpost }}=\mathrm{b}_{1} \mathrm{X}_{\mathrm{PKpre}}+\mathrm{b}_{2} \mathrm{X}_{\mathrm{CEpre}}+\mathrm{a}+\mathrm{E}$ \\
\hline $5 \mathrm{~F}$ & $\mathrm{Y}_{\text {CEpost }}=\mathrm{b}_{1} \mathrm{X}_{\mathrm{PKpre}}+\mathrm{b}_{2} \mathrm{X}_{\text {CEpre }}+\mathrm{b}_{3} \mathrm{X}_{\text {group }}+\mathrm{a}+\mathrm{E}$ \\
\hline $6 \mathrm{R}$ & $\mathrm{Y}_{\text {CEpost }}=b_{1} X_{\text {PKpre }}+b_{2} X_{\text {PKpost }}+b_{3} X_{\text {CEpre }}+a+E$ \\
\hline $6 \mathrm{~F}$ & $Y_{\text {CEpost }}=b_{1} X_{\text {PKpre }}+b_{2} X_{\text {PKpost }}+b_{3} X_{\text {CEpre }}+b_{4} X_{\text {group }}+a+E$ \\
\hline
\end{tabular}

Note: $\mathrm{F}=$ Full model, $\mathrm{R}=$ Restricted model, $\mathrm{CE}=$ Likelihood to Pursue Continuing Education, $\mathrm{PK}=$ Perceived Knowledge (mean score), $\mathrm{E}=$ Error vector (calculated as $\mathrm{Y}_{1}$ $\hat{Y})$ 
Knowledge gap was calculated as the difference between the normalized scores for pre-PKQ and AKA and between the post-PKQ and AKA to determine pre-test and post-test knowledge gap calculations, respectively. MLR was used to identify the degree to which pre-test knowledge gap can predict post-test knowledge gap (Table 10).

Table 10

Multiple Linear Regression Models to Analyze Linear and Second Degree Relationship between Pre-test and Post-test Knowledge Gap

Model

Number Regression Model

$$
\begin{array}{ll}
\text { 7R } & \mathrm{Y}_{\mathrm{KGpost}}=\mathrm{b}_{1} \mathrm{X}_{\mathrm{KGpre}}+\mathrm{a}+\mathrm{E} \\
7 \mathrm{~F} & \mathrm{Y}_{\mathrm{KGpost}}=\mathrm{b}_{1} \mathrm{X}_{\mathrm{KGpre}}+\mathrm{b}_{2} \mathrm{X}_{\text {group }}+\mathrm{a}+\mathrm{E} \\
8 \mathrm{R} & \mathrm{Y}_{\mathrm{KGpost}}=\mathrm{b}_{1} \mathrm{X}_{\mathrm{KGpre}}+\mathrm{b}_{2} \mathrm{X}_{\mathrm{KGpre}}{ }^{2}+\mathrm{a}+\mathrm{E} \\
8 \mathrm{~F} & \mathrm{Y}_{\mathrm{KGpost}}=\mathrm{b}_{1} \mathrm{X}_{\mathrm{KGpre}}+\mathrm{b}_{2} \mathrm{X}_{\mathrm{KGpre}}{ }^{2}+\mathrm{b}_{3} \mathrm{X}_{\text {group }}+\mathrm{a}+\mathrm{E}
\end{array}
$$

Note: $\mathrm{F}=$ Full model, $\mathrm{R}=$ Restricted model, $\mathrm{KG}=$ Knowledge Gap (calculated as AKA$\mathrm{PK}), \mathrm{E}=$ Error vector (calculated as $\mathrm{Y}_{1}-\hat{\mathrm{Y}}$ )

MLR was also implemented to identify the degree to which knowledge gap can predict likelihood to pursue $\mathrm{CE}$ (Table 11).

MLR was implemented to identify the degree to which gender, occupational setting, occupational region, level of expertise, and level of education affected the predictive relationship between knowledge gap and likelihood to pursue CE (Table 12). 
Table 11

Multiple Linear Regression Models to Analyze Relationship between Knowledge Gap and Likelihood to Pursue Continuing Education

\section{Model}

Number

Regression Model

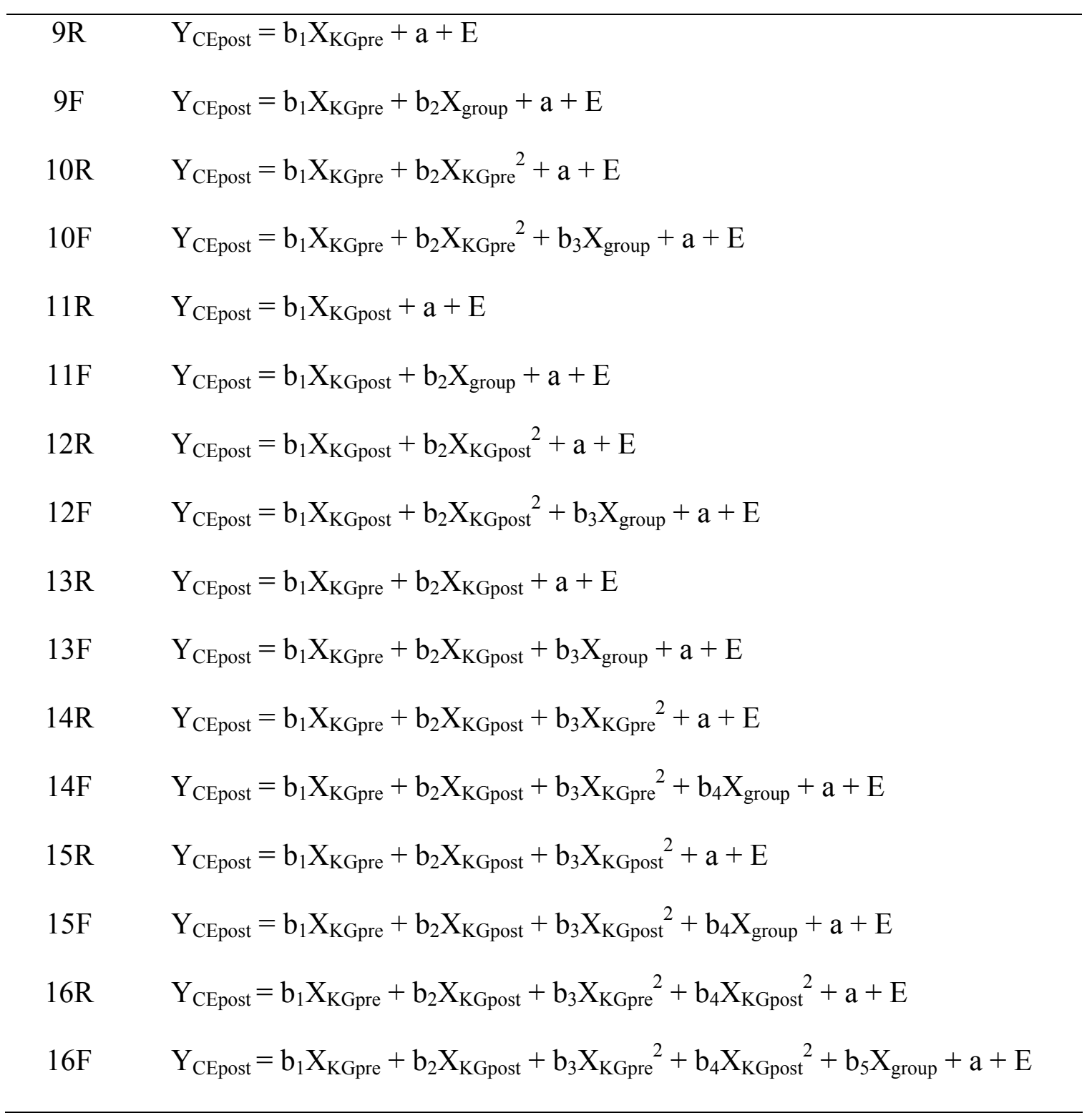

Note: $\mathrm{F}=$ Full model, $\mathrm{R}=$ Restricted model, $\mathrm{CE}=$ Likelihood to Pursue Continuing Education, $\mathrm{KG}=$ Knowledge Gap (calculated as AKA-PK), E= Error vector (calculated as $\left.\mathrm{Y}_{1}-\hat{\mathrm{Y}}\right)$ 


\section{Table 12}

Multiple Linear Regression Models to Analyze Relationship between Linear and Second Degree Relationships and Likelihood to Pursue Continuing Education When Controlling for Selected Demographic Variables

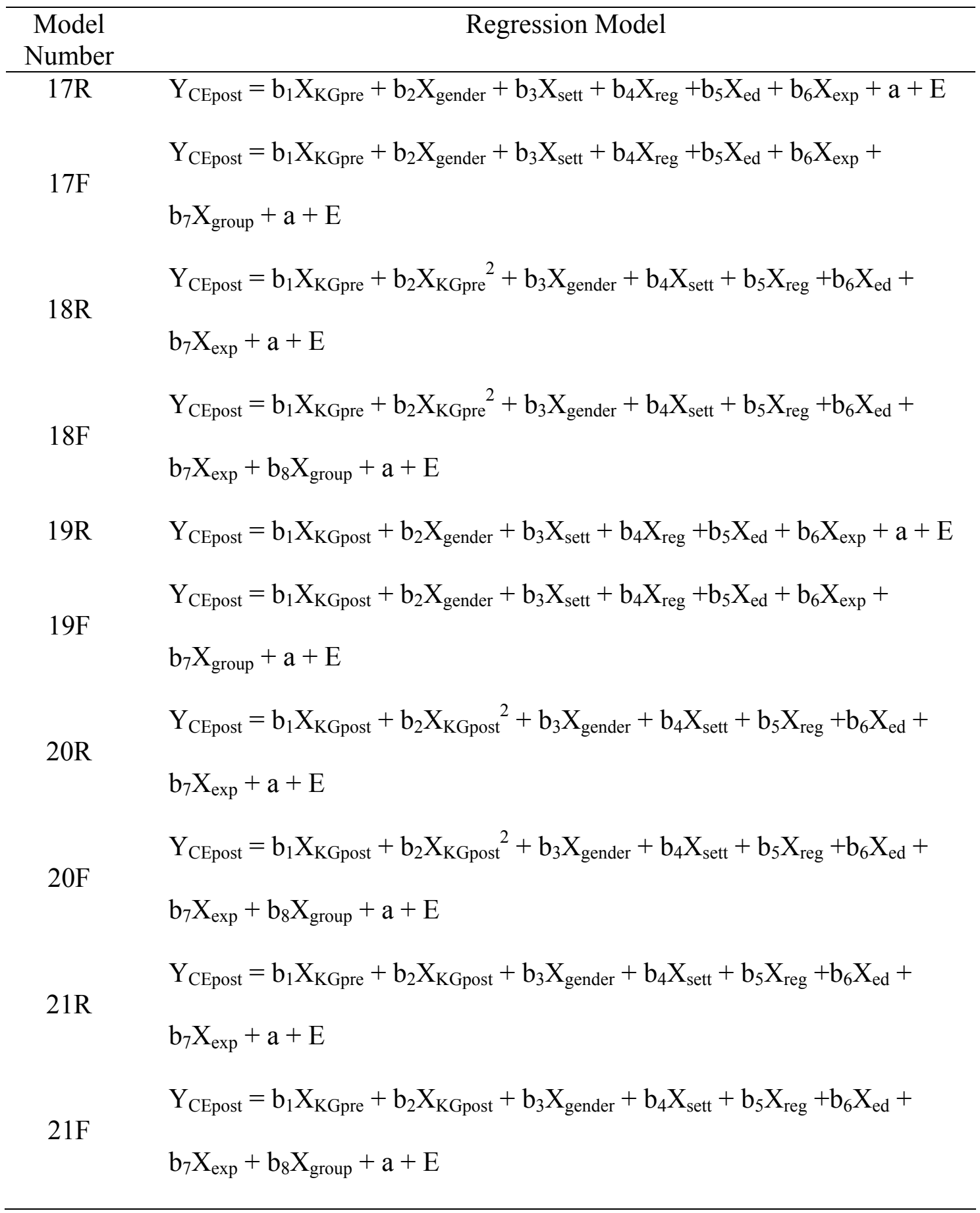


Table 12

Multiple Linear Regression Models to Analyze Relationship between Linear and Second Degree Relationships and Likelihood to Pursue Continuing Education When Controlling for Selected Demographic Variables (cont.)

Model

Number Regression Model

\begin{tabular}{|c|c|}
\hline $22 R$ & $\begin{array}{l}Y_{\text {CEpost }}=b_{1} X_{K G p r e}+b_{2} X_{K G p o s t}+b_{3} X_{\text {KGpre }}^{2}+b_{4} X_{\text {gender }}+b_{5} X_{\text {sett }}+b_{6} X_{\text {reg }} \\
+b_{7} X_{\text {ed }}+b_{8} X_{\text {exp }}+a+E\end{array}$ \\
\hline $22 \mathrm{~F}$ & $\begin{array}{l}Y_{\text {CEpost }}=b_{1} X_{K G p r e}+b_{2} X_{K G p o s t}+b_{3} X_{K G p r e}^{2}+b_{4} X_{\text {gender }}+b_{5} X_{\text {sett }}+b_{6} X_{\text {reg }} \\
+b_{7} X_{\text {ed }}+b_{8} X_{\text {exp }}+b_{9} X_{\text {group }}+a+E\end{array}$ \\
\hline $23 R$ & $\begin{array}{l}\mathrm{Y}_{\text {CEpost }}=\mathrm{b}_{1} \mathrm{X}_{\mathrm{KGpre}}+\mathrm{b}_{2} \mathrm{X}_{\mathrm{KGpost}}+\mathrm{b}_{3} \mathrm{X}_{\mathrm{KGpost}}^{2}+\mathrm{b}_{4} \mathrm{X}_{\text {gender }}+\mathrm{b}_{5} \mathrm{X}_{\text {sett }}+\mathrm{b}_{6} \mathrm{X}_{\mathrm{reg}} \\
+\mathrm{b}_{7} \mathrm{X}_{\mathrm{ed}}+\mathrm{b}_{8} \mathrm{X}_{\mathrm{exp}}+\mathrm{a}+\mathrm{E}\end{array}$ \\
\hline $23 \mathrm{~F}$ & $\begin{array}{l}Y_{\text {CEpost }}=b_{1} X_{K G p r e}+b_{2} X_{\text {KGpost }}+b_{3} X_{\text {KGpost }}^{2}+b_{4} X_{\text {gender }}+b_{5} X_{\text {sett }}+b_{6} X_{\text {reg }} \\
+b_{7} X_{\text {ed }}+b_{8} X_{\text {exp }}++b_{9} X_{\text {group }}+a+E\end{array}$ \\
\hline $24 R$ & $\begin{array}{l}Y_{\text {CEpost }}=b_{1} X_{\text {KGpre }}+b_{2} X_{\text {KGpost }}+b_{3} X_{K G p r e}^{2}+b_{4} X_{K G p o s t}^{2}+b_{5} X_{\text {gender }}+ \\
b_{6} X_{\text {sett }}+b_{7} X_{\text {reg }}+b_{8} X_{\text {ed }}+b_{9} X_{\text {exp }}+a+E\end{array}$ \\
\hline $24 \mathrm{~F}$ & $\begin{array}{l}Y_{\text {CEpost }}=b_{1} X_{\text {KGpre }}+b_{2} X_{\text {KGpost }}+b_{3} X_{\text {KGpre }}^{2}+b_{4} X_{\text {KGpost }}^{2}+b_{5} X_{\text {gender }}+ \\
b_{6} X_{\text {sett }}+b_{7} X_{\text {reg }}+b_{8} X_{\text {ed }}+b_{9} X_{\text {exp }}+b_{10} X_{\text {group }}+a+E\end{array}$ \\
\hline
\end{tabular}

Note: $\mathrm{F}=$ Full model, $\mathrm{R}=$ Restricted model, $\mathrm{CE}=$ Likelihood to Pursue Continuing Education, $\mathrm{KG}=$ Knowledge Gap (calculated as AKA-PK), Gender= Participant Gender, Sett $=$ Participant Occupational Setting, Reg= Participant Occupational Region, Ed= Participant Level of Education, Ex= Participant Level of Experience, E= Error vector (calculated as $\mathrm{Y}_{1}-\hat{\mathrm{Y}}$ ) 
Table 13

Multiple Linear Regression Models to Analyze the Relationship between Actual Knowledge Gap and the Dependent Variables: Post-test Perceived Knowledge and Likelihood to Pursue Continuing Education

Model

Number Regression Model

\begin{tabular}{ll}
\hline $25 \mathrm{R}$ & $\mathrm{Y}_{\text {PKpost }}=\mathrm{b}_{1} \mathrm{X}_{\mathrm{AKA}}+\mathrm{a}+\mathrm{E}$ \\
$25 \mathrm{~F}$ & $\mathrm{Y}_{\text {PKpost }}=\mathrm{b}_{1} \mathrm{X}_{\mathrm{AKA}}+\mathrm{b}_{2} \mathrm{X}_{\mathrm{AKA}}{ }^{2}+\mathrm{a}+\mathrm{E}$ \\
$26 \mathrm{R}$ & $\mathrm{Y}_{\mathrm{CEpost}}=\mathrm{b}_{1} \mathrm{X}_{\mathrm{AKA}}+\mathrm{a}+\mathrm{E}$ \\
$26 \mathrm{~F}$ & $\mathrm{Y}_{\text {CEpost }}=\mathrm{b}_{1} \mathrm{X}_{\mathrm{AKA}}+\mathrm{b}_{2} \mathrm{X}_{\mathrm{AKA}}{ }^{2}+\mathrm{a}+\mathrm{E}$
\end{tabular}

Note: $\mathrm{F}=$ Full model, $\mathrm{R}=$ Restricted model, $\mathrm{CE}=$ Likelihood to Pursue Continuing Education, $\mathrm{PK}=$ Perceived Knowledge (mean score), AKA= Actual Knowledge Assessment, $\mathrm{E}=$ Error vector (calculated as $\left.\mathrm{Y}_{1}-\hat{\mathrm{Y}}\right)$

\section{Control for Type I Buildup}

Multiple tests of significance between the various groups will increase the likelihood of finding significance and therefore, alpha error buildup occurs as the number of comparisons increase (Hinkle, Wiersma, \& Jurs, 2002). When making multiple comparisons, the probability of making a Type I error that is greater then the initial alpha level set increases. Common tests to control for alpha error buildup include those of Newman-Keul, Tukey, Dunn, Scheffe, Duncan, and Dunnett. However, correcting Type I error rate should not be mechanical. If the hypotheses are based on theory, and there is a reason to believe they are true, a correction may be, in reality, an overcorrection (Newman, Fraas \& Laux, 2000). 


\section{A-Priori Power Analyses}

Two power analyses were performed, one for t-test and one for multiple regression. The t-test power analysis was run to determine the necessary sample size for a power of 0.70 , for an $\alpha$ of 0.05 , and for a medium effect size (Cohen, 1988). The analysis determined that an $\mathrm{N}$ of 102 would be necessary to meet the above parameters. A second power analysis for multiple regression was performed to estimate sample size necessary to detect a medium effect size for an $\alpha$ of .05 and a power of 0.70 when there were 10 or fewer predictors. It was determined that $\mathrm{N}=99$ would be necessary to meet the above parameters.

\section{Summary}

This chapter provided a discussion of the methods. A critical analysis of previous methodology created a clear rationale for the design, sampling, and statistical decision making. All Athletic Training research regarding knowledge of EHI has been nonexperimental in nature and has yet to provide the rigor of this investigation. The randomized pretest-posttest control group design protects against threats to internal validity and was designed to help understand the cause and effect relationship between performance feedback and perceived knowledge. 


\section{CHAPTER IV}

\section{RESULTS}

\section{Effect of Performance Feedback}

Levene's statistic indicated the groups were heterogenic $(p>0.05)$ and therefore equal variances were assumed for the comparison of groups on the difference between pre and post PKQ mean scores and pre and post likelihood to pursue CE scores. No significant differences were found with the independent samples t-tests between groups on difference scores of the pre and post PKQ means $\left(\mathrm{t}_{101}=-0.66, p=0.50,1-\beta=0.54\right)$. However, there was a $68.4 \%$ significant difference $\left(\mathrm{t}_{101}=2.72, p=0.01, \mathrm{ES}=0.45\right)$ between groups in the change scores for likelihood to pursue $\mathrm{CE}$ because of the performance feedback. The experimental group demonstrated a $13.7 \%$ increase in the likelihood to pursue $\mathrm{CE}$ after the AKA in the experimental group, as compared to only a $4.3 \%$ in the control group.

\section{Relationship between Perceived Knowledge and Pursuing Continuing Education}

The relationship between pre-test and post-test measures of perceived knowledge and likelihood to pursue CE are summarized in Table 14 (all table formatting from McNeil, Newman, \& Kelly, 1996). Further, significant models are described in detail in the appendices in Figures 2-7 for Models 1F, 2R, 3R, 3F, 5R, and 5F. The strongest relationship among these variables was the relationship between pre-test and post-test measures of likelihood to pursue CE (Model 3R: $\left.r=0.73, \mathrm{R}^{2}=0.53\right)$. The pre- and posttest predictive relationship was enhanced when group was included in the model and group accounted for a significant amount of unique variance in predicting $\mathrm{CE}$ while the pre-test likelihood to pursue CE variable was held constant (Model 3F: $r=0.74, \mathrm{R}^{2}=0.55$ ). 
In this model, the negative weight of the group predictor was indicative of an increased post-test likelihood to pursue $\mathrm{CE}$ when pre-test likelihood to pursue $\mathrm{CE}$ was held constant. Note that experimental group was coded 1 and that control group was coded 2.

$$
\mathrm{Y}_{\text {CEpost }}=0.76 \mathrm{X}_{\text {CEpre }}-0.34 \mathrm{X}_{\text {group }}+2.24+\mathrm{E}
$$

Table 14

Model Summary for Relationships between Perceived Knowledge and Likelihood to

Pursue Continuing Education

\begin{tabular}{|c|c|c|c|c|c|c|c|c|c|}
\hline \multirow[t]{2}{*}{$\begin{array}{c}\text { Model } \\
\text { Number }\end{array}$} & \multirow{2}{*}{$\mathrm{R}_{\mathrm{f}}^{2}$} & \multirow[t]{2}{*}{ df } & \multirow[t]{2}{*}{$\mathrm{F}$} & \multirow[t]{2}{*}{$p$} & \multirow[t]{2}{*}{ Sign. } & \multicolumn{2}{|c|}{ Partial } & \multirow{2}{*}{$p$} & \multirow[t]{2}{*}{ Sign. } \\
\hline & & & & & & Variable & Value & & \\
\hline $1 \mathrm{~F}$ & 0.14 & $1 / 102$ & 16.76 & $<0.01$ & S & & & & \\
\hline $2 \mathrm{R}$ & 0.10 & $1 / 102$ & 11.04 & $<0.01$ & $\mathrm{~S}$ & & & & \\
\hline $2 \mathrm{~F}$ & 0.10 & $2 / 102$ & 5.47 & 0.01 & $\mathrm{~S}$ & $X_{\text {group }}$ & -0.01 & 0.90 & NS \\
\hline $3 R$ & 0.53 & $1 / 102$ & 113.91 & $<0.01$ & $\mathrm{~S}$ & & & & \\
\hline $3 \mathrm{~F}$ & 0.55 & $2 / 102$ & 60.55 & $<0.01$ & $\mathrm{~S}$ & $X_{\text {group }}$ & -0.19 & 0.05 & $\mathrm{~S}$ \\
\hline $4 \mathrm{R}$ & 0.03 & $1 / 102$ & 3.37 & 0.70 & NS & & & & \\
\hline $4 \mathrm{~F}$ & 0.03 & $2 / 102$ & 1.67 & 0.19 & NS & $X_{\text {group }}$ & -0.01 & 0.94 & NS \\
\hline $5 R$ & 0.53 & $2 / 102$ & 56.80 & $<0.01$ & $\mathrm{~S}$ & $\mathrm{X}_{\text {CEpre }}$ & 0.70 & $<0.01$ & $\mathrm{~S}$ \\
\hline $5 \mathrm{~F}$ & 0.55 & $3 / 102$ & 40.28 & $<0.01$ & $\mathrm{~S}$ & $X_{\text {group }}$ & -0.20 & 0.05 & $\mathrm{~S}$ \\
\hline \multirow{2}{*}{$6 \mathrm{R}$} & 0.55 & $3 / 102$ & 40.96 & $<0.01$ & $\mathrm{~S}$ & $\mathrm{X}_{\text {PKpost }}$ & -0.12 & 0.24 & NS \\
\hline & & & & & & $\mathrm{X}_{\text {CEpre }}$ & 0.70 & $<0.01$ & $\mathrm{~S}$ \\
\hline \multirow{2}{*}{$6 \mathrm{~F}$} & 0.57 & $4 / 102$ & 32.31 & $<0.01$ & $\mathrm{~S}$ & $X_{\text {group }}$ & -0.18 & 0.07 & NS \\
\hline & & & & & & $X_{\text {PKpost }}$ & -0.22 & 0.03 & $\mathrm{~S}$ \\
\hline
\end{tabular}

Note: $\mathrm{F}=$ Full model, $\mathrm{R}=$ Restricted model, $\mathrm{CE}=$ Likelihood to Pursue Continuing Education, $\mathrm{PK}=$ Perceived Knowledge (mean score), $\mathrm{S}=$ Significant at the $p \leq 0.05$ level, $\mathrm{NS}=$ Not significant at the $p>.05$ level

See Table 9 for more model details.

\section{Knowledge Gap}

Knowledge gap describes the differences between perceived knowledge and actual knowledge. The linear and second-degree curvilinear relationships between pre- 
test and post-test measures of knowledge gap are summarized in Table 15. No second degree relationships were found to be significant. Further, a significant linear model is described in detail in the appendices in Figure 8 for Model 7R. The strongest observed predictive relationship among these variables was the relationship between pre-test and post-test knowledge gap (Model 7R: $r=0.88, \mathrm{R}^{2}=0.77$ ):

$$
\mathrm{Y}_{\mathrm{KGpost}}=0.88 \mathrm{X}_{\mathrm{KGpre}}+0.002+\mathrm{E}
$$

Table 15

Model Summary for Linear and Second Degree Relationships between Pre-test and Posttest Knowledge Gap

\begin{tabular}{|c|c|c|c|c|c|c|c|c|c|}
\hline \multirow[t]{2}{*}{$\begin{array}{l}\text { Model } \\
\text { Number }\end{array}$} & \multirow[t]{2}{*}{$\mathrm{R}_{\mathrm{f}}^{2}$} & \multirow[t]{2}{*}{ df } & \multirow[t]{2}{*}{$\mathrm{F}$} & \multirow[t]{2}{*}{$p$} & \multirow[t]{2}{*}{ Sign. } & \multicolumn{2}{|c|}{$\begin{array}{c}\text { Partial } \\
\text { Correlation }\end{array}$} & \multirow[t]{2}{*}{$p$} & \multirow[t]{2}{*}{ Sign. } \\
\hline & & & & & & Variable & Value & & \\
\hline $7 \mathrm{R}$ & 0.77 & $1 / 102$ & 345.37 & $<0.01$ & $\mathrm{~S}$ & & & & \\
\hline $7 F$ & 0.78 & $2 / 102$ & 177.98 & $<0.01$ & S & $\mathrm{X}_{\text {group }}$ & 0.07 & 0.50 & NS \\
\hline $8 \mathrm{R}$ & 0.78 & $2 / 102$ & 172.99 & $<0.01$ & S & $\mathrm{X}_{\mathrm{KGpre}}{ }^{2}$ & 0.10 & 0.34 & NS \\
\hline $8 \mathrm{~F}$ & 0.78 & $3 / 102$ & 114.87 & $<0.01$ & S & $X_{\text {group }}$ & 0.07 & 0.50 & NS \\
\hline
\end{tabular}

Note: $\mathrm{F}=$ Full model, $\mathrm{R}=$ Restricted model, $\mathrm{KG}=$ Knowledge Gap (calculated as AKA$\mathrm{PK}), \mathrm{S}=$ Significant at the $p \leq 0.05$ level, $\mathrm{NS}=$ Not significant at the $p>.05$ level. See Table 10 for more model details.

Predictors of Pursuing Continuing Education and Perceived Knowledge

The linear and second-degree curvilinear relationships between pre-test and posttest measures of knowledge gap and post-test likelihood to pursue CE are summarized in Table 16. Further, significant models are described in detail in the appendices in Figures 9-10 for Models 9R and 11R. The strongest observed predictive relationship among these variables was the relationship between pre-test knowledge gap and post-test likelihood to pursue $\mathrm{CE}$ (Model 9R: $\mathrm{r}=0.31, \mathrm{R}^{2}=0.10$ ) regardless of group allocation: 


$$
\mathrm{Y}_{\text {CEpost }}=0.31 \mathrm{X}_{\mathrm{KGpre}}+4.80+\mathrm{E}
$$

Table 16

Model Summary for Relationships between Knowledge Gap and Likelihood to Pursue Continuing Education

\begin{tabular}{|c|c|c|c|c|c|c|c|c|c|}
\hline \multirow[t]{2}{*}{$\begin{array}{c}\text { Model } \\
\text { Number }\end{array}$} & \multirow[t]{2}{*}{$\mathrm{R}_{\mathrm{f}}^{2}$} & \multirow[t]{2}{*}{$\mathrm{df}$} & \multirow[t]{2}{*}{$\mathrm{F}$} & \multirow[t]{2}{*}{$p$} & \multirow[t]{2}{*}{ Sign. } & \multicolumn{2}{|c|}{ Partial Correlation } & \multirow[t]{2}{*}{$p$} & \multirow[t]{2}{*}{ Sign. } \\
\hline & & & & & & Variable & Value & & \\
\hline $9 \mathrm{R}$ & 0.10 & $1 / 102$ & 10.90 & $<0.01$ & $\mathrm{~S}$ & & & & \\
\hline $9 \mathrm{~F}$ & 0.10 & $2 / 102$ & 5.40 & 0.01 & S & $\mathrm{X}_{\text {group }}$ & 0.01 & 0.94 & NS \\
\hline $10 \mathrm{R}$ & 0.10 & $2 / 102$ & 5.42 & 0.01 & $\mathrm{~S}$ & $\mathrm{X}_{\mathrm{KGpre}}{ }^{2}$ & -0.02 & 0.84 & NS \\
\hline $10 \mathrm{~F}$ & 0.10 & $3 / 102$ & 3.58 & 0.02 & S & $\mathrm{X}_{\text {group }}$ & 0.01 & 0.94 & NS \\
\hline $11 \mathrm{R}$ & 0.05 & $1 / 102$ & 5.38 & 0.02 & $\mathrm{~S}$ & & & & \\
\hline $11 \mathrm{~F}$ & 0.05 & $2 / 102$ & 2.67 & 0.08 & NS & $\mathrm{X}_{\text {group }}$ & 0.00 & 0.98 & NS \\
\hline $12 \mathrm{R}$ & 0.05 & $2 / 102$ & 2.72 & 0.07 & NS & $X_{\text {KGpost }}^{2}$ & -0.03 & 0.74 & NS \\
\hline $12 \mathrm{~F}$ & 0.05 & $3 / 102$ & 1.80 & 0.15 & NS & $X_{\text {group }}$ & 0.00 & 0.99 & NS \\
\hline $13 \mathrm{R}$ & 0.11 & $2 / 102$ & 6.07 & $<0.01$ & $\mathrm{~S}$ & $\mathrm{X}_{\text {KGpost }}$ & -0.22 & 0.27 & NS \\
\hline $13 \mathrm{~F}$ & 0.11 & $3 / 102$ & 4.01 & 0.01 & $\mathrm{~S}$ & $X_{\text {group }}$ & 0.02 & 0.88 & NS \\
\hline $14 \mathrm{R}$ & 0.11 & $3 / 102$ & 4.01 & 0.01 & S & $\mathrm{X}_{\mathrm{KGpre}}{ }^{2}$ & -0.01 & 0.92 & NS \\
\hline $14 \mathrm{~F}$ & 0.11 & $4 / 102$ & 2.98 & 0.02 & S & $\mathrm{X}_{\text {group }}$ & 0.02 & 0.88 & NS \\
\hline $15 \mathrm{R}$ & 0.11 & $3 / 102$ & 4.11 & 0.01 & S & $\mathrm{X}_{\text {KGpost }}^{2}$ & 0.05 & 0.59 & NS \\
\hline $15 \mathrm{~F}$ & 0.11 & $4 / 102$ & 3.06 & 0.02 & S & $\mathrm{X}_{\text {group }}$ & 0.01 & 0.91 & NS \\
\hline \multirow{2}{*}{$16 \mathrm{R}$} & 0.12 & $4 / 102$ & 3.23 & 0.02 & S & $X_{\mathrm{KGpre}}{ }^{2}$ & -0.01 & 0.92 & NS \\
\hline & & & & & & $\mathrm{X}_{\mathrm{KGpost}}^{2}$ & -0.05 & 0.59 & NS \\
\hline $16 \mathrm{~F}$ & 0.12 & $5 / 102$ & 2.56 & 0.03 & $\mathrm{~S}$ & $X_{\text {group }}$ & 0.00 & 0.97 & NS \\
\hline
\end{tabular}

Note: $\mathrm{F}=$ Full model, $\mathrm{R}=$ Restricted model, $\mathrm{KG}=$ Knowledge Gap (calculated as AKA$\mathrm{PK}), \mathrm{S}=$ Significant at the $p \leq 0.05$ level, NS $=$ Not significant at the $p>.05$ level. See Table 11 for more model details.

The linear and second-degree curvilinear relationships between pre-test and posttest measures of knowledge gap and post-test likelihood to pursue CE with demographic characteristics included in the models are summarized in Table 17. Further, significant 
models are described in detail in the appendices in Figures 11-12 for Models 17R and 21R. Although these models indicated significance, none of the demographic variables were significant predictors within the model. As such, the previous relationship that indicated pre-test knowledge gap was a strong predictor of likelihood to pursue CE regardless of group allocation was also true regardless of demographic characteristics.

Table 17

Model Summary Analyzing Relationship between Linear and Second Degree

Relationships and Likelihood to Pursue Continuing Education When Controlling for

Selected Demographic Variables

\begin{tabular}{|c|c|c|c|c|c|c|c|c|c|}
\hline \multirow[t]{2}{*}{$\begin{array}{l}\text { Model } \\
\text { Number }\end{array}$} & \multirow[t]{2}{*}{$R_{f}^{2}$} & \multirow[t]{2}{*}{ df } & \multirow[t]{2}{*}{$\mathrm{F}$} & \multirow[t]{2}{*}{$p$} & \multirow[t]{2}{*}{ Sign. } & \multicolumn{2}{|c|}{ Partial Correlation } & \multirow[t]{2}{*}{$p$} & \multirow[t]{2}{*}{ Sign. } \\
\hline & & & & & & Variable & Value & & \\
\hline $17 \mathrm{R}$ & 0.13 & $6 / 102$ & 2.34 & 0.04 & $\mathrm{~S}$ & & & & \\
\hline $17 \mathrm{~F}$ & 0.13 & $7 / 102$ & 1.99 & 0.07 & NS & $X_{\text {group }}$ & -0.01 & 0.90 & NS \\
\hline $18 \mathrm{R}$ & 0.13 & $7 / 102$ & 1.99 & 0.07 & NS & & & & \\
\hline $18 \mathrm{~F}$ & 0.13 & $8 / 102$ & 1.72 & 0.10 & NS & $X_{\text {group }}$ & -0.01 & 0.90 & NS \\
\hline $19 \mathrm{R}$ & 0.10 & $6 / 102$ & 1.81 & 0.10 & NS & & & & \\
\hline $19 \mathrm{~F}$ & 0.10 & $7 / 102$ & 1.55 & 0.16 & NS & $X_{\text {group }}$ & -0.02 & 0.82 & NS \\
\hline $20 \mathrm{R}$ & 0.10 & $7 / 102$ & 1.54 & 0.16 & NS & & & & \\
\hline $20 \mathrm{~F}$ & 0.10 & $8 / 102$ & 1.34 & 0.23 & NS & $X_{\text {group }}$ & -0.02 & 0.82 & NS \\
\hline $21 \mathrm{R}$ & 0.13 & $7 / 102$ & 2.09 & 0.05 & $\mathrm{~S}$ & & & & \\
\hline $21 \mathrm{~F}$ & 0.13 & $8 / 102$ & 1.81 & 0.08 & NS & $X_{\text {group }}$ & -0.01 & 0.95 & NS \\
\hline $22 \mathrm{R}$ & 0.13 & $8 / 102$ & 1.81 & 0.08 & NS & & & & \\
\hline $22 \mathrm{~F}$ & 0.13 & $9 / 102$ & 1.59 & 0.13 & NS & $X_{\text {group }}$ & -0.01 & 0.96 & NS \\
\hline $23 \mathrm{R}$ & 0.13 & $8 / 102$ & 1.81 & 0.08 & NS & & & & \\
\hline $23 \mathrm{~F}$ & 0.13 & $9 / 102$ & 1.60 & 0.13 & NS & $\mathrm{X}_{\text {group }}$ & -0.01 & 0.93 & NS \\
\hline $24 \mathrm{R}$ & 0.14 & $9 / 102$ & 1.67 & 0.11 & NS & & & & \\
\hline $24 \mathrm{~F}$ & 0.14 & $10 / 102$ & 1.49 & 0.16 & NS & $\mathrm{X}_{\text {group }}$ & -0.02 & 0.88 & NS \\
\hline
\end{tabular}


AKA scores did not significantly account for unique variance in predicting posttest perceived knowledge or likelihood to pursue CE in the experimental group. Also, there were no significant second-degree curvilinear relationships between AKA and the dependent variables. The linear and second-degree curvilinear relationships between these variables are summarized in Table 18 .

Table 18

Model Summary for Relationships between Actual Knowledge Gap and the Dependent Variables: Post-test Perceived Knowledge and Likelihood to Pursue Continuing Education

\begin{tabular}{|c|c|c|c|c|c|c|c|c|c|}
\hline \multirow[t]{2}{*}{$\begin{array}{c}\text { Model } \\
\text { Number }\end{array}$} & \multirow[t]{2}{*}{$\mathrm{R}_{\mathrm{f}}^{2}$} & \multirow[t]{2}{*}{$\mathrm{df}$} & \multirow[t]{2}{*}{$\mathrm{F}$} & \multirow[t]{2}{*}{$p$} & \multirow[t]{2}{*}{ Sign. } & \multicolumn{2}{|c|}{$\begin{array}{c}\text { Partial } \\
\text { Correlation } \\
\end{array}$} & \multirow[t]{2}{*}{$p$} & \multirow[t]{2}{*}{ Sign. } \\
\hline & & & & & & Variable & Value & & \\
\hline $25 R$ & 0.04 & $1 / 44$ & 1.20 & 0.17 & NS & & & & \\
\hline $25 \mathrm{~F}$ & 0.05 & $2 / 44$ & 1.12 & 0.34 & NS & $\mathrm{X}_{\mathrm{AKA}}{ }^{2}$ & 0.08 & 0.60 & NS \\
\hline $26 \mathrm{R}$ & 0.04 & $1 / 44$ & 1.92 & 0.17 & NS & & & & \\
\hline $26 \mathrm{~F}$ & 0.04 & $2 / 44$ & 0.96 & 0.39 & NS & $X_{\text {AKA }}{ }^{2}$ & -0.04 & 0.84 & NS \\
\hline
\end{tabular}




\section{CHAPTER V}

\section{DISCUSSION}

\section{Effect of Performance Feedback}

The primary purpose of this investigation was to measure the effect of performance feedback on perceived knowledge and likelihood to pursue CE regarding EAMC. The hypotheses were that performance feedback would affect both perceived knowledge and likelihood to pursue CE. The findings suggest that performance feedback did not have a significant effect on perceived knowledge, but did significantly increase the likelihood to pursue CE regarding EAMC. Furthermore, there was a $13.7 \%$ increase in the likelihood to pursue $\mathrm{CE}$ after the $\mathrm{AKA}$ in the experimental group, as compared to $4.3 \%$ in the control group. As such, performance feedback can facilitate a learner to recognize the need for new knowledge, but may not change his or her perception of knowing.

The findings contradict previous literature that states feedback will alter selfefficacy (Bandura \& Cervone, 1983, 1986; Early, 1990; Erez, 1977), but parallels these previous studies indicating feedback will alter behavior. The discrepancy between goals and outcome feedback has had an impact on self-efficacy ratings and goal setting (Earley), particularly where the discrepancy is large (Bandura \& Cervone, 1986; Locke \& Latham, 1990). In this investigation, two forms of outcome feedback (item-by item and summative) were used in the experimental group. The results indicate only a small discrepancy between the pre-test and post-test perceived knowledge scores in both groups. Therefore, the lack of performance feedback's effect on perceived knowledge may have resulted from the small difference scores. 
Previous literature has supported the rationale that computerized, summative feedback will alter behavior (Gehlbach, Wilkinson, Hammond, Clapp, Finn, \& Taylor et al., 1984). The findings of this investigation support these findings, but the hypothesis that both the perceived knowledge and likelihood to pursue $\mathrm{CE}$ would change together due to feedback were not supported by the results. The literature suggests that performance feedback that identifies a knowledge gap may trigger a learner to reassess and identify the need for CE, improving the likelihood of engaging in CE opportunities (Bandura, 1986; Gist et al., 1989; Hill et al., 1987; Locke et al., 1984). The theories of "the definition of the situation" (Thomas \& Thomas, 1928) and the "illusion of knowing," (Glenberg et al., 1982) both suggest that perceived knowledge drives behavior. The literature describes an almost causal relationship between these dependent variables, which is further reviewed in the subsequent analyses.

Relationship between Perceived Knowledge and Pursuing Continuing Education The framework for this investigation was based on the theories about perceived knowledge (Glenberg et al., 1982; Thomas \& Thomas, 1928). Literature describes a strong relationship about perception of the situation and subsequent behavior (Glenberg et al.; Thomas \& Thomas). One of the purposes of this investigation was to identify the relationship between perceived knowledge and likelihood to pursue $\mathrm{CE}$ and if performance feedback impacts this relationship. Two hypotheses were supported through the literature. Self-efficacy theory suggests that students' perception of ability is positively related to their level of engagement in strategies to improve a task (Bandura, 1986; Schunk, 1991). Further, as a student's interest in learning for the sake of improving knowledge increases, the use of strategies to improve knowledge also 
increases (Ames \& Archer, 1988; Meece, Blumenfeld, \& Hoyle, 1988; Miller, Behrens, Greene, \& Newman, 1993). Therefore, a strong, direct relationship between perceived knowledge and likelihood to pursue $\mathrm{CE}$ was supported in the literature. Alternatively, a strong, inverse relationship between perceived knowledge and likelihood to pursue CE was also supported because as participants report a high level of perceived knowledge, they would also report a low likelihood to pursue CE (and vice versa).

The results indicate that pre and post perceived knowledge scores are not strong predictors, but that there was a strong relationship $\left(r=0.73, \mathrm{R}^{2}=0.53\right.$; Cohen, 1988) between pre-test and post-test likelihood to pursue CE. Further, the negative weight of the group predictor indicated an increased post-test likelihood to pursue CE because of coding (i.e, the experimental group was coded 1 and the control group 2).

\section{Knowledge Gap}

Multiple linear regression models were used to identify the prediction relationship between pre and post-test knowledge gap. Because most previous investigations have used a correlation analysis to compare perceived knowledge and actual knowledge scores to establish knowledge gap, the comparison with this measure of knowledge gap is relatively difficult. Previous research has indicated on several occasions that participant perceived and actual knowledge was poorly correlated (Haywood et al., 1994; Khan et al., 2001; van den Arend et al., 2000). In this investigation, knowledge gap was measured as a difference between perceived knowledge and actual knowledge. The findings indicate that pre-test knowledge gap was a strong and significant predictor of post-test knowledge gap. 
Predictors of Pursuing Continuing Education and Perceived Knowledge

Multiple linear regression was also used to identify predictors of likelihood to pursue $\mathrm{CE}$ and in some cases, post-test perceived knowledge. The findings indicate that pre-test knowledge gap was a moderate and significant predictor of likelihood to pursue CE. The findings failed to indicate a difference between groups, however. No researchers have incorporated the theory of external or performance feedback in investigations comparing actual and perceived knowledge across disciplines. Research suggests that learners are more effective when responding to externally provided feedback, (Bangert-Drowns et al., 1991; Meyer, 1986) like that provided through peer evaluation, teacher remarks on class work, or answer sections of a textbook (Butler \& Winne, 1995). This external feedback is most often provided after a task is completed and is therefore feedback about performance directed toward improving student scores on the task (Butler \& Winne).

Performance feedback may also serve an alternative purpose, especially in selfdirected or adult learners. Carver and Scheier (1990) suggest that self-directed learners who experience an impediment to learning, which may come in the form of negative performance feedback, will trigger reassessment of the educational goal. This would then suggest that once learners identify a knowledge gap or experiences an interruption, they will estimate how probable it is to achieve the goal and will assess whether to invest further effort, modify their plan or both. Researchers theorize that performance feedback that identifies a knowledge gap may trigger a learner to reassess and identify the need for CE, improving the likelihood of engaging in CE opportunities (Bandura, 1986; Gist et al., 1989; Hill et al., 1987; Locke et al., 1984). The findings of this investigation support the 
concept that once a knowledge gap is identified, learners will readjust and show an intention to seek new knowledge, yet this change will be regardless of performance feedback. This may suggest that identifying a knowledge gap may be a response to internal as well as external feedback to test-taking.

\section{Limitations}

Participant self-selection was the primary limitation of this investigation, as with most survey-type research. To control for this threat to external validity, a planned comparison of participant demographics was performed to examine generalizability of the findings. The random assignment to the experimental and control groups controlled the threat to internal validity. Further, this investigation was content specific and those who may lack interest in EAMC may have selected not to participate. Another possible justification for the choice not to participate may have been related to the barriers to $\mathrm{CE}$ and CE seeking behavior (Bennett, Casebeer, Kristofco, \& Strasser, 2004; Cuppett, 2001; Hughes, 2005). Physicians most commonly seek new information related to a specific patient problem (Bennett et al.). When practitioners seek CE based on the immediacy of application, this indicates a reactionary response. The purpose of this investigation was to provide an alternative to reactionary medicine by allowing practitioners to test their knowledge before a catastrophic event occurred. The response rate $(5.15 \%)$ indicated that ATs do not inherently seek opportunities to test their knowledge.

Another limitation of this investigation was participant mortality. Several participants in both the control $(n=4)$ and experimental $(n=9)$ groups completed the pretest PKQ and AKA. Although the original thought was that participants in the experimental group may have quit based on a low AKA score, the results indicate that 
these participants scored $2.61 \%$ higher (mean $\mathrm{AKA}=15.29$ score) than those in the experimental group who completed the series of three assessments (mean AKA=14.89 score). Therefore, motivation to continue based on a low AKA score may not be a suitable rationale for participant mortality.

The research design selected for this investigation is inherently strong and effectively controls for threats against internal validity. History, maturation, testing, instrumentation, statistical regression, and experimental mortality were not concerns with this research design (Campbell \& Stanley, 1966). Additionally, the testing procedures and instrumentation in this investigation were designed to account for the effects of history, maturation, and experimental mortality.

\section{Conclusions}

Performance feedback had a significant effect on participants' likelihood to pursue CE. Although performance feedback increased the likelihood to pursue CE, it did not alter participants' perceived knowledge score. Adult learning theory describes the process for motivated learners to seek new information through setting educational content, participating in education decisions, and setting goals (Hewson, 1992). Further, adult learning is initiated when students reflect, assess a deficit, and seek methods to meet the inadequacy. Although participants in this investigation were unable to recognize the deficit from the performance feedback through the post-test perceived knowledge scores, they were able to recognize the need for new knowledge.

There was a large relationship between pre and post-test likelihood to pursue CE, yet the relationship between perceived knowledge the subsequent behavior, likelihood to pursue CE was weak and not significant. "The definition of the situation" and the 
"illusion of knowing" both suggest that perceived knowledge drives behavior (Glenberg et al., 1982; Thomas \& Thomas, 1928). This was the basis for this investigation, yet this causal relationship described in the literature was not established.

The most significant finding was that knowledge gap (the difference between actual and perceived knowledge) was a strong and significant predictor of likelihood to pursue $\mathrm{CE}$, regardless of whether performance feedback was provided. Previous literature that states that the discrepancy between actual knowledge and perceived knowledge significantly contributes to learning supports these findings (Getner \& Collins, 1981; Glenberg et al., 1982; Park et al., 1988; Radecki \& Jaccard, 1995). Individuals often overestimate actual knowledge and therefore create a barrier to acquiring new information (Glenberg et al.). When adults are confronted with a knowledge gap they are likely to re-evaluate their perception of knowledge (Bandura, 1986; Gist et al., 1989; Hill et al., 1987; Locke et al., 1984), and change behavior. Perceived knowledge, as a dependent variable, was not significantly changed, but as a derivative of knowledge gap, demonstrated a strong and significant prediction value for changes in the desire to pursue new information. Perhaps the role of internal feedback, as a result of self-assessment through test-taking, rather than the previously suggested external feedback (Bangert-Drowns et al., 1991; Meyer, 1986), may be the trigger necessary to seek new knowledge through CE.

\section{Recommendations for Future Research}

Although not the scope of this investigation, future research should follow-up on CE seeking behavior. Participants suggested that they would find new information to resolve their knowledge gap, yet we were unable to capture actual behavior. Therefore, 
research that included on-line self-assessments with performance feedback and linked CE opportunities may identify those that will actually resolve the knowledge gap through CE. Incentives based assessments may also help to increase sample sizes and provide ATs with CE units for participation.

Students still enrolled in Entry-level Athletic Training Education Programs may also benefit from on-line based assessments in preparation for the certification examination. Investigations that incorporated only entry-level content may help students to identify weaker areas, which could easily be followed by CE opportunities at the entrylevel or beyond the scope of clinical competency. These investigations would not only benefit investigators, but also students of the profession.

Further evaluation of internal versus external feedback may be the most appropriate response to the findings of this investigation. Because knowledge gap was predictive, regardless if performance feedback was provided, the role of test-taking and self-assessment through internal recognition may be the trigger necessary for behavioral changes. Various methods of internal and external feedback should be investigated. 


\section{LIST OF REFERENCES}

Ames, C., \& Archer, J. (1988). Achievement goals in the classroom: Students' learning strategies and motivation processes. Journal of Educational Psychology, 80, 260267.

Arnold, B. L., Gansneder, B. M., \& Perrin, D. H. (2005). Research methods in athletic training. Philadelphia: F. A. Davis.

Arnold, J. C., \& Keller, J. L. (2002, April). Cultures of medicine: A technology based learning environment to enhance critical thinking skills. Paper presented at the Annual Meeting of the American Educational Research Association, New Orleans, LA.

Bandura, A. (1986). Social foundations of thought and action: A social cognitive theory. Englewood Cliffs, NJ: Prentice-Hall.

Bandura, A,. \& Cervone, D. (1983). Self-evaluative and self-efficacy mechanisms governing the motivational effects of goal systems. Journal of Personality and Social Psychology, 45, 1017-1028.

Bandura, A., \& Cervone, D. (1986). Differential engagement of self-reactive influences in cognitive motivation. Organizational Behavior and Human Decision Processes, 38, 92-113.

Bangert-Drowns, R. L., Kulik, C. C., Kulik, J. A., \& Morgan, M. T. (1991). The instructional effect of feedback in test-like events. Review of Educational Research, 61, 213-238.

Barrows, H. S., \& Tamblyn, R. (1980). Problem-based learning. New York: Springer Publishing.

Bellack, J. P., \& O’Neil, E. H. (2002). Recreating nursing practice for a new century: Recommendations and implications of the Pew Health Profession's final report. Nursing and Health Care Perspectives, 21, 14-21.

Bennett, N., L., Cassebeer, L. L., Kristofco, R. E., \& Strasser, S. M. (2004). Physicians' internet information-seeking behaviors. The Journal of Continuing Education in the Health Professions, 24, 31-38.

Bentley, S. (1996). Exercise-induced muscle cramp. Proposed mechanisms and management. Sports Medicine, 21, 409-420. 
Bergeron, M. F. (1996) Heat cramps during tennis: A case report. International Journal of Sport Nutrition, 6, 62-68.

Bergeron, M. F. (2003a). Heat cramps: Fluid and electrolyte challenges during tennis in the heat. Journal of Science and Medicine in Sport, 6, 19-27.

Bergeron, M. F. (2003b). Exertional Heat Cramps. In Exertional Heat Illnesses, edited by Armstrong, L. E., 91-102. Champaign, IL: Human Kinetics.

Bigard, A. X., Sanchez, H., Claveyrolas, G., Martin, S., Thimonier, B., \& Arnaud, M. J. (2001). Effects of dehydration and rehydration on EMG changes during fatiguing contractions. Medicine and Science in Sports and Exercise, 33, 1294-1300.

Binkley, H. M., Beckett, J., Casa, D. J., Kleiner, D. M., \& Plummer, P. E. (2002). National Athletic Trainers' Association position statement: Exertional heat illnesses. Journal of Athletic Training, 37, 329-343.

Board of Certification for the Athletic Trainer. Continuing Education. Retrieved on November 2, 2006. http://www.bocatc.org/

Brookfield, S. D. (1986). Understanding and facilitating adult learning. San Francisco, CA: Jossey-Bass.

Butler, D. L., \& Winne, P. H. (1995). Feedback and self-regulated learning: A theoretical synthesis. Review of Educational Research, 65, 245-281.

Campbell, D. T., \& Stanley, J. C. (1966). Experimental and quasi-experimental designs for research. Dallas, TX: Houghton Mifflin.

Carr, W. D., \& Drummond, J. L. (2002). Collaboration between athletic training clinical and classroom instructors. Journal of Athletic Training, 37, S182-S188.

Carver, C. S., \& Scheier, M. F. (1990). Origins and functions of positive and negative affect: A control-process view. Psychological Review, 97, 19-35.

Casa, D. J., Armstrong, L. E., Hillman, S. K., Montian, S. J., Reiff, R. V., \& Rich, B. S. E., et al. (2000). National Athletic Trainers' Association Position Statement: Fluid replacement for athletes. Journal of Athletic Training, 35, 212-224.

Clark, L. R., Jackson, M., \& Allen-Taylor, L. (2002). Adolescent knowledge about sexually transmitted diseases. Sexually Transmitted Diseases, 29, 436-443.

Cohen, J. (1988). Statistical power analysis for the behavioral sciences (2nd ed.). Hillsdale, NJ: Erlbaum. 
Cooper, E. R., Ferrara, M. S., \& Broglio, S. P. (2006). Exertional heat illness and environmental conditions during a single football season in the southeast. Journal of Athletic Training, 41, 332-336.

Craig, D. I. (2003). Educational reform in athletic training: a policy analysis. Journal of Athletic Training, 38, 351-357.

Cuppett, M. M. (2001). Self-perceived continuing education needs of certified athletic trainers. Journal of Athletic Training, 36, 388-395.

Davis, C. \& Misasi, S. (2001, August). Student athletic trainer vs. athletic training student: Get over it and get on with it! NATA News, 16.

Davis, D., Thomson O'Brien, M. A., Freemantle, N., Wolf, F. M., Mazmanian, P., \& Taylor-Vaisey, A. (1999). Impact of formal continuing medical education: Do conferences, workshops, rounds, and other traditional continuing education activities change physician behavior or health care outcomes? Journal of the American Medical Association, 282, 867-874.

Dombek, P. M., Casa, D. J., Yeargin, S. W., Mazzerole, S. M., Ganio, M. S., Armstrong, L. E., et al. (2006). Athletic trainers' knowledge and behavior regarding the prevention, recognition, and treatment of exertional heat stroke at the high school level. Journal of Athletic Training, 41, S-47.

Dougherty, K. A., Baker, L. B., Chow, M., \& Kenney, W. L. (2006). Two percent dehydration impairs and six percent carbohydrate drink improves boys' basketball skills. Medicine and Science in Sports Exercise, 38, 1650-1658.

Dowd, S. B. (1994). Education as a change strategy for allied health. Report from the University of Alabama Birmingham.

Drass, J. A., Muir-Nash, J., Boykin, P. C., Turek, J. M., \& Baker, K. L. (1989). Perceived and actual level of knowledge of diabetes mellitus among nurses. Diabetes Care, $12,351-356$.

Early, P. C., Northcraft, G. B., Lee, C., \& Lituchy, T. R. (1990). Impact of process and outcome feedback on the relation of goal setting to task performance. The Academy of Management Journal, 33, 87-105.

El-Deirawi, K. M., \& Zuraikat, N. (2001). Registered nurses' actual and perceived knowledge of diabetes mellitus. Journal for Nurses in Staff Development, 17, 511.

Erez, M. (1977). Feedback: A necessary condition for the goal setting-performance relationship. Journal of Applied Psychology, 62, 624-627. 
Flynn, L. R., \& Goldsmith, R. E. (1999). A short, reliable measure of subjective knowledge. Journal of Business Research, 46, 57-66.

Ford, C. E. (1978). Clinical education for the allied health professions. St Louis, MO: Mosby.

Gall, M. D., Gall, J. P., \& Borg, W. R. (2003). Educational research: An introduction. $\left(7^{\text {th }}\right.$ ed.). Boston: Pearson Education.

Gehlbach, S. H., Wilkinson, W. E., Hammond, W. E., Clapp, N. E., Finn, A. L., \& Taylor, W. J., et al. (1984). Improving drug prescribing in a primary care practice. Medical Care, 22, 193-201.

Gentner, D., \& Collins, A. (1981). Studies of inference from lack of knowledge. Memory and Cognition, 9, 434-443.

Gist, M. E., Schwoerer, U., \& Rosen, B. (1989). Effects of alternative training methods on self-efficacy and performance in computer software training. Journal of Applied Psychology, 74, 884-891.

Glenberg, A. M., Wilkinson, A. C., \& Epstein, W. (1982). The illusion of knowing: Failure in the self-assessment of comprehension. Memory and Cognition, 10, 597602.

Gonzalez-Alonso, J., Calbet, J. A. L., \& Nielsen B. (1999). Metabolic and thermodynamic responses to dehydration-induced reductions in muscle blood flow in exercising humans. Journal of Applied Physiology, 85, 577-589.

Goodfellow, L. T., \& Valentine, T. (2002, May). The deep structure of situated thinking in professionals. Paper presented at the Annual Meeting of the Adult Education Research Conference, Raleigh, NC.

Griscti, O., \& Jacono, J. (2006). Effectiveness of continuing education programmes in nursing: Literature review. Journal of Advanced Nursing, 55, 449-456.

Harris, D., \& Naylor, S. (1992). Case study: learner physiotherapists' perceptions of clinical education. Education Training Technology International, 29, 124-131.

Haywood, J. L., Goldenberg, R. L., Bronstein, J., Nelson, K. G., \& Waldemar, A. (1994). Comparison of perceived and actual rates of survival and freedom from handicap in premature infants. American Journal of Obstetrics and Gynecology, 171, 432439.

Hewson, M. G. (1992). Clinical teaching in the ambulatory setting. Journal of General Internal Medicine, 7, 76-82. 
Hill, T., Smith, N. D., \& Mann, M. F. (1987). Role of efficacy expectations in predicting the decision to use advanced technologies: The case of computers. Journal of Applied Psychology, 72, 307-313.

Hinkle, D.E., Wiersma, W., \& Jurs, S. G. (2002). Applied statistics for the behavioral sciences $\left(5^{\text {th }}\right.$ ed.). Houghton Mifflin: Dallas, TX.

Hounsell, D. (1984). Learning and essay-writing. In F. Marton, D. Hounsell \& N. Entwistle (Eds.), The experience of learning (pp. 103-123). Edinburgh: Scottish Academic Press.

Hughes, B. J. (2005). Identifying attitudes and deterring factors towards continuing education among certified athletic trainers. The Internet Journal of Allied Health Science and Practice, 3. Retrieved April 17, 2008, from http://ijahsp.nova.edu/articles/vol3num1/hughes.htm

Jansen, P. H., Joosten, E. M., \& Vingerhoets, H. M. (1990). Muscle cramp: main theories as to aetiology. European Archives of Psychiatry and Neuroscience, 29, 337-342.

Jones, E. A. Curriculum reforms in the professions: Preparing students for a changing world. [Electronic version]. ERIC Digest. No. ED470541, 2002. Retrieved November 1, 2005 from ERIC DIGESTS.

Jung, A. P., Bishop, P. A., Al-Nawwas, A., \& Dale, R. B. (2005). Influence of hydration and electrolyte supplementation on incidence and time to onset of exerciseassociated muscle cramps. Journal of Athletic Training, 40, 71-75.

Khan, K. S., Awonuga, A. O., Dwarakanath, L. S., \& Taylor R. (2001). Assessments in evidence-based medicine workshops: loose connection between perception of knowledge and its objective assessment. Medical Teacher, 23, 92-94.

Knight, K. L. (1990). Clinical experiences in athletic training. Champaign, IL: Human Kinetics.

Knowles, M. S. (1968). Androgogy, not pedagogy. Adult Leadership, 16, 350-352, 386.

Kulhavy, R. W., \& Stock, W. A. (1989). Feedback in written instruction: The place of response certitude. Educational Psychology Review, 1, 279-308.

Laurent, T., \& Weidner, T. G. (2002). Clinical-education-setting standards are helpful in the professional preparation of employed, entry-level certified athletic trainers. Journal of Athletic Training, 37, S248-S254.

Layzer, R. B. (1994). The origin of muscle fasciculations and cramps. Muscle and Nerve, 17, 1243-1249. 
Lippard, V. W. (1974). A half-century of American medical education. New York: Macy Foundation.

Locke, E. A., Frederick, E., Lee, C., \& Bobko, P. (1984). Effects of self-efficacy, goals, and task strategies on task performance. Journal of Applied Psychology, 69, 241251.

Locke, E. A., \& Latham, G. P. (1990). A theory of goal setting and task performance. New York: Prentice-Hall.

Ludmerer, K. M. (1985). The plight of clinical teaching. In: Learning to heal. New York: Basic Books; 152-165.

McMullen, D. (1997, February). NATA board takes first step in reform. NATA News, 4-6.

McNeil, K., Newman, I., \& Kelly, F. J. (1996). Testing research hypotheses with the general linear model. Carbondale, IL: Southern Illinois University Press.

Meece, J. L., Blumenfeld, P. C., \& Hoyle, R. H. (1988). Students' goal orientation and cognitive engagement in classroom activities. Journal of Educational Psychology, $80,514-523$.

Melia, K. (1987). Learning and working: The occupational socialization of nurses. London, UK: Tavistock.

Mensch, J. M., \& Ennis, C. D. (2002). Pedagogic strategies perceived to enhance student learning in athletic training education. Journal of Athletic Training, 37, S199S207.

Meyer, L. (1986). Strategies for correcting students' wrong responses. Elementary School Journal, 87, 227-241.

Miller, R. B., Behrens, J. T., Greene, B. A., \& Newman, D. (1993). Goals and perceived ability: Impact on student valuing, self-regulation, and persistence. Contemporary Educational Psychology, 18, 2-14.

Montain, S. J., Smith, S. A., Mattot, R. P., Zientara, G. P., Jolesz, F. A., \& Sawka, M. N. (1998). Hypohydration effects on skeletal muscle performance and metabolism: A P-MRS31study. Journal of Applied Physiology, 84, 1889-1894.

National Athletic Trainers' Association. (2003). Inter-association task force on exertional heat illness consensus statement. Retrieved February 27, 2007, from http://www.nata.org/publicinformation/files/heatillnessconsensusstatement.pdf 
National Athletic Trainers' Association Education Council. Clinical education definitions. Retrieved on March 13, 2006. www.nataec.org

National Athletic Trainers' Association Education Council. Continuing education committee. Retrieved on November 2, 2006. http://206.211.148.195/ cec/index.html

National Athletic Trainers' Association Membership Statistics. Retrieved on February 10, 2008. http://www.nata.org/members1/documents/MembStats/2008_01.htm

Newman, I., Fraas, J., \& Laux, J. M. (2000). Adjusting the alpha levels of multiple statistical tests: Using a three-step approach. Journal of Research in Education, 10(1), 84-90.

Park, C. W., Gardner, M. P., \& Thukral, V. K. (1988). Self-perceived knowledge: Some effects on information processing for a choice task. The American Journal of Psychology, 101, 401-424.

Pitney, W. A. (1998). Continuing education in athletic training: An alternative approach based on adult learning theory. Journal of Athletic Training, 33, 72-76.

Osgood, C. E., Suci, C. J., \& Tannenbaum, P. H. (1957). The measurement of meaning. Urbana: University of Illinois Press.

Osler, W. (1928). The hospital as a college: Aequanimitas and other addresses. Philadelphia, PA: Blakiston's Son \& Co; 121.

Radecki, C. M., \& Jaccard, J. (1995). Perceptions of knowledge, actual knowledge, and information search behavior. Journal of Experimental and Social Psychology, 31, 107-138.

Schunk, D. H. (1991). Self-efficacy and academic motivation. Educational Psychologist, 26, 207-231.

Schwellnus, M. P., Derman, E. W., \& Noakes, T. D. (1997). Aetiology of skeletal muscle 'cramps' during exercise: a novel hypothesis. Journal of Sports Science, 15, 277285.

Schwellnus, M. P., Nicol, J., Laubscher, R., \& Noakes, T. D. (2004). Serum electrolyte concentrations and hydration status are not associated with exercise associated muscle cramping (EAMC) in distance runners. British Journal of Sports Medicine, 38, 488-492.

Smith, C. A. (1995). Features section: Problem based learning. Biochemistry and Molecular Biology Education, 23, 149-152. 
Sonmez, D. L. H. Problem-based learning in science. [Electronic version]. ERIC Digest. No. ED482724, 2003. Retrieved November 1, 2005 from ERIC DIGESTS.

Starkey, C. (1997). Reforming athletic training education. Journal of Athletic Training, $32,113-114$.

Stofan, J. R., Zachwieja, J. J., Horswill, C. A., Murray, R., Anderson, S. A., \& Eichner, E. R. (2005). Sweat and sodium losses in NCAA football players: a precursor to heat cramps? International Journal of Sports Nutrition and Exercise Metabolism, $15,641-652$.

Stone, M. B., Edwards, J. E., Stemmans, C. L., Ingersoll, C. D., Palmieri, R. M., \& Krause, B. A. (2003). Certified athletic trainers' perceptions of exerciseassociated muscle cramps. Journal of Sport Rehabilitation, 12, 333-342.

Sulzer, N. U., Schwellnus, M. P., \& Noakes, T. D. (2005). Serum electrolytes in Ironman triathletes with exercise-associated muscle cramping. Medicine Science and Sports Exercise, 37, 1081-1085.

Thomas, W. I., \& Thomas, D. S. (1928). The child in America: Behavior problems and programs. New York: Alfred A. Knopf.

Turocy, P. S. (2002). Overview of athletic training education research publications. Journal of Athletic Training, 37, S-162-S-167.

van den Arend, I. J. M., Stolk, R. P., Rutten, G. E. H. M., \& Schrijvers, G. J. P. (2000). Education integrated into structured general practice care for Type 2 diabetic patients results in sustained improvement of disease knowledge and self-care. Diabetic Medicine, 17, 190-197.

Van den Hurk, M. M., Dolmans, D. H. J. M., Wolfhagen, I. H. A. P., \& van der Vleuten, C. P. M. (2001). Quality of student-generated learning issues in a problem-based curriculum. Medical Teacher, 23, 567-571.

Wallace, J. L., Wu, J., Weinstein, J., Gorenflo, D. W., \& Fetters, M. D. (2004). Emergency contraceptives: Knowledge and attitudes of family medicine providers. Family Medicine, 36, 417-422.

Weidner, T. G., \& Henning, J. M. (2002). Historical perspective of athletic training clinical education. Journal of Athletic Training, 37, S222-S228.

Weidner, T. G., \& Henning, J. M. (2004). Development of standards and criteria for selection, training, and evaluation of athletic training approved clinical instructors. Journal of Athletic Training, 39, 335-343. 
Weidner, T. G., \& Laurent, T. (2001). Selection and evaluation guidelines for clinical education settings in athletic training. Journal of Athletic Training, 36, 62-67.

Weidner, T. G., \& Pipkin J. (2002). Clinical supervision of athletic training students at colleges and universities needs improvement. Journal of Athletic Training, 37, S241-S247.

Wexler, R. K. (2002). Evaluation and treatment of heat-related illnesses. American Family Physician, 65, 2307-2314.

Wilson, S. H., Gallagher, J. D., Elbaum, L., \& Smith, D. M. (2001, April). Problem-based learning in a physical therapy program and subsequent clinical practice: The practitioners' perspectives. Paper presented at the Annual Meeting of the American Educational Research Association, Seattle, WA. 


\section{APPENDICES}

Institutional Review Board Approval Memorandum

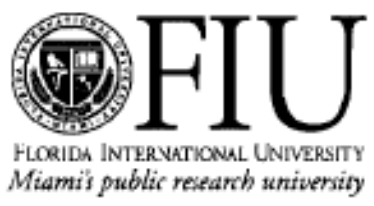

Office of Research Integrity

Researeh Compliance, MARC 430

\section{MEMORANDUM}
To: $\quad$ Lindsey Eberman
CC: $\quad$ Dr. Brady Tripp
File
From: Chris Grayson, CIM, Asst. Director of Research Compliance
Date: $\quad$ November 28, 2007
Proposal Title: Effect of Performance Feedback on Certified Athletic Trainers' Perceived Knowledge and Likelihood to Pursue Continuing Education on Exercise Associated Muscle Cramps.

Approval \# 112107-00

Your study was deemed Exempt by the Institutional Review Board at Florida International University on November 21, 2007.

As a requirement of IRB approval you are required to:

1) Submit a completion report (Form B-2) upon completion of your project in order for the file to be closed.

2) Submit a proposal and receive approval for any additions or changes in the procedures involving human subjects.

3) Provide immediate written notification to the IRB of every serious or unusual or unanticipated adverse event as well as problems with the rights or welfare of the human subjects. You must confirm the receipt of serious AE reports with the IRB office.

Special Conditions: N/A

Please note your approval number is indicated above. For further information, you may contact the IRB Coordinator by email at irbiacuc@fiu.edu or visit the OSRA - Human Subjects website at www.osra.fiu.edu. 
Table 19

Additional Results

Actual Regression Models for Relationships between Perceived Knowledge and Likelihood to Pursue Continuing Education

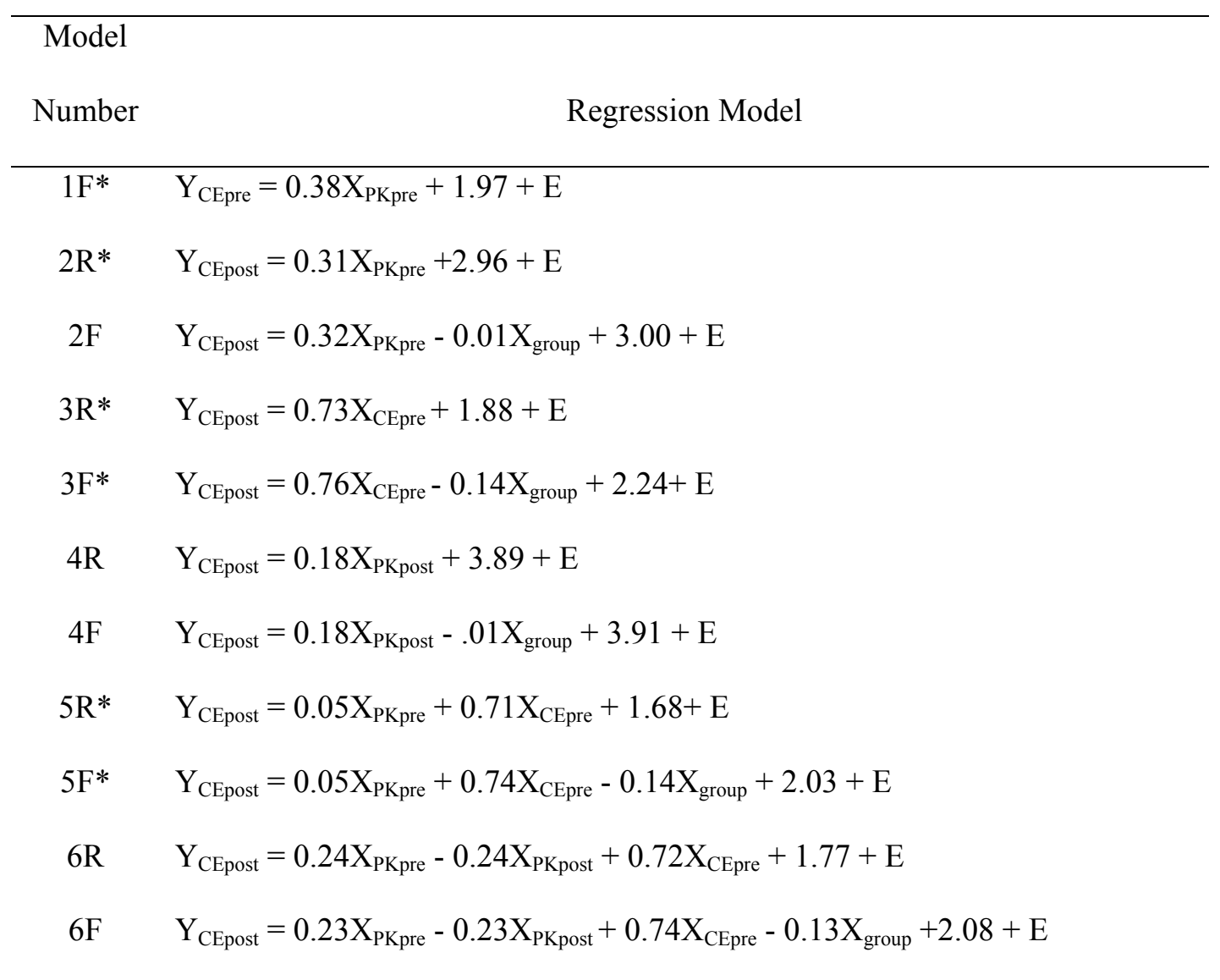

Note: $\mathrm{F}=$ Full model, $\mathrm{R}=$ Restricted model, $\mathrm{CE}=$ Likelihood to Pursue Continuing Education, $\mathrm{PK}=$ Perceived Knowledge (mean score), $\mathrm{E}=$ Error vector (calculated as $\mathrm{Y}_{1}-\hat{\mathrm{Y}}$ ), * indicates significance at the $p \leq 0.05$ level 
Figure 2

IF Model Summary and Table of Coefficients

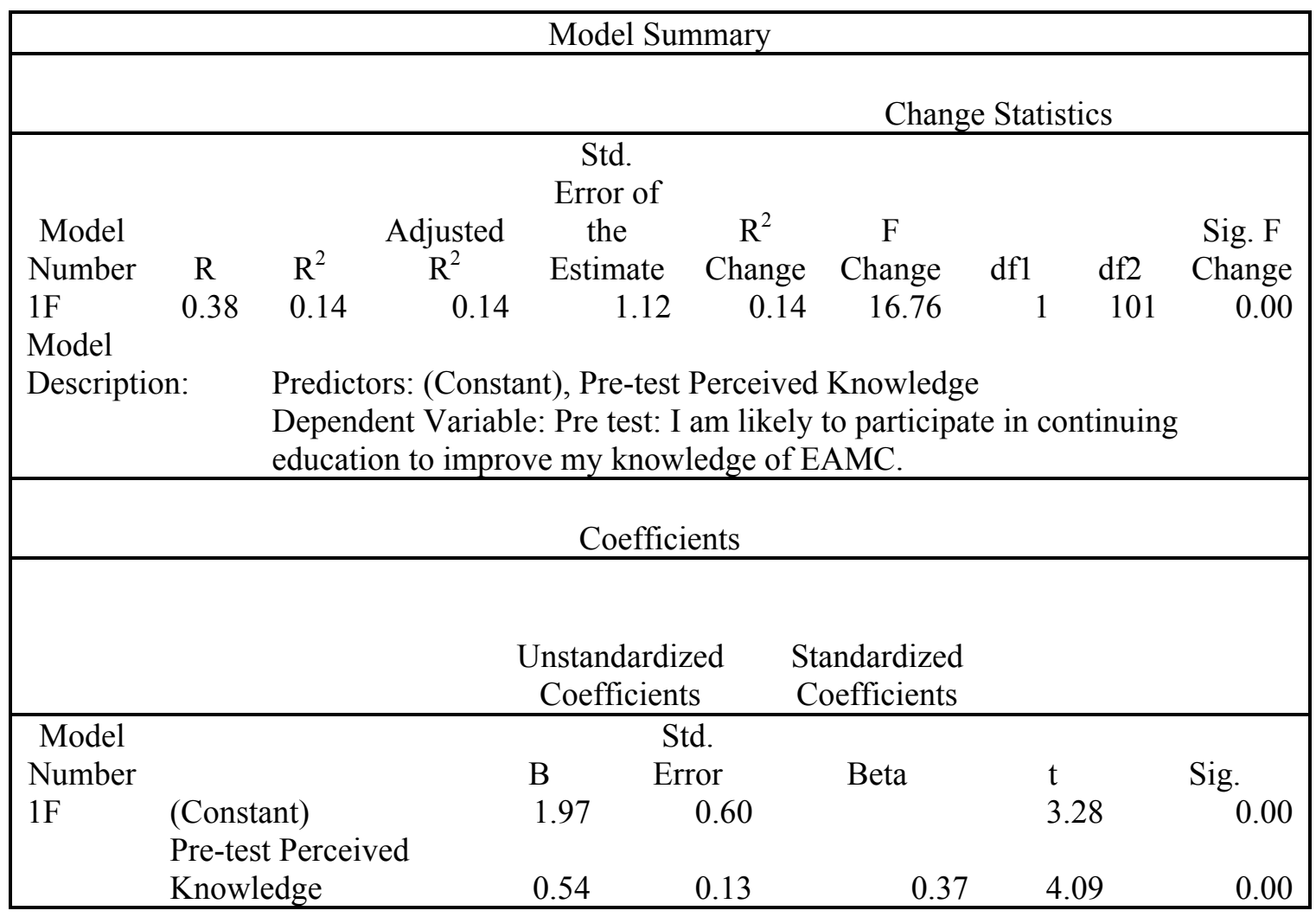


Figure 3

2R Model Summary and Table of Coefficients

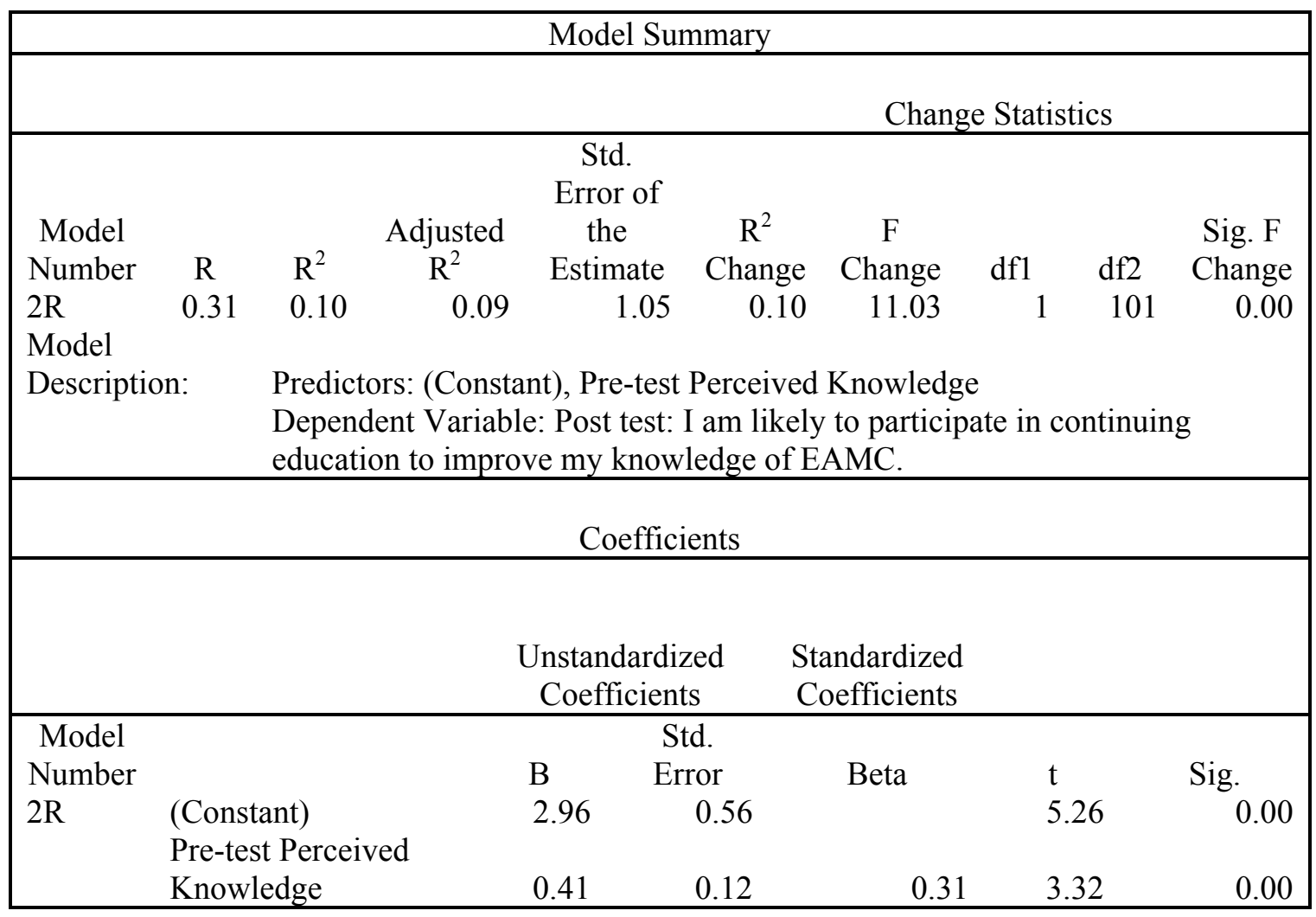


Figure 4

3R Model Summary and Table of Coefficients

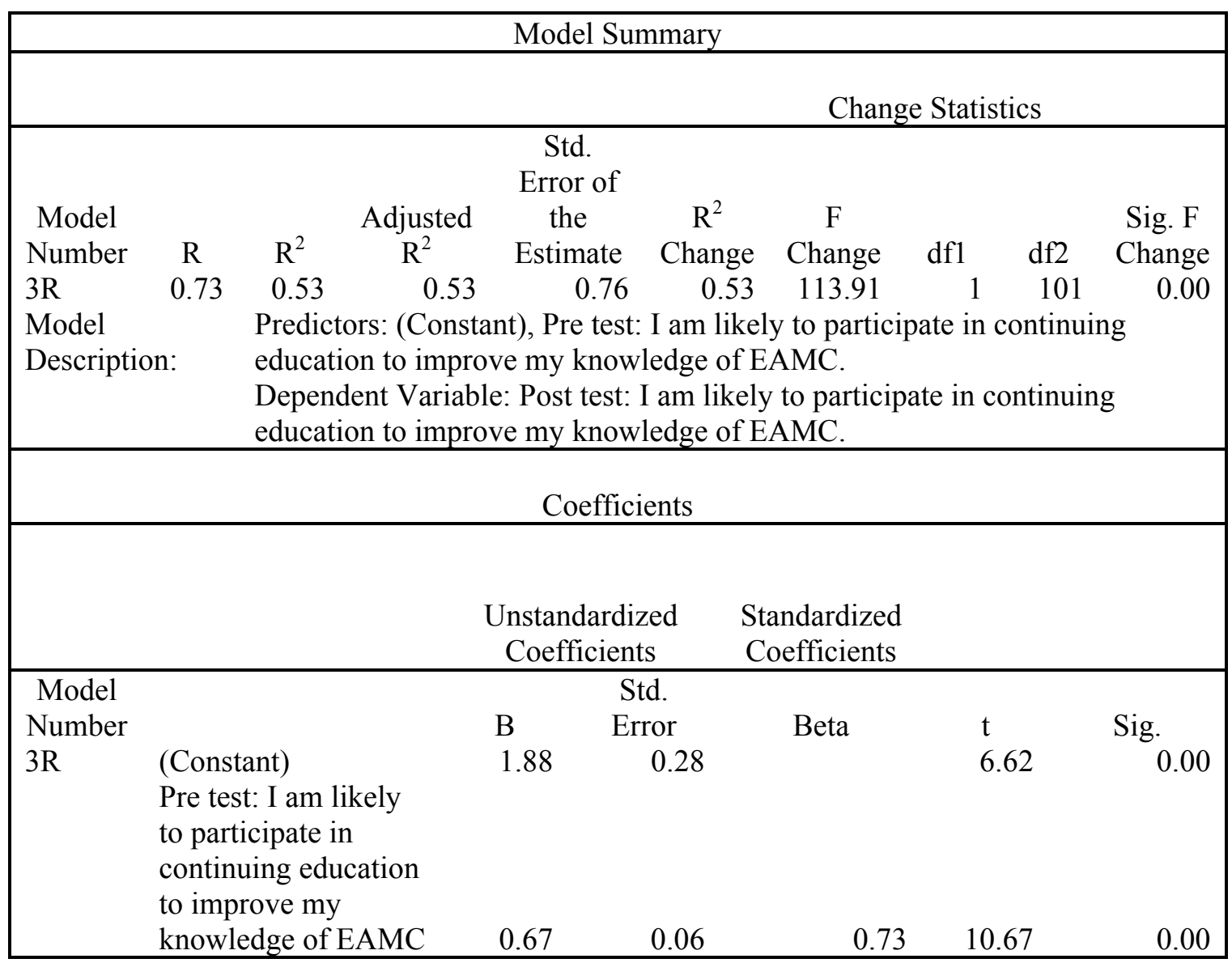


Figure 5

3F Model Summary and Table of Coefficients

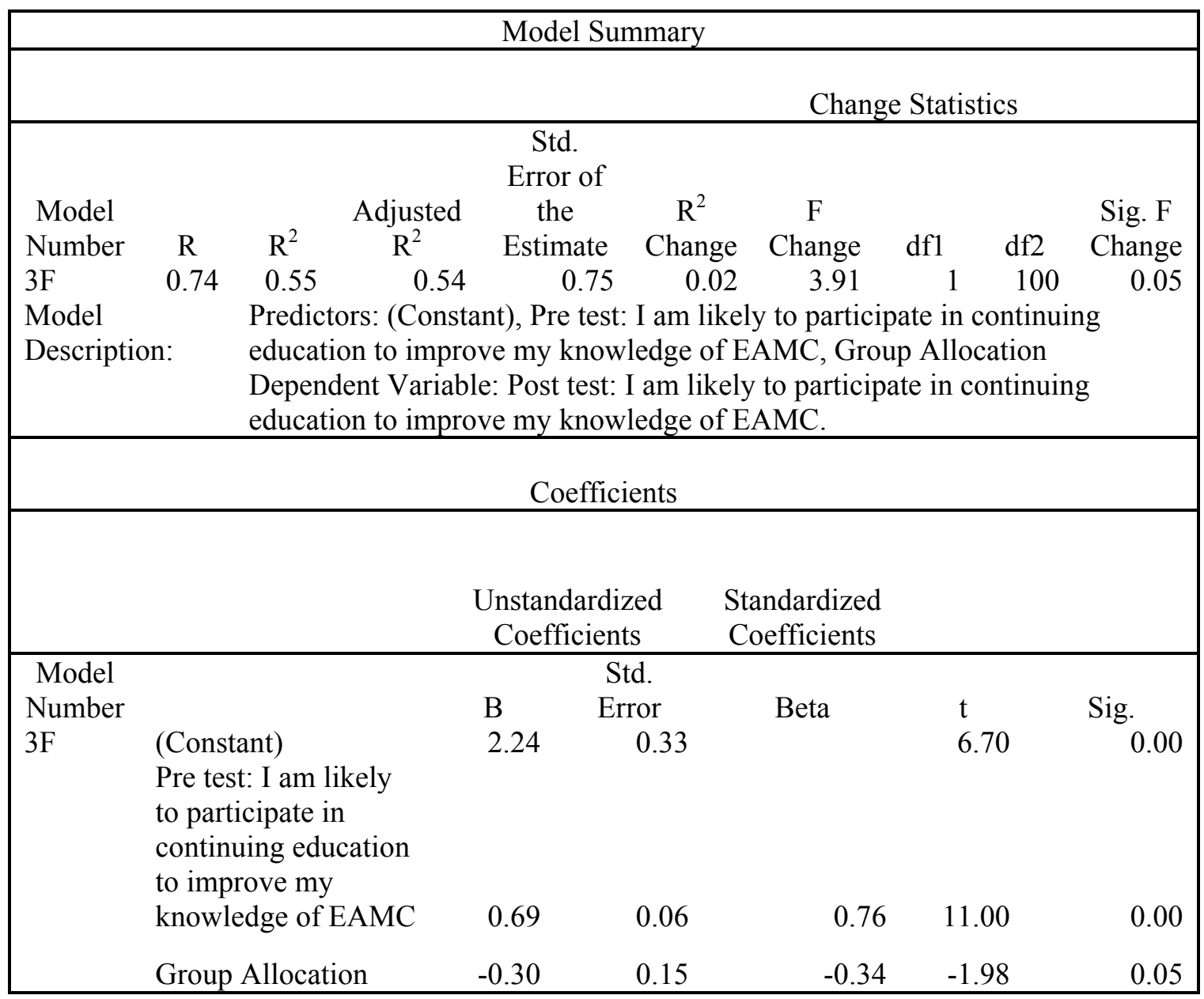


Figure 6

5R Model Summary and Table of Coefficients

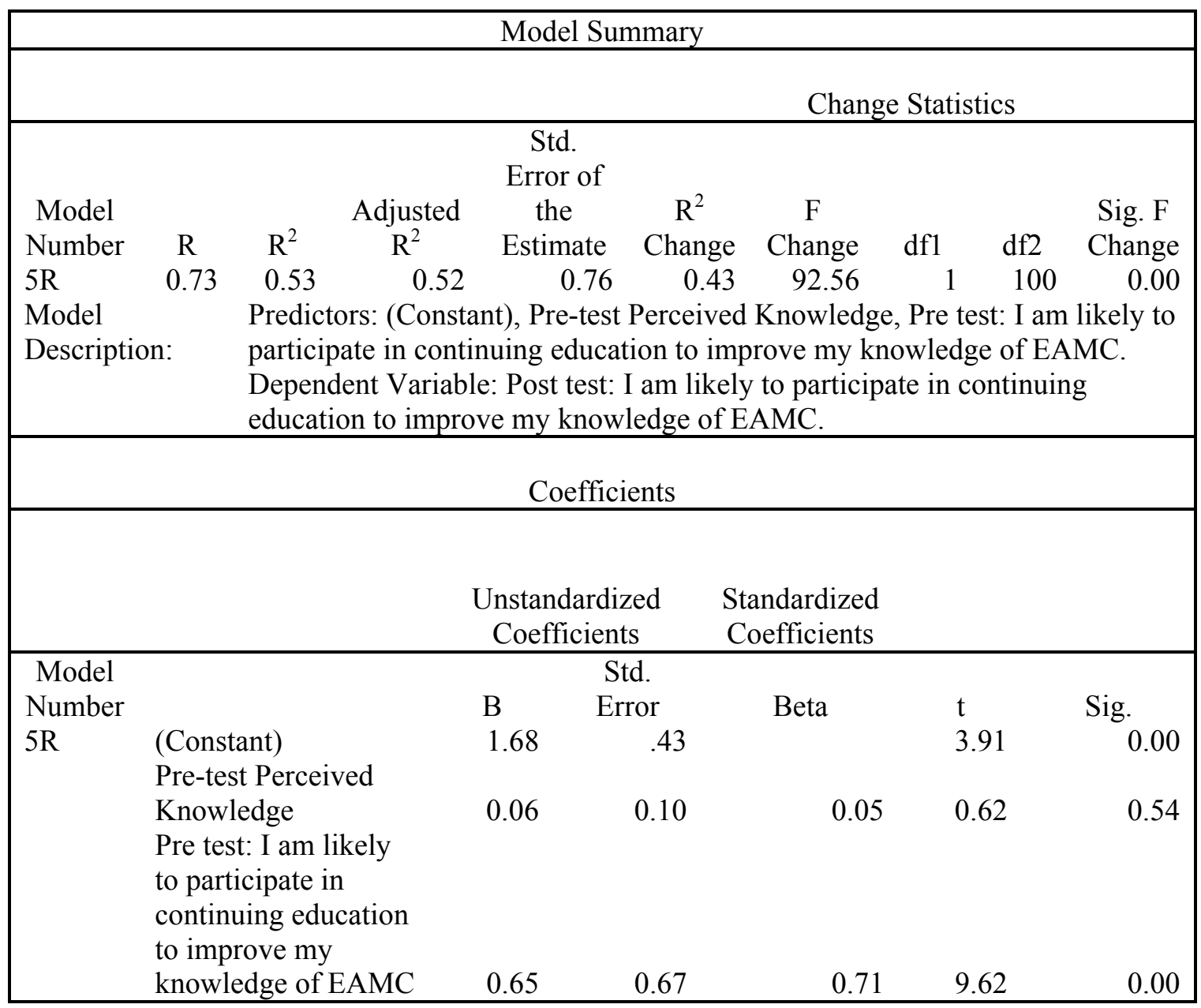


Figure 7

5F Model Summary and Table of Coefficients

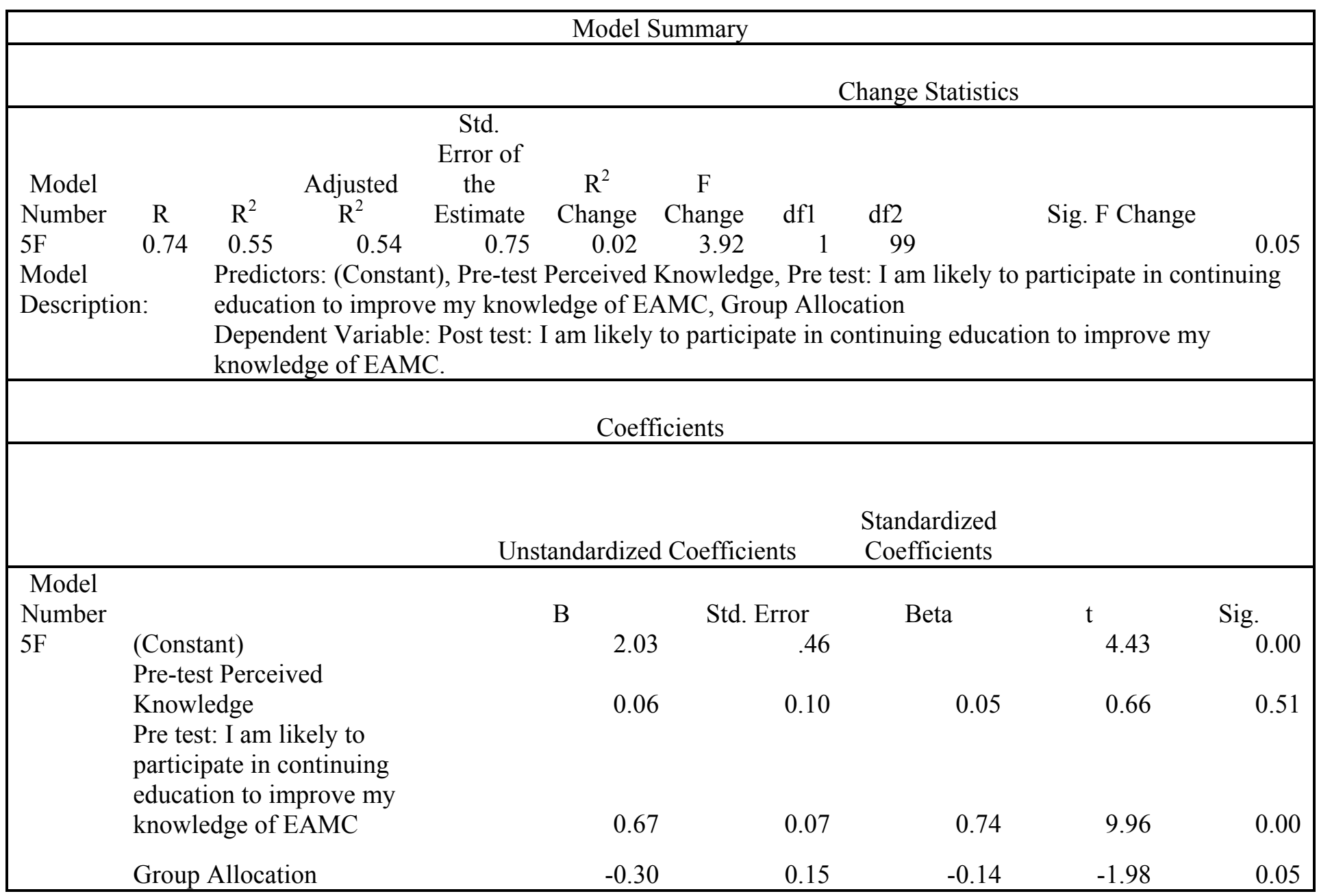


Table 20

Actual Regression Models for Relationships between Pre-test and Post-test Knowledge Gap

\section{Model}

Number

Regression Model

$$
\begin{array}{ll}
7 \mathrm{R}^{*} & \mathrm{Y}_{\mathrm{KGpost}}=0.88 \mathrm{X}_{\mathrm{KGpre}}+0.002+\mathrm{E} \\
7 \mathrm{~F} & \mathrm{Y}_{\mathrm{KGpost}}=0.88 \mathrm{X}_{\mathrm{KGpre}}+0.03 \mathrm{X}_{\text {group }}-0.13+\mathrm{E} \\
8 \mathrm{R} & \mathrm{Y}_{\mathrm{KGpost}}=0.88 \mathrm{X}_{\mathrm{KGpre}}+0.05 \mathrm{X}_{\mathrm{KGpre}}{ }^{2}-0.04+\mathrm{E} \\
8 \mathrm{~F} & \mathrm{Y}_{\mathrm{KGpost}}=0.88 \mathrm{X}_{\mathrm{KGpre}}+0.05 \mathrm{X}_{\mathrm{KGpre}}{ }^{2}+0.03 \mathrm{X}_{\text {group }}-0.17+\mathrm{E}
\end{array}
$$

Note: $\mathrm{F}=$ Full model, $\mathrm{R}=$ Restricted model, $\mathrm{KG}=$ Knowledge Gap (calculated as AKA-

$\mathrm{PK}), \mathrm{E}=$ Error vector (calculated as $\left.\mathrm{Y}_{1}-\hat{\mathrm{Y}}\right), *$ indicates significance at the $p \leq 0.05$ level

Figure 8

7R Model Summary and Table of Coefficients

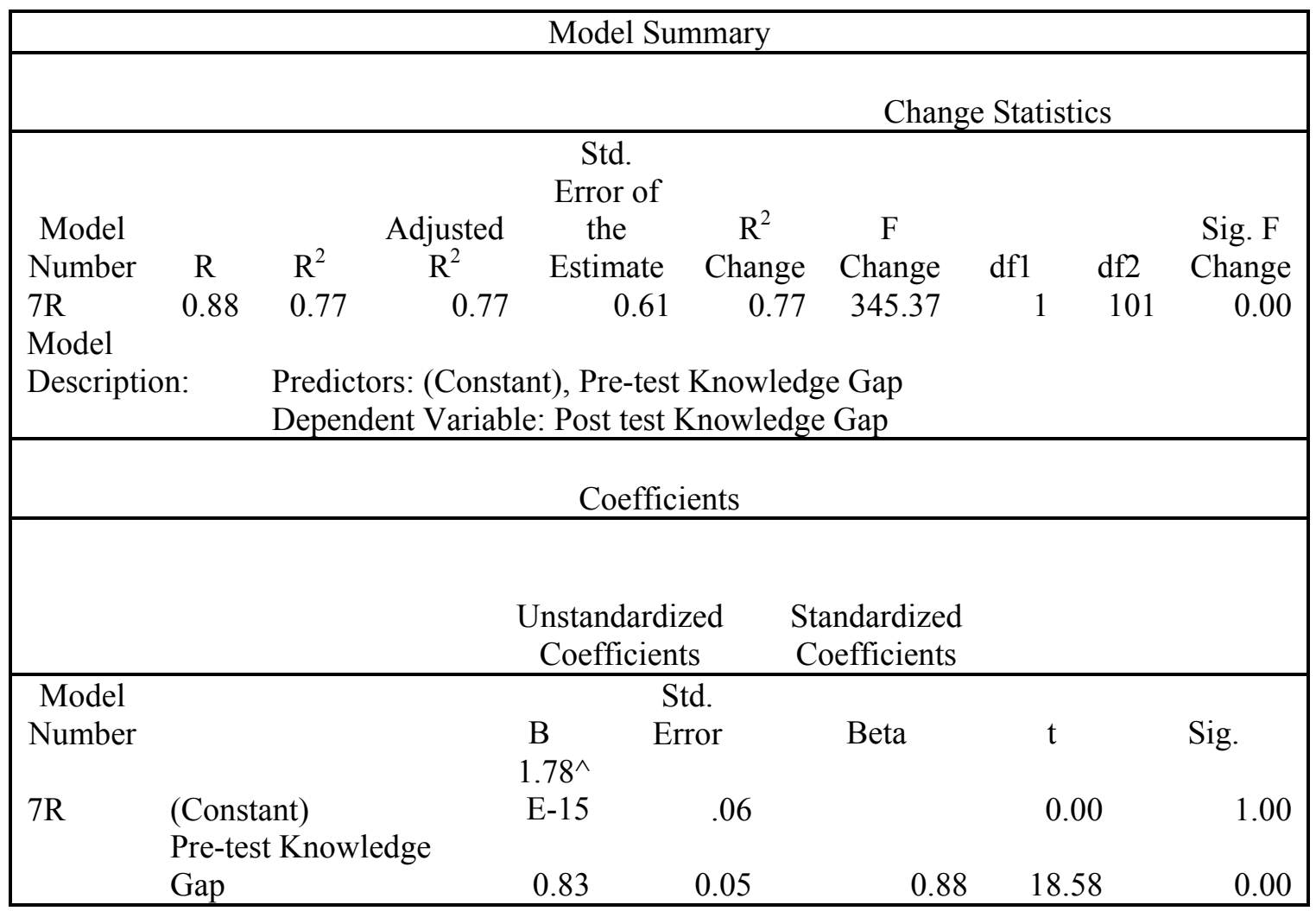


Table 21

Actual Regression Models for Relationships between Knowledge Gap and Likelihood to Pursue Continuing Education

\begin{tabular}{|c|c|}
\hline Model & \\
\hline Number & Regression Model \\
\hline $9 \mathrm{R}^{*}$ & $\mathrm{Y}_{\text {CEpost }}=0.31 \mathrm{X}_{\mathrm{KGpre}}+4.80+\mathrm{E}$ \\
\hline $9 \mathrm{~F}$ & $\mathrm{Y}_{\text {CEpost }}=0.31 \mathrm{X}_{\mathrm{KGpre}}+0.01 \mathrm{X}_{\text {group }}+4.77+\mathrm{E}$ \\
\hline $10 \mathrm{R}$ & $\mathrm{Y}_{\text {CEpost }}=0.31 \mathrm{X}_{\mathrm{KGpre}}-0.02 \mathrm{X}_{\mathrm{KGpre}}{ }^{2}+4.81+\mathrm{E}$ \\
\hline $10 \mathrm{~F}$ & $\mathrm{Y}_{\text {CEpost }}=0.31 \mathrm{X}_{\mathrm{KGpre}}-0.02 \mathrm{X}_{\mathrm{KGpre}}{ }^{2}+0.01 \mathrm{X}_{\text {group }}+4.79+\mathrm{E}$ \\
\hline $11 R^{*}$ & $\mathrm{Y}_{\text {CEpost }}=0.23 \mathrm{X}_{\mathrm{KGpost}}+4.80+\mathrm{E}$ \\
\hline $11 \mathrm{~F}$ & $\mathrm{Y}_{\text {CEpost }}=0.23 \mathrm{X}_{\mathrm{KGpost}}+0.003 \mathrm{X}_{\text {group }}+4.79+\mathrm{E}$ \\
\hline $12 \mathrm{R}$ & $\mathrm{Y}_{\text {CEpost }}=0.23 \mathrm{X}_{\mathrm{KGpost}}-0.03 \mathrm{X}_{\mathrm{KGpost}}^{2}+4.82+\mathrm{E}$ \\
\hline $12 \mathrm{~F}$ & $\mathrm{Y}_{\text {CEpost }}=0.23 \mathrm{X}_{\mathrm{KGpost}}-0.03 \mathrm{X}_{\mathrm{KGpost}}^{2}+0.001 \mathrm{X}_{\text {group }}+4.82+\mathrm{E}$ \\
\hline $13 \mathrm{R}$ & $\mathrm{Y}_{\text {CEpost }}=0.51 \mathrm{X}_{\mathrm{KGpre}}-0.22 \mathrm{X}_{\mathrm{KGpost}}+4.80+\mathrm{E}$ \\
\hline $13 \mathrm{~F}$ & $\mathrm{Y}_{\text {CEpost }}=0.51 \mathrm{X}_{\mathrm{KGpre}}-0.22 \mathrm{X}_{\mathrm{KGpost}}+0.02 \mathrm{X}_{\text {group }}+4.75+\mathrm{E}$ \\
\hline $14 \mathrm{R}$ & $\mathrm{Y}_{\text {CEpost }}=0.50 \mathrm{X}_{\mathrm{KGpre}}-0.22 \mathrm{X}_{\mathrm{KGpost}}-0.01 \mathrm{X}_{\mathrm{KGpre}}{ }^{2}+4.80+\mathrm{E}$ \\
\hline $14 \mathrm{~F}$ & $\mathrm{Y}_{\text {CEpost }}=0.51 \mathrm{X}_{\mathrm{KGpre}}-0.22 \mathrm{X}_{\mathrm{KGpost}}-0.01 \mathrm{X}_{\mathrm{KGpre}}{ }^{2}+0.01 \mathrm{X}_{\text {group }}+4.75+\mathrm{E}$ \\
\hline $15 \mathrm{R}$ & $\mathrm{Y}_{\text {CEpost }}=0.51 \mathrm{X}_{\mathrm{KGpre}}-0.22 \mathrm{X}_{\mathrm{KGpost}}-0.05 \mathrm{X}_{\mathrm{KGpost}}^{2}+4.83+\mathrm{E}$ \\
\hline $15 \mathrm{~F}$ & $\mathrm{Y}_{\text {CEpost }}=0.51 \mathrm{X}_{\mathrm{KGpre}}-0.22 \mathrm{X}_{\mathrm{KGpost}}-0.05 \mathrm{X}_{\mathrm{KGpost}}{ }^{2}+0.01 \mathrm{X}_{\text {group }}+4.79+\mathrm{E}$ \\
\hline $16 \mathrm{R}$ & $\mathrm{Y}_{\mathrm{CEpost}}=0.56 \mathrm{X}_{\mathrm{KGpre}}-0.26 \mathrm{X}_{\mathrm{KGpost}}+0.16 \mathrm{X}_{\mathrm{KGpre}}{ }^{2}-0.19 \mathrm{X}_{\mathrm{KGpost}}^{2}+4.81+\mathrm{E}$ \\
\hline $16 \mathrm{~F}$ & $\begin{array}{l}\mathrm{Y}_{\text {CEpost }}=0.56 \mathrm{X}_{\mathrm{KGpre}}-0.26 \mathrm{X}_{\mathrm{KGpost}}+0.16 \mathrm{X}_{\mathrm{KGpre}}^{2}-0.19 \mathrm{X}_{\mathrm{KGpost}}^{2}-0.004 \mathrm{X}_{\text {group }}+ \\
4.80+\mathrm{E}\end{array}$ \\
\hline
\end{tabular}

Note: $\mathrm{F}=$ Full model, $\mathrm{R}=$ Restricted model, $\mathrm{CE}=$ Likelihood to Pursue Continuing Education, $\mathrm{KG}=$ Knowledge Gap (calculated as AKA-PK), E= Error vector (calculated as $\left.\mathrm{Y}_{1}-\hat{\mathrm{Y}}\right), *$ indicates significance at the $p \leq 0.05$ level 
Figure 9

9R Model Summary and Table of Coefficients

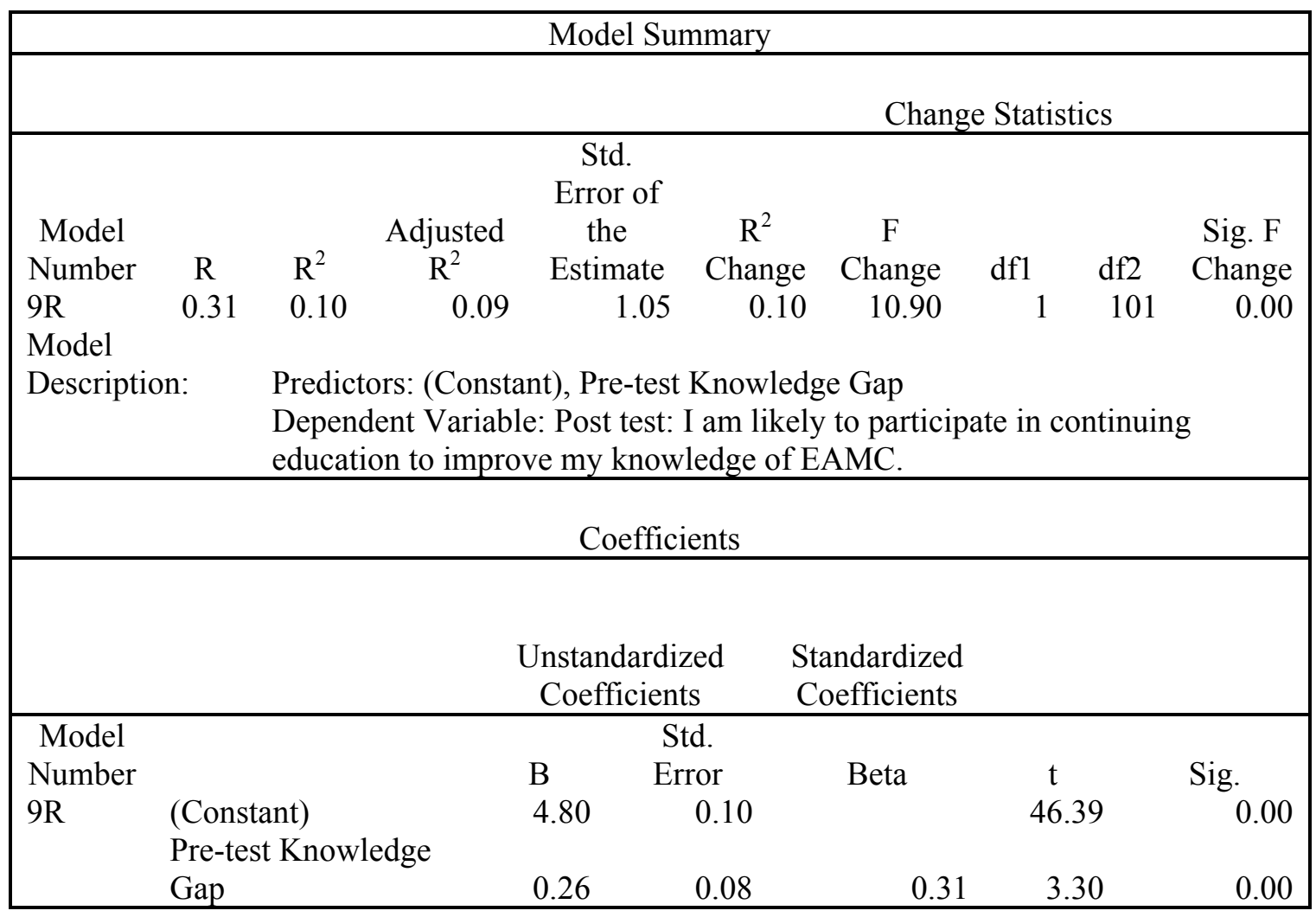


Figure 10

11R Model Summary and Table of Coefficients

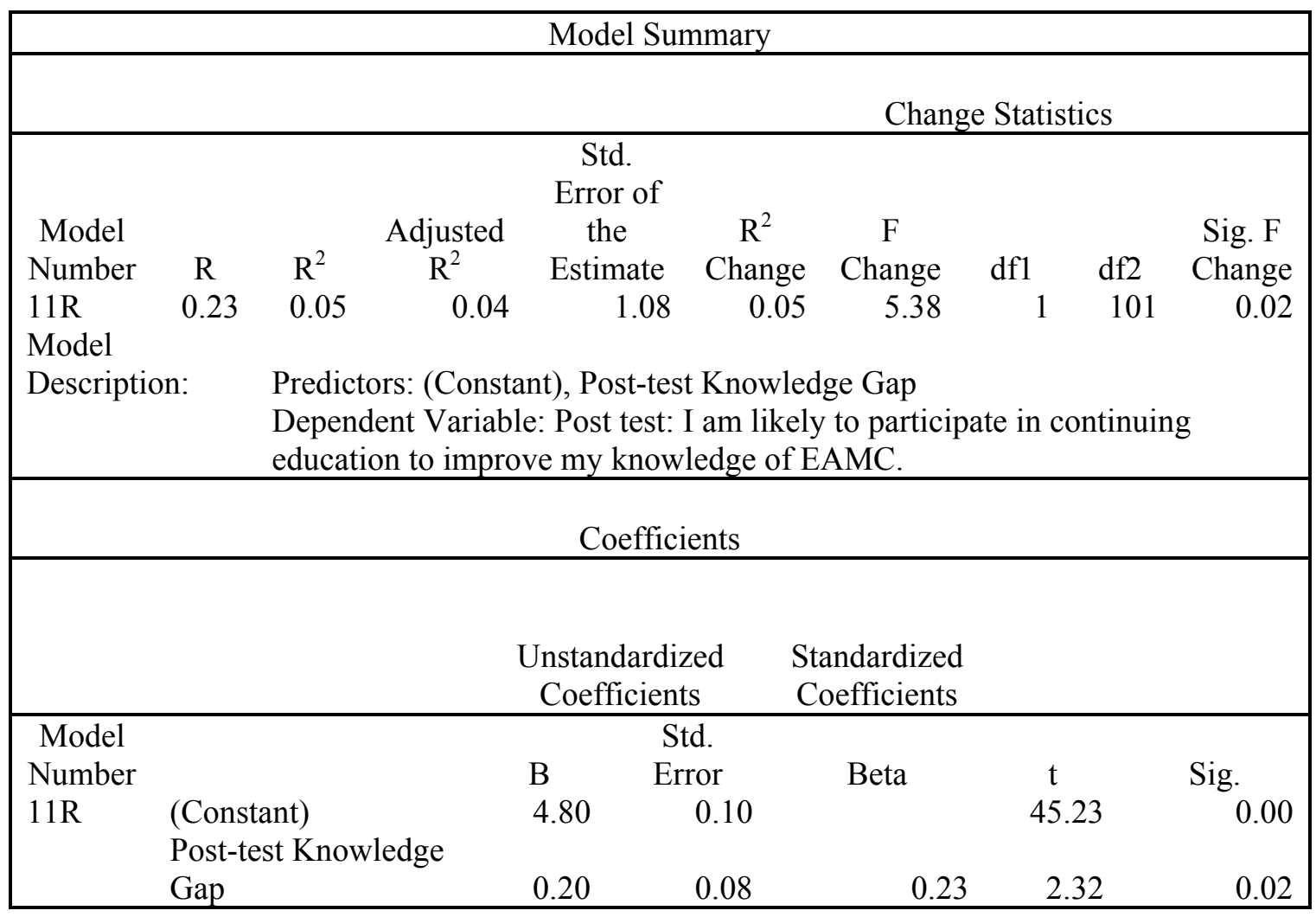


Table 22

Actual Regression Models for Analyzing Effects of Demographic Variables on the Relationship between Knowledge Gap and Likelihood to Pursue Continuing Education

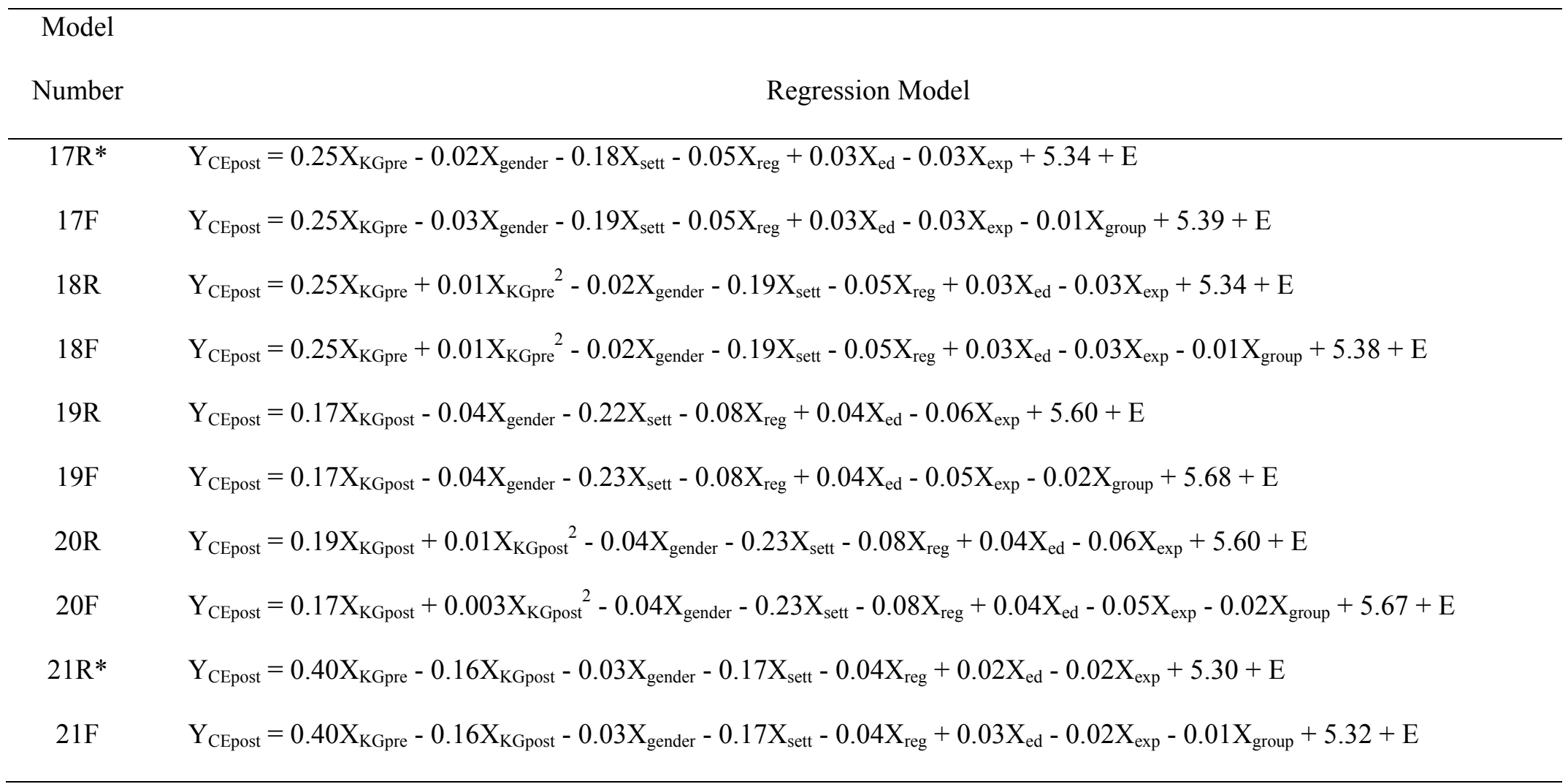


Table 22

Actual Regression Models for Analyzing Effects of Demographic Variables on the Relationship between Knowledge Gap and Likelihood to Pursue Continuing Education (cont.)

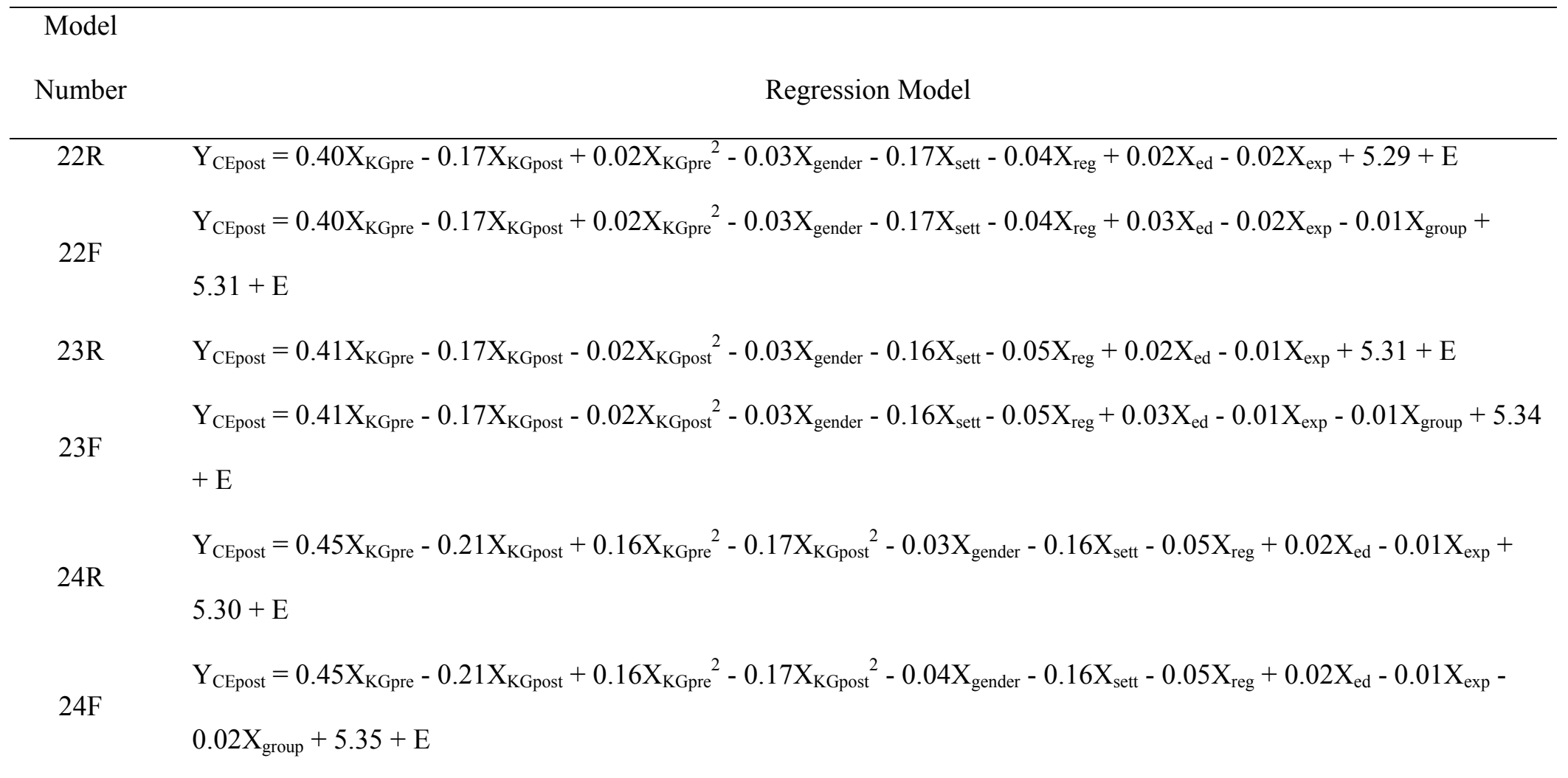

Note: $\mathrm{F}=$ Full model, $\mathrm{R}=$ Restricted model, $\mathrm{CE}=$ Likelihood to Pursue Continuing Education, $\mathrm{KG}=$ Knowledge Gap (calculated as AKA-PK), Gender $=$ Participant Gender, Sett= Participant Occupational Setting, Reg= Participant Occupational Region, Ed= Participant Level of Education, Ex= Participant Level of Experience, E= Error vector (calculated as $\mathrm{Y}_{1}-\hat{\mathrm{Y}}$ ) 
Figure 11

17R Model Summary and Table of Coefficients

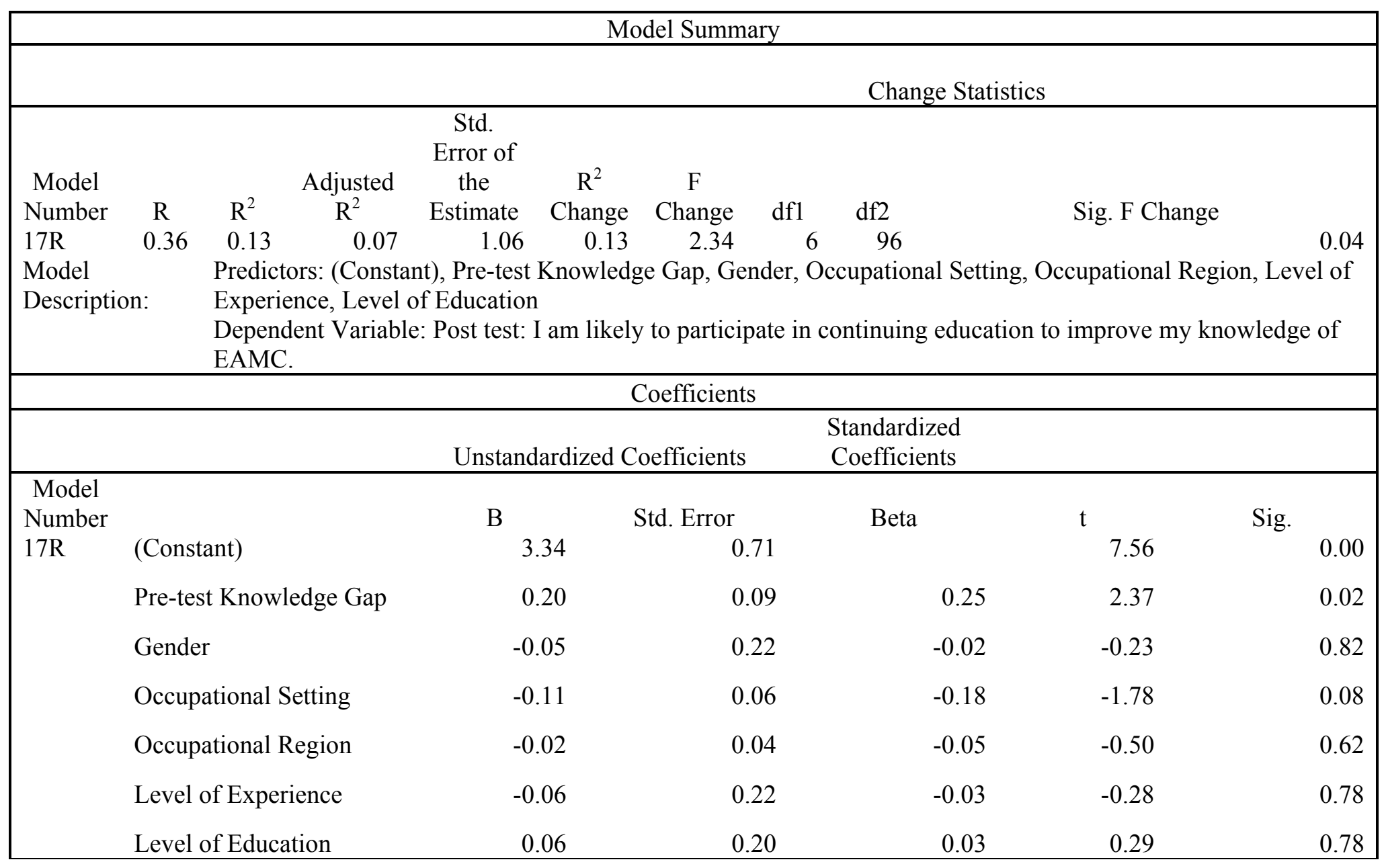


Figure 12

21R Model Summary and Table of Coefficients

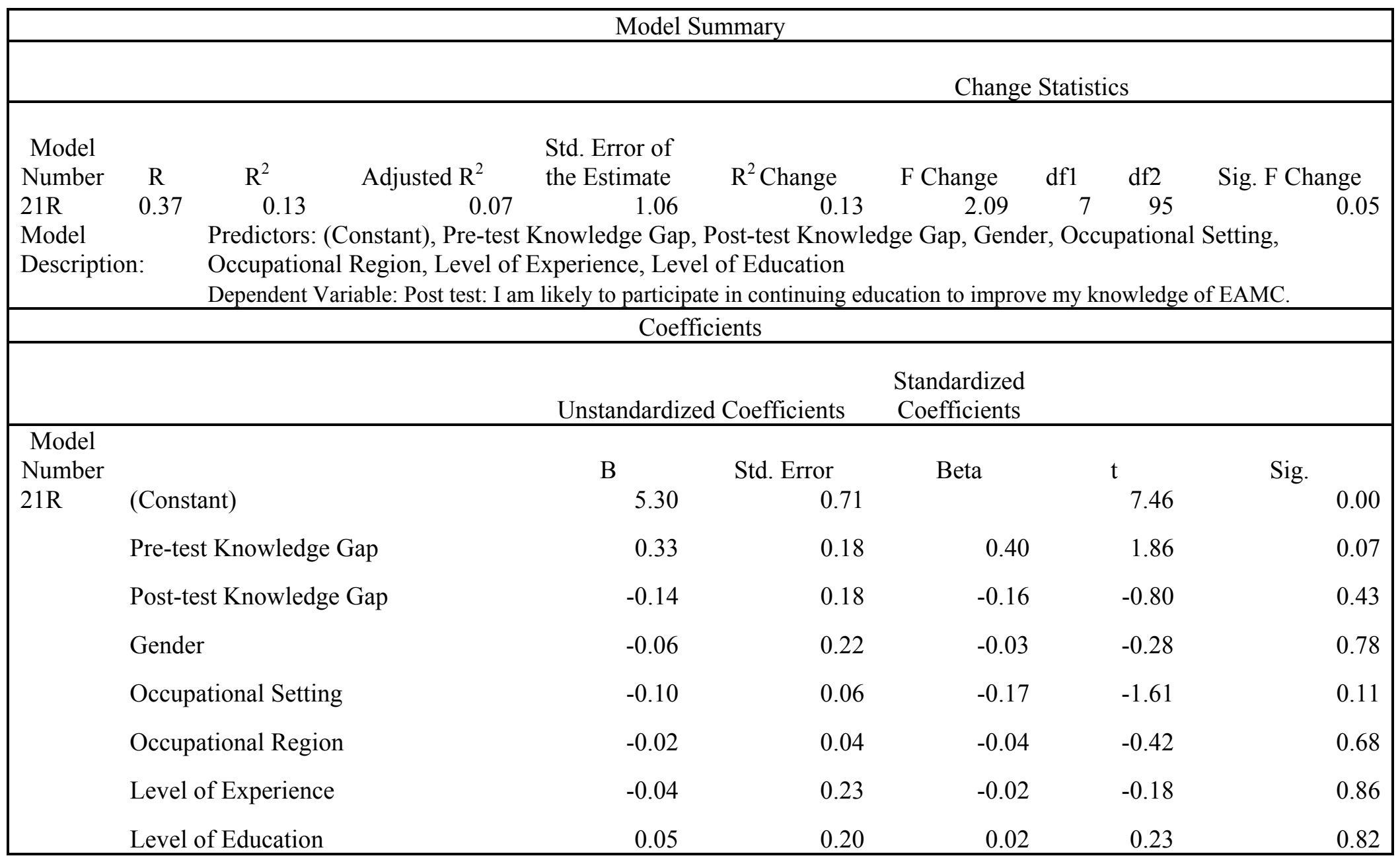


Table 23

Actual Regression Models for Relationships between Actual Knowledge Gap and the Dependent Variables: Post-test Perceived Knowledge and Likelihood to Pursue Continuing Education

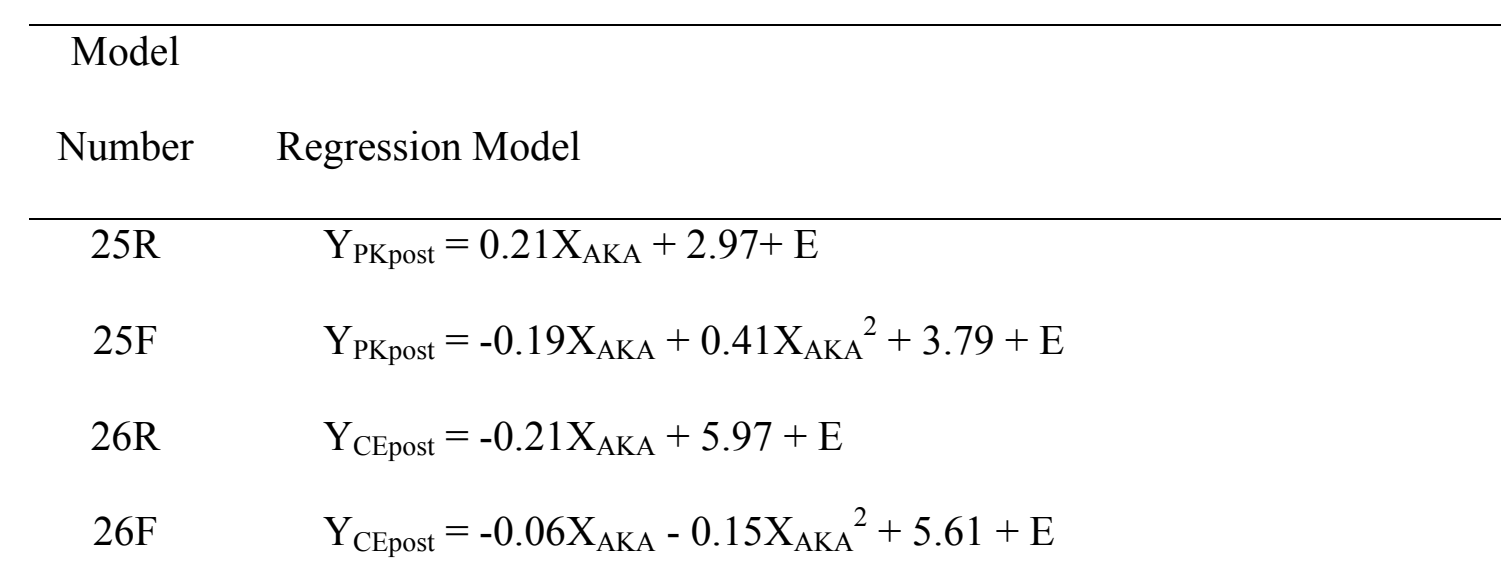

Note: $\mathrm{F}=$ Full model, $\mathrm{R}=$ Restricted model, $\mathrm{CE}=$ Likelihood to Pursue Continuing Education, $\mathrm{PK}=$ Perceived Knowledge (mean score), $\mathrm{AKA}=$ Actual Knowledge Assessment, $\mathrm{E}=$ Error vector (calculated as $\mathrm{Y}_{1-} \hat{\mathrm{Y}}$ ) 
VITA

LINDSEY E. EBERMAN

1998-2003

B.S., Athletic Training

Northeastern University

Boston, Massachusetts

2003-2005

M.S., Exercise and Sport Science

Florida International University

Miami, Florida

2004- 2008

Part Time Faculty

Florida International University

Miami, Florida

PUBLICATIONS AND PRESENTATIONS

Publications

Publications in Peer-Reviewed Journals (4)

Abstracts Published in Professional Journals (16)

Publications in Peer-Reviewed, Competitive Proceedings (20)

Publications in Peer-Reviewed, Less Competitive Proceedings (18)

Publications in Review or in Progress (8)

Presented Papers, Speaking Engagements, Presentations

National Peer-Reviewed (16)

Regional Peer-Reviewed (2)

State / Local Peer-Reviewed (18)

\section{OTHER PROFESSIONAL ACTIVITY}

Funded Grant Proposals

Approved clinical instructor estimates of Athletic Training learning style:

Southeastern Athletic Trainers' Association Research and Education

Committee Grant (2008, \$1,000)

Validation of a heat illness risk assessment instrument and incidents of exertional heat illness in American football players in the southeastern US:

Southeastern Athletic Trainers' Association Research and Education

Committee Grant (2006, \$1,500)

Graduate Student Mentorship

Masters' Student Theses (9)

Masters' Student Independent Research Projects (12)

Bachelors' Student Independent Research Projects (1)

External Review of Peer-Reviewed Journals

Journal of Psychosomatic Research

Journal of Sport Rehabilitation

Journal of Athletic Training 